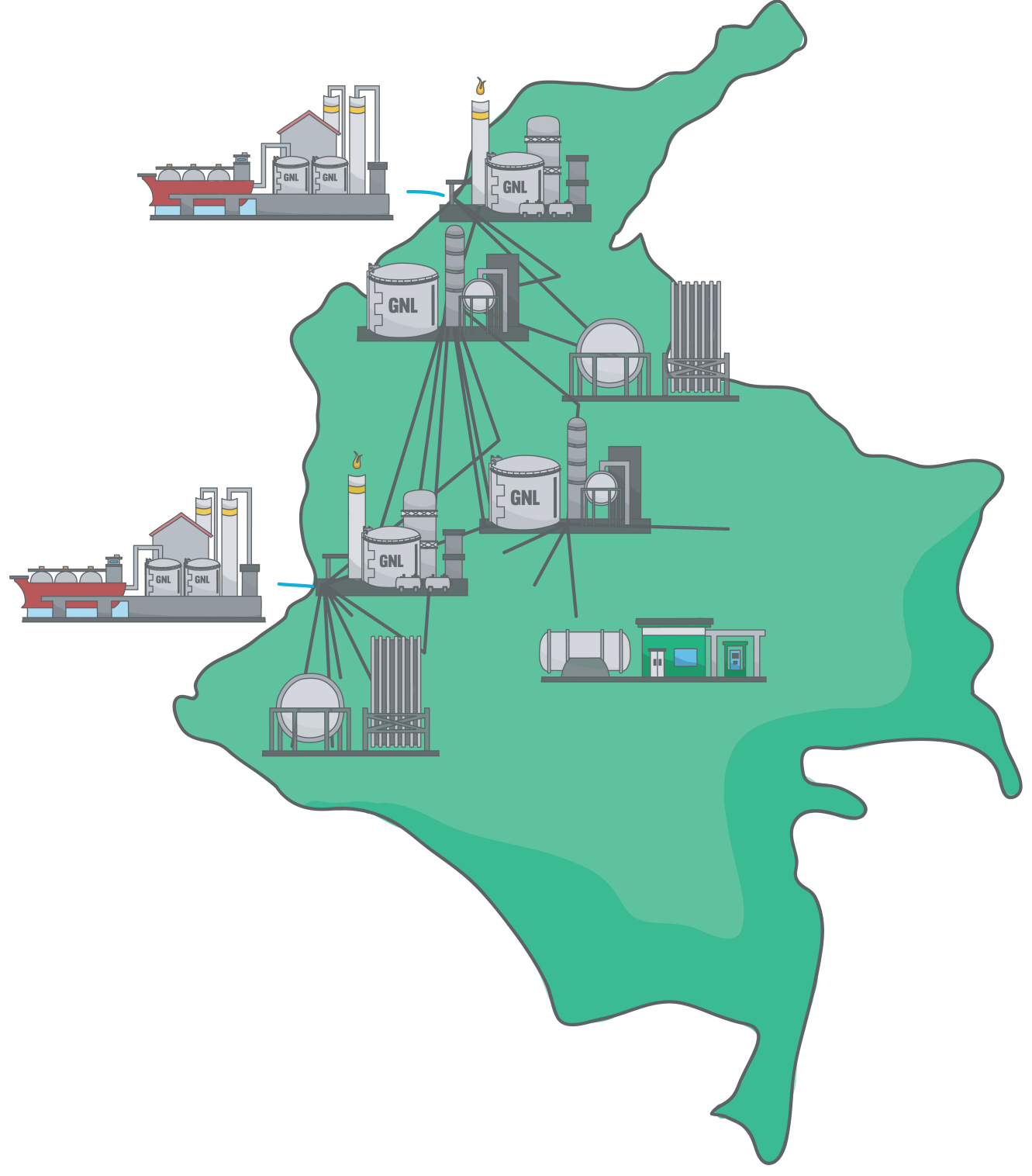

\title{
Gas natural licuado: una opción para la transición energética de Colombia
}

Álvaro Restrepo

Carlos A. Saldarriaga

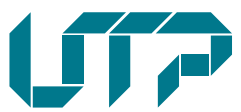

Universidad Tecnológica de Pereira

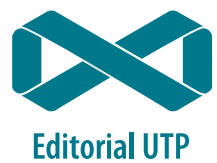

Harold Salazar Isaza Juan Camilo López Juan Esteban Tibaquirá 
Álvaro Restrepo (Buga, valle del cauca, Colombia, 1973).

Ph.D. en Ingeniería Mecánica - Universidade Federal de Santa Catarina, Ingeniero Mecánico - Universidad Autónoma de Occidente.

Profesor Titular Facultad de Ingeniería Mecánica.

Coautor de libros: Procesamiento de señales no intrusivas para el monitoreo de condición de emisiones y análisis energético en un motor de combustión interna diésel (2021), Contaminación Ambiental por Fuentes Móviles Área Metropolitana Centro Occidente -AMCO-Pereira, Dosquebradas, La Vigimia (2007).

Miembro del grupo de Investigación en Gestión Energética - GENERGÉTICA.

\section{arestrep@utp.edu.co}

Carlos A. Saldarriaga (Pereira, Risaralda, Colombia, 1986).

Doctor en ingeniería e Ingeniero electricista de la Universidad Tecnológica de Pereira.

Docente catedrático en el pregrado de ingeniería eléctrica de la UTP y docente de la maestría en ingeniería eléctrica de la UTP.

Ha publicado artículos en revistas especializadas nacionales e internacionales.

Estudiante distinguido pregrado ingeniería eléctrica, 5 to puesto nacional en las pruebas ECAES 2008, tesis de maestría laureada.

Miembro del grupo de investigación: Desarrollo en Investigación Operativa. (DINOP).

\section{casaldarriaga@utp.edu.co}

Harold Salazar Isaza (Pereira, Risaralda, Colombia, 1986).

Ph.D. Electrical Engineering, lowa State University, Ingeniero Eléctico, Universidad Tecnológica de Pereira.

Profesor titular Facultad de Ingenierías Universidad Tecnológica de Pereira.

Ha publicado artículos en revistas especializadas nacionales e internacionales.

Miembro del grupo de investigación: Desarrollo en Investigación Operativa. (DINOP).

hsi@utp.edu.co
Juan Camilo López (Cartago, Valle del Cauca, Colombia, 1993).

Magíster en Ingeniería Mecánica, Ingeniero Mecánico, Universidad Tecnológica de Pereira.

Profesor Auxiliar Facultad de Ingeniería Mecánica.

Coautor de libros: Deteminación del consumo de combustibles y emisiones en vehículos livianos bajo pruebas dinámicas (2020).

Miembro del grupo de Investigación en Gestión Energética - GENERGÉTICA.

juanc.lopez@utp.edu.co

Juan Esteban Thbaquirá(BogotáD.C, Cundinamarca, Colombia, 1975).

Ph.D. en Ingeniería Mecánica - Arizona State University e Ingeniero Mecánico - UTP.

Profesor titular Facultad de Ingeniería Mecánica Universidad Tecnológica de Pereira.

Coautor de libros: Procesamiento de señales no intrusivas para el monitoreo de condición de emisiones y análisis energético en un motor de combustión intema diésel (2021), Efecto de la Mezcla De Combustible E20 en el Parque Automotor Colombiano (2017), Water Recovery from Hydrogen Fuel Cells And Other Energy Productions Systems En: Estados Unidos (2011), Ed: Water Research Foundation, Contaminación Ambiental por Fuentes Móviles Área Metropolitana Centro Occidente -AMCO-Pereira, Dosquebradas, La Vigimia (2007), Conceptos Físico - Mecánicos (2005) Cenpapel.

Miembro del grupo de Investigación en Gestión Energética - GENERGÉTICA.

juantiba@utp.edu.co

La Editorial de la Universidad Tecnológica de Pereira tiene como

política la divulgación del saber científico, técnico y humanístico para fomentar la cultura escrita a través de libros y revistas científicas especializadas.

Las colecciones de este proyecto son:

Trabajos de Investigación, Ensayos, Textos Académicos y Tesis Laureadas.

Este libro pertenece a la Colección Trabajos de Investigación. 


\title{
Gas natural licuado: una opción para la transición energética de Colombia
}

\author{
Álvaro Restrepo \\ Carlos A. Saldarriaga \\ Harold Salazar Isaza \\ Juan Camilo López \\ Juan Esteban Tibaquirá
}

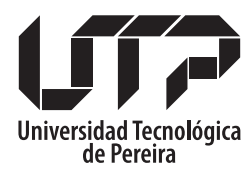

Colección Trabajos de Investigación

Facultad de Ingenierías

2021 


\section{Agradecimientos}

Los autores desean agradecer muy especialmente el apoyo de:

La Unidad de Planeación Minero-Energética (UPME) y al Ministerio de Ciencia y Tecnología de Colombia (MinCiencias) por los recursos que dispusieron para llevar a cabo el proyecto llamado Desarrollo de una herramienta de modelamiento y optimización para la introducción de gas natural a pequeña escala en distintos sectores de consumo final de energía en Colombia.

Los funcionarios de la Vicerrectoría de Investigaciones, Innovación y Extensión de la Universidad Tecnológica de Pereira (UTP).

Los siguientes integrantes del Grupo de Investigación en Gestión Energética: Tatiana Loaiza Vera, Juan Carlos Castillo Herrera, David Andrés Serrato Tobón, Jorge Eliécer Torres Quiñonez y Juan Camilo Zapata Mina.

Los siguientes integrantes del grupo de investigación en Desarrollo en Investigación de Operaciones (DINOP): Julián Eduardo Ibarra Vadillo, María Victoria Gasca Segura, David Leonardo Beltrán Coy y Nicolás Duque Arango. 


\section{CONTENIDO}

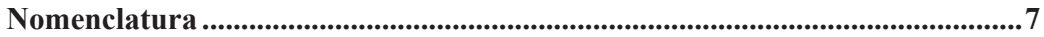

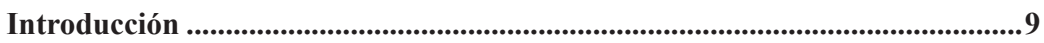

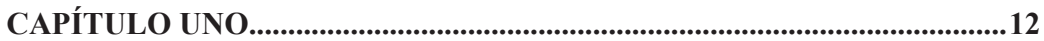

El gas natural (GN)....................................................................................................13

1.1. El gas natural como fuente de energía ...................................................13

1.2. El gas natural en Colombia.......................................................................15

1.2.1. Proyecciones de producción y demanda ..........................................17

1.2.2. Cadena de valor y escenarios para inclusión de GNL ...................18

1.3. Ventajas y desventajas del uso del gas natural.......................................19

1.4. Sectores de consumo del gas natural..........................................................21

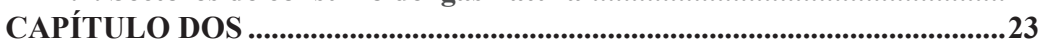

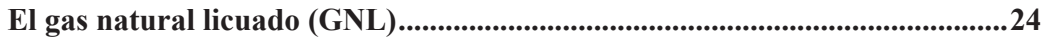

2.1. Gas natural licuado (GNL) ......................................................................224

2.2. Producción de GNL ........................................................................................25

2.2.1. Pretratamiento .............................................................................227

2.2.2. Licuefacción..........................................................................................28

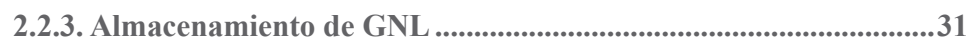

2.2.4. Transporte de GNL ..............................................................................34

2.2.5. Regasificación del GNL ...................................................................36

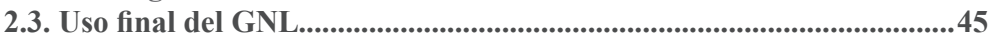

2.3.1. Sector transporte..........................................................................................46

2.3.2. Sectores termoeléctrico, industrial y residencial............................55

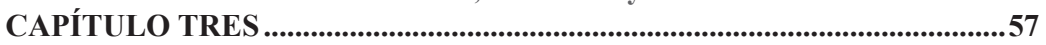

GNL a pequeña escala en Colombia: producción ..................................................58

3.1. Tecnologías de licuefacción a pequeña escala..........................................58

3.2. Requerimientos de gas para producción de GNL...................................60

3.3. Potencial producción de GNL en Colombia .............................................61

3.4. Manejo y/o tratamiento del BOG en estaciones de GNL a pequeña

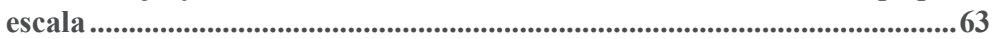

3.4.1. Generación de potencia ..........................................................................63

3.4.2. Relicuefacción del BOG.................................................................63

3.5. Aspectos de seguridad .............................................................................64

3.6. Mantenimiento e inspección .......................................................................72

3.7. Aspectos normativos de las plantas de producción de GNL a pequeña

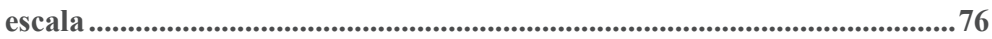

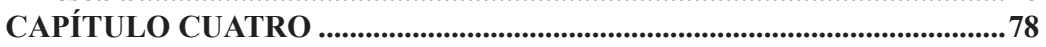

GNL a pequeña escala en Colombia: aprovechamiento ......................................79

4.1. Importación de GNL en el país.......................................................79

4.2. Potencial de aprovechamiento de GNL en Colombia ..............................82

4.2.1. Sector transporte...................................................................................82

4.2.2. Sectores termoeléctrico, industrial y residencial...............................86

4.3. Ajustes normativos para uso de GNL en Colombia...............................90

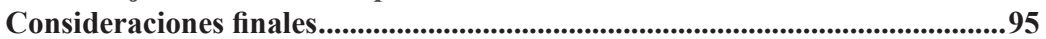

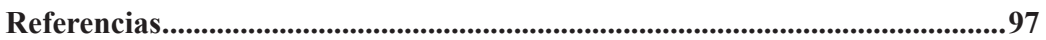




\section{FIGURAS}

Figura NRo. 1. Oferta de energía primaria en el mundo y en Colombia...............9

FigURA NRO. 2. Esquema de la clasificación del gas natural .............................14

FigurA NRo. 3. Red de transporte de GN en Colombia. ...................................16

Figura NRo. 4. Cadenas de valor del GNL. a) Solo licuefacción nacional. b) Solo importación. c) Combinación importación-licuefacción nacional.........................19

Figura NRo. 5. Consumo de gas natural en Colombia 2018 .............................22

Figura NRo. 6. Cadena de valor del GNL ...........................................................2.25

Figura NRo. 7. Disposición de los tanques por tipo. ........................................... 33

Figura NRo. 8. Proceso de generación de BOG-Estratificación y roll over. .......34

FigURA NRO. 9. Tecnología de los camiones cisterna..........................................35

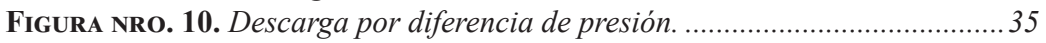

Figura NRo. 11. Central de regasificación a pequeña escala .............................. 41

FigURA NRO. 12. Esquema de un sistema de odorización de gas natural............. 43

FigURA NRO. 13. Sistema de regasificación a pequeña escala ............................ 45

Figura NRo. 14. Esquema de distribución y suministro de GNL. (Los valores en USD mostrados fueron obtenidos para el año 2019). ......................................... 45

Figura NRo. 15. Proceso de acondicionamiento de GNL en EDS: (a) acondicionamiento en masa y (b) acondicionamiento sobre la marcha................ 48

Figura NRo. 16. Esquema de funcionamiento de un dispensador estándar de

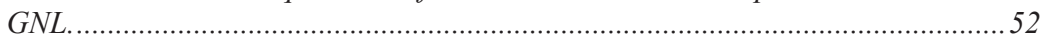

Figura NRO. 17. Diagrama de un sistema de suministro de GNL con bomba.....55

Figura NRo. 18. Esquema de producción de GNL a pequeña escala...................58

Figura NRO. 19. Diagrama de un sistema de criogenización de BOG................ 64

FigurA NRO. 20. Cadena de valor del GNL........................................................8 80 


\section{TABLAS}

TABLA NRO. 1. Producción nacional de gas natural-principales yacimientos......15 TABLA NRO. 2. Tasas de crecimiento anual promedio por sector de consumo,

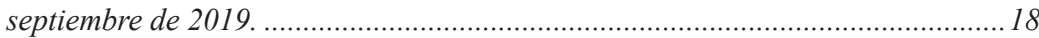

TABLA NRO. 3. Escalas de las plantas de licuefacción de GN..............................26

TABLA NRO. 4. Remoción de impurezas en el proceso de pretratamiento. .............27

TABLA NRO. 5. Composición típica del GN y del GNL........................................28

TABLA NRo. 6. Consumo de energía de los ciclos de licuefacción. ..........................30

TABLA NRO. 7. Ventajas y desventajas de los ciclos de licuefacción de gas

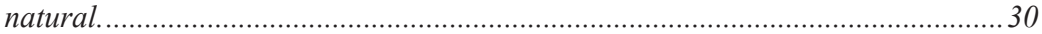

TABLA NRO. 8. Valor de presión de acuerdo al uso de GN ......................................38

TABLA NRO. 9. Compresor de BOG de etapa simple........................................4 40

TABLA NRO. 10. Características técnicas de una bomba criogénica sumergible

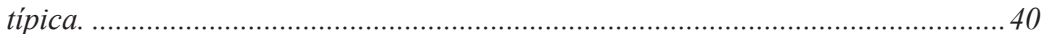

TABLA NRO. 11. Características técnicas de vaporizadores de GNL. .................. 42

TABLA NRO. 12. Especificaciones técnicas: sistema de regasificación de Chart

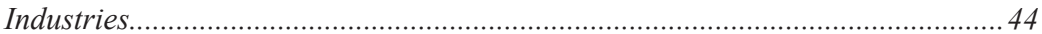

TABLA NRO. 13. Características técnicas de un sistema portable de almacenamiento y regasificación de GNL-Worthington Industries.....................................................4 44

TABLA NRO. 14. Oferta comercial de tecnologías de licuefacción. ........................59

TABLA NRO. 15. Requerimientos de gas y de energía para producción de GNL a

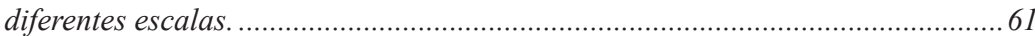

Tabla NRO. 16. Potencial de producción de GNL en pozos con quema de gas en el

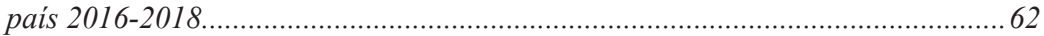

TABLA NRO. 17. Clasificación por capacidad de almacenamiento.........................6 68

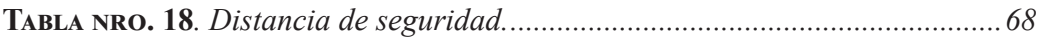

TABLA NRO. 19. Recomendaciones normativas para complementar la

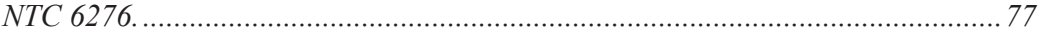

TABLA NRO. 20. Proyección de demanda de GNL por regiones para el sector termoeléctrico.

TABLA NRO. 21. Demanda de GNL de termoeléctricas susceptibles a cambio de tecnología.

TABLA NRO. 22. Proyección de demanda de GNL por regiones para el sector industrial.

TABLA NRO. 23. Proyección de demanda de GNL por regiones para el sector residencial.

TABla NRo. 24. Porcentaje de cubrimiento de gas natural por departamento.....89 89

TABla NRo. 25. Proyección de demanda de GNL para departamentos con cubrimiento parcial del servicio de gas natural 2020-2030. 90

TABLA NRO. 26. Recomendaciones normativas para el transporte por carretera. 


\section{Nomenclatura}

\begin{tabular}{|c|c|}
\hline AILAC & Asociación Independiente de Latinoamérica y el Caribe \\
\hline ANSI & American National Standards Institute \\
\hline API & American Petroleum Institute \\
\hline ASME & American Society of Mechanical Engineers \\
\hline BOG & Boil-off gas: gas evaporado \\
\hline $\mathrm{BP}$ & British Petroleum \\
\hline BSI & British Standards Institution \\
\hline $\mathrm{CH}_{4}$ & Metano \\
\hline $\mathrm{C}_{2} \mathrm{H}_{6}$ & Etano \\
\hline $\mathrm{C}_{3} \mathrm{H}_{8}$ & Propano \\
\hline $\mathrm{C}_{4} \mathrm{H}_{10}$ & Butano \\
\hline $\mathrm{C}_{5} \mathrm{H}_{12}$ & Pentano \\
\hline $\mathrm{CO}$ & Monóxido de carbono \\
\hline $\mathrm{CO}_{2}$ & Dióxido de carbono \\
\hline DIIS & Departament of Industry, Innovation and Science-Australia \\
\hline DMS & Dimethyl sulfate: sulfato de dimetilo \\
\hline EDS & Estación de servicio \\
\hline EMS & Environment Management System \\
\hline FLNG & $\begin{array}{l}\text { Floating Liquefied Natural Gas: instalación flotante de gas natural } \\
\text { licuado (GNL) }\end{array}$ \\
\hline FSRU & $\begin{array}{l}\text { Floating Storage Regasification Unit: unidad flotante de } \\
\text { almacenamiento y regasificación de GNL }\end{array}$ \\
\hline GBTUD & $\begin{array}{l}\text { Giga BTU por día. Se usa esta unidad que no pertenece al Sistema } \\
\text { Internacional (SI), dado su amplio uso en el gremio de los } \\
\text { hidrocarburos }\end{array}$ \\
\hline GEI & Gases de efecto invernadero \\
\hline GLP & Gas licuado de petróleo \\
\hline GNC & Gas natural comprimido \\
\hline GN & Gas natural \\
\hline GNL & Gas natural licuado \\
\hline GPC & $\begin{array}{l}\text { Giga pies cúbicos. Se usa esta unidad que no pertenece al SI, dado su } \\
\text { amplio uso en el gremio de los hidrocarburos }\end{array}$ \\
\hline ITC-BT & $\begin{array}{l}\text { Instrucciones técnicas complementarias del reglamento electrotécnico } \\
\text { de baja tensión }\end{array}$ \\
\hline $\mathrm{H}_{2} \mathrm{~S}$ & Ácido sulfúrico \\
\hline ISO & International Organization for Standardization \\
\hline $\mathrm{LN}_{2}$ & Nitrógeno líquido \\
\hline MBTUD & $\begin{array}{l}\text { Mega BTU por día. Se usa esta unidad que no pertenece al SI, dado su } \\
\text { amplio uso en el gremio de los hidrocarburos }\end{array}$ \\
\hline
\end{tabular}


MPCD

MinCiencias

MTPA

NFPA

NOx

NTC

ODS

OMS

PM

$\mathrm{PM}_{2.5}$

ppm

SAE

SNT

SOx

RUNT

TBM

THT

TPA

TPD

UNE

UPME

YPF
Millones de pie cúbicos por día. Se usa esta unidad que no pertenece al SI, dado su amplio uso en el gremio de los hidrocarburos Ministerio de Ciencia y Tecnología de Colombia

Millones de toneladas por año. Se usa esta unidad que no pertenece al SI, dado su amplio uso en el gremio de los hidrocarburos

National Fire Protection Association

Óxidos de nitrógeno

Norma técnica colombiana

Objetivos de desarrollo sostenible

Organización Mundial de la Salud

Material particulado

Material particulado con partículas con diámetro inferior a $2.5 \mu \mathrm{m}$

Partes por millón

Society of Automotive Engineers

Sistema Nacional de Transporte

Óxidos de azufre

Registro Único Nacional de Tránsito

Terbutilmercaptano

Tetrahidrotiofeno

Toneladas por año (t/año)

Tonelada por día ( $\mathrm{t} /$ día)

Una norma española

Unidad de Planeación Minero Energética de Colombia

Yacimientos Petrolíferos Fiscales 


\section{Introducción}

Durante las últimas décadas, la oferta de energía en el mundo estuvo caracterizada por ser dependiente de los recursos fósiles y llegó a estimarse que más del $80 \%$ de la energía ofertada había sido provista por estos recursos [1]. El gas natural, al ser un recurso fósil, es la tercera fuente de energía primaria en el mundo, con una participación del $22 \%$ del total. Colombia no es ajena a esta realidad; aunque es un país que usa sus fuentes hídricas para generar energía eléctrica, en otros sectores económicos tales como la industria, el transporte, el comercio y el residencial cerca del $75 \%$ de la energía ofertada proviene de recursos fósiles (ver Figura NRO. 1) [2].
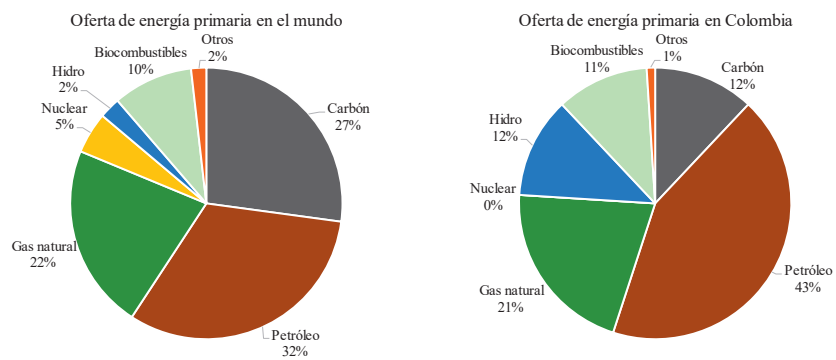

Figura NRO. 1. Oferta de energía primaria en el mundo y en Colombia. Tomada de [1], [2]. 
Como ha sido ampliamente divulgado, la combustión de recursos fósiles genera compuestos contaminantes como los óxidos de azufre $\left(\mathrm{SO}_{\mathrm{x}}\right)$, los óxidos de nitrógeno $\left(\mathrm{NO}_{\mathrm{x}}\right)$ y el material particulado $(\mathrm{PM})$, los cuales causan fenómenos de contaminación del aire atmosférico sea directamente o una vez transformados en otros compuestos a través de reacciones químicas en la atmósfera. Según la Organización Mundial de la Salud (OMS), uno de los principales precursores tanto de la contaminación del aire como del cambio climático es la combustión de recursos fósiles. Uno de los mayores riesgos ambientales para la salud de los seres vivos son los contaminantes microscópicos en el aire como el $\mathrm{PM}_{2.5}$ (material particulado que contiene fragmentos con tamaño inferior a $2.5 \mu \mathrm{m}$ ), los cuales pueden ingresar al sistemas respiratorio y circulatorio, y causar daños a nivel del corazón, los pulmones y el cerebro. Se estima que cada año en el mundo, alrededor de 7 millones de personas mueren prematuramente a raíz de morbilidades como el cáncer, enfermedades cardíacas, afecciones pulmonares y derrames cerebrales, todas ellas relacionadas con la contaminación atmosférica [3].

Teniendo en cuenta la dependencia energética y la contaminación ambiental generada por los recursos fósiles empleados en la generación de energía en Colombia, se hace necesario buscar tecnologías limpias y de baja o cero emisiones, las cuales aprovechen recursos energéticos renovables disponibles en Colombia. Estas tecnologías permitirían alcanzar los objetivos trazados por la humanidad para mitigar el cambio climático, alcanzar el acceso universal a la energía y mejorar la calidad del aire. Sin embargo, las tendencias actuales indican que en las próximas décadas los combustibles fósiles continuarán dominando la generación de energía primaria a nivel mundial y que la transición hacia políticas energéticas de bajas y cero emisiones serán procesos a largo plazo, los cuales necesitarán mejoras en la eficiencia energética y en la innovación tecnológica.

Existen dos grandes barreras para lograr una transición rápida hacia estas tecnologías. La primera es que actualmente el $80 \%$ de la energía mundial se genera a partir de combustibles fósiles; asociado a esto, existe una infraestructura integrada de los recursos fósiles, la cual 
se ha construido durante décadas y es distinta a la necesitada por las tecnologías que aprovechan las fuentes renovables. La segunda barrera es la incertidumbre asociada con los recursos naturales para generar energía renovable y el mayor costo de estas tecnologías frente al uso de los recursos fósiles [4]. Se habla entonces de una etapa de «transición energética» que comprometa varias generaciones durante un periodo de tiempo considerable y que pueda conducir a una mayor diversidad en el mercado energético, pero al mismo tiempo que permita avanzar hacia estas tecnologías más limpias y de bajas o cero emisiones, pues solo así se podrá reducir progresivamente el uso de recursos fósiles para llegar a la utilización generalizada de energías renovables como principal medio de producción energética.

Colombia ha asumido esta transición energética mundial en su compromiso con los propósitos pactados en el Acuerdo de París y busca dar cumplimiento a los objetivos 7 y 11 del documento Objetivos de Desarrollo Sostenible (ODS). Dicho país encamina su búsqueda hacia combustibles de transición energética que le permitan avanzar hacia energías más limpias y sustentables. Así, el gas natural licuado (GNL) emerge como una respuesta para esta transición, dado que, sin ser una fuente de energía renovable, su uso disminuye las emisiones de Gases Efecto Invernadero (GEI); tiene alta competitividad económica; posee un alto poder calorífico y brinda condiciones de seguridad, abundancia e infraestructura confiable.

Este documento se desarrolló en el marco del proyecto Desarrollo de una herramienta de modelamiento y optimización para la introducción de gas natural a pequeña escala en distintos sectores de consumo final de energía en Colombia, el cual se ejecutó desde la Universidad Tecnológica de Pereira (UTP); con recursos de la Unidad de Planeación Minero Energética (UPME) y a través del Ministerio de Ciencia, Tecnología e Innovación (MinCiencias) de Colombia. Los grupos de investigación de la UTP involucrados en la ejecución del proyecto fueron: Gestión Energética (GENERGÉTICA) y Desarrollo en Investigación de Operaciones (DINOP). 


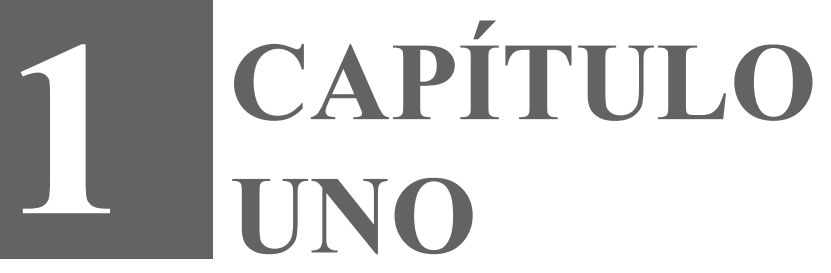




\section{El gas natural (GN)}

\subsection{El gas natural como fuente de energía}

El GN es un recurso fósil compuesto por una serie de hidrocarburos livianos en fase gaseosa. Este se constituye principalmente de metano $\left(\mathrm{CH}_{4}\right)$ y etano $\left(\mathrm{C}_{2} \mathrm{H}_{6}\right)$ con cantidades menores de propano $\left(\mathrm{C}_{3} \mathrm{H}_{8}\right)$, butano $\left(\mathrm{C}_{4} \mathrm{H}_{10}\right)$, pentano $\left(\mathrm{C}_{5} \mathrm{H}_{12}\right)$ y otros hidrocarburos más pesados. Adicionalmente, contiene impurezas tales como dióxido de carbono $\left(\mathrm{CO}_{2}\right)$, agua, nitrógeno, sulfuro de hidrógeno $\left(\mathrm{H}_{2} \mathrm{~S}\right)$, entre otros [5]. La composición puede variar según las características del yacimiento donde se encuentra confinado, pues según el contenido de hidrocarburos pesados y metano, el gas natural puede clasificarse en gas seco si el contenido de metano es mayor y en gas rico (gas húmedo) si el contenido de hidrocarburos pesados también es mayor. Además, según el contenido de sulfuro, si es bajo o alto, puede clasificarse en gas dulce o gas agrio respectivamente; y según su origen, puede ser gas convencional o gas no convencional. Esta última clasificación se debe a la facilidad de extracción asociada a la permeabilidad del yacimiento donde se encuentra [6]. La FIGURA NRO. 2 esquematiza la clasificación descrita anteriormente. 


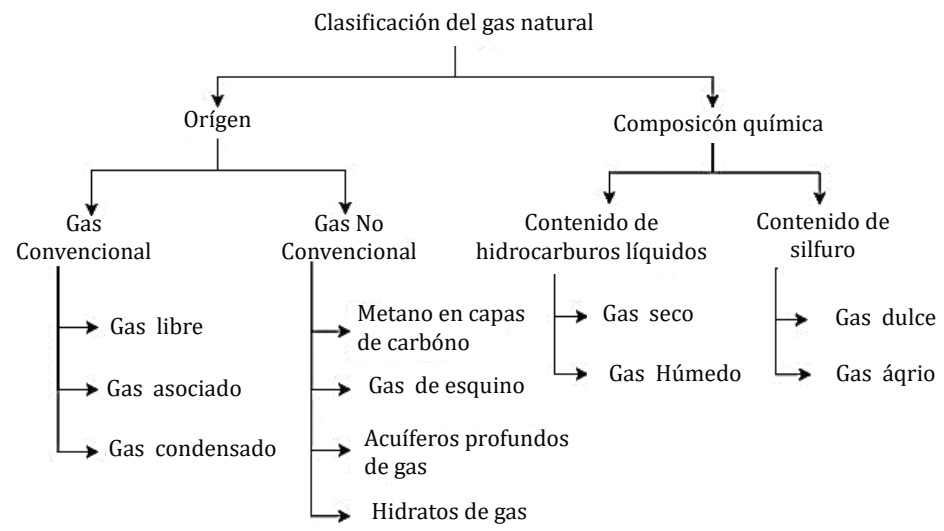

Figura NRO. 2. Esquema de la clasificación del gas natural. Tomada de [6], [7].

El GN en un yacimiento puede estar libre o asociado al petróleo líquido, también puede encontrarse en depósitos superficiales asociados al carbón o en espacios no convencionales donde se encuentran hidrocarburos. Dichos lugares contienen normalmente agua, lodo y otro tipo de impurezas, por lo cual la extracción del gas natural exige un proceso de filtrado y limpieza para su posterior comercialización.

Las propiedades del GN, tales como la densidad y el peso molecular, dependen de su composición química, la cual, a su vez, depende de las condiciones del yacimiento en el que se encuentre, pues esta puede variar significativamente cuando en superficie se mezclan gases de diferentes fuentes, regiones o yacimientos. Su componente principal, después de ser procesado para su disposición final, es el metano, el cual es un gas incoloro, inodoro y más liviano que el aire. Este elemento presenta una gravedad específica que puede oscilar entre 0.5 y 0.8 y tiene un rango de inflamabilidad muy limitado. Se necesita de una composición entre un 5 y un $15 \%$ por volumen de metano en el aire para generar una mezcla combustible; adicionalmente, su temperatura de autoencendido es alta, alrededor de $540{ }^{\circ} \mathrm{C}$, por lo anterior, se considera un hidrocarburo seguro para su transporte y uso [8].

El poder calorífico superior del GN también depende de su composición. Para el caso del gas extraído de los yacimientos en la cuenca de La Guajira en Colombia, este presenta una mezcla de 97.96 
$\%$ metano, $1.51 \%$ nitrógeno, $0.175 \%$ dióxido de carbono, $0.256 \%$ etano, $0.053 \%$ propano y menores cantidades de i-butano, n-butano, i-pentano, n-pentano y n-hexano. Dicho gas puede llegar a indicar un poder calorífico superior de $37 \mathrm{MJ} / \mathrm{m}^{3}$ a 1 atm y $15.5^{\circ} \mathrm{C}$ [9].

\subsection{El gas natural en Colombia}

Para el año 2018, Colombia contaba con 95 campos de GN con reservas probadas de 3782 GPC (giga pies cúbicos), 48 pozos exploratorios y un punto de importación de gas natural licuado denominado terminal portuario de SPEC LNG en Cartagena. En el mismo año se tuvo un decrecimiento de $2.9 \%$ respecto a las reservas probadas del año 2017 y de un $4.7 \%$ en las reservas totales. Las provisiones probables y posibles para finales del año 2018 se contabilizaron en 770 GPC y 410 GPC respectivamente. Los campos de gas natural más representativos son Cupiagua, Cusiana y La Guajira, los cuales tuvieron una participación de aproximadamente el $55.7 \%$ del GN ofertado en Colombia en el año 2018 (ver TABLA NRO. 1).

\begin{tabular}{lll}
\hline Pozo & Producción [GBTUD] & \% Participación \\
\hline Guajira & 253 & 19.52 \\
\hline Cupiagua & 240 & 18.52 \\
\hline Cusiana & 229 & 17.67 \\
\hline Floreña-Pauto & 148 & 11.42 \\
\hline Otros costa & 143 & 11.03 \\
\hline Otros interior & 65 & 5.02 \\
\hline Zonas aisladas & 63 & 4.86 \\
\hline Nelson C. de Oro & 53 & 4.09 \\
\hline Gibraltar & 41 & 3.16 \\
\hline Clariente & 36 & 2.78 \\
\hline La Creciente & 25 & 1.93 \\
\hline
\end{tabular}

TABLA NRO. 1. Producción nacional de gas natural-principales yacimientos. Tomada de [10].

Nota: giga BTU por día (GBTUD).

En relación con el sistema nacional de transporte, para el año 2018 se contaba con una red de gasoductos de $7460 \mathrm{~km}$ donde cerca del $54 \%$ pertenece a la empresa TGI y un $34 \%$ a la empresa Promigas. El restante $12 \%$ corresponde a las siguientes empresas: Coinigas, Progasur, Promioriente, Transmetano y Transoccidente. Por la red de gasoductos de TGI se transportaron 460 MPCD (mega pies cúbicos 
diarios) equivalentes a cerca del $46 \%$ del total de gas natural conducido para el mismo año. La Figura NRO. 23 esquematiza la distribución de la red de transporte de GN a través del territorio nacional, en ella se señala la conexión con los campos de producción, las líneas de gasoductos y compresores, y las estaciones de regasificación de GNL. Además del punto de importación de gas natural licuado terminal portuario de SPEC LNG en Cartagena, en la misma figura está incluida la Unidad Flotante de Regasificación y Almacenamiento (FSRU), la cual, se espera, entre en operación en la Bahía de Buenaventura en el año 2030.

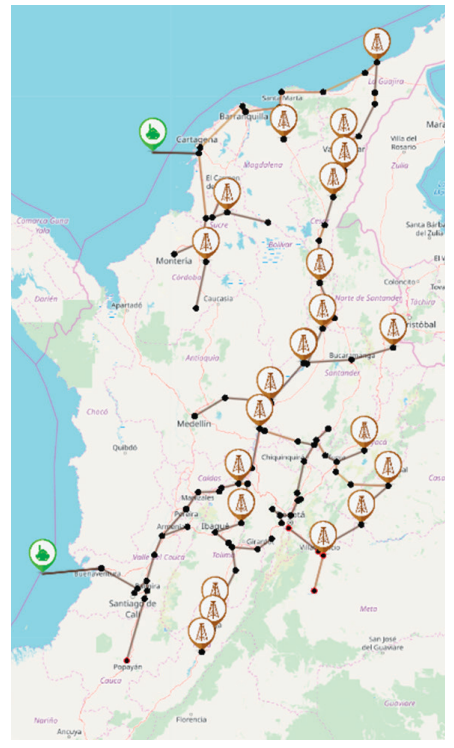

Figura NRo. 3. Red de transporte de GN en Colombia. Elaboración propia.

En relación a la cobertura, al año 2018, la red de gasoductos se extendió a 26 de los 32 departamentos de Colombia y 741 de los 1103 municipios. Solo el $11.5 \%$ de los municipios (Valle del Cauca, Bogotá y Boyacá) tuvo una cobertura de más del $95 \%$ (ver FiguRA NRO. 3) [11]. Cerca del $64.4 \%$ de la población colombiana en el mismo año estaba interconectada a la red de distribución de GN. En el tercer trimestre del año 2019, el $98.1 \%$ del total de usuarios conectados a la red eran residenciales, el $1.8 \%$ comerciales y, el restante, $0.1 \%$ industriales [12]. 


\subsubsection{Proyecciones de producción y demanda}

El factor R/P (Reserva/Producción) estima la vida útil de las reservas de GN probadas en años. El Ministerio de Minas y Energía junto con la Agencia Nacional de Hidrocarburos anunciaron, a mediados del año 2019, un factor R/P de 9.8 años para las reservas probadas en Colombia, al considerar $3782 \mathrm{GPC}$ de reservas probadas y un supuesto de producción de 386 GPC al año 2018. Sin embargo, la cifra real de producción para este año fue de $454 \mathrm{GPC}$, por tanto, el factor R/P real sería de 8.3 años en un escenario donde se tiene en cuenta, además de las reservas probadas, las reservas probables y posibles hasta el 2017, así como el gas importado durante 18 años. El factor R/P asciende a 20 años, de los cuales 3.4 años corresponden a las reservas adicionadas y 6.8 años se deben a la importación de GNL [10].

Según la UPME, entre el 2019 y el 2033, se espera un crecimiento anual promedio del $2.96 \%$ en la demanda total de GN del país. Lo sectores petrolero $(6.34 \%)$, termoeléctrico $(4.3 \%)$ y vehicular $(3.52$ $\%)$ son los que proyectan el mayor crecimiento en la demanda de GN. El aumento en el sector petrolero se debe a las necesidades esperadas por Ecopetrol para el abastecimiento de combustibles líquidos y a la implementación de técnicas de recuperación mejorada para la extracción de petróleo. Debido a este, se espera que la demanda para el año 2030 alcance un valor cercano a los 270 GBTUD.

El crecimiento en el sector termoeléctrico está asociado a la optimización del uso de los recursos hídricos para la generación eléctrica y a posibles fenómenos océano-atmosféricos como el fenómeno del niño, el cual limita la oferta de energía eléctrica por medios hidrológicos. El crecimiento en el sector vehicular que opera con GNV se debe a la posible entrada de automóviles al país de, tanto convertidos como dedicados a gas natural; en este sentido, se espera que para el año 2035 la demanda en dicho sector alcance un valor cercano a los 100 GBTUD. En cuanto al sector residencial, el consumo promedio actual de GN por familia en Colombia es de $13.7 \mathrm{~m}^{3}$ mensuales, por lo que se espera que para el año 2030 supere los 180 GBTUD, lo cual indica un aumento anual del $1.7 \%$ [13], [15]. 
La TABLA NRO. 2 presenta una proyección en tasa de crecimiento de demanda anual promedio sectorial hasta 2033. Los resultados de la proyección realizada por la UPME indican, para el período de análisis 2019-2033, un crecimiento total de $2.01 \%$ promedio anual [16].

\begin{tabular}{ll}
\hline Sector & $\mathbf{2 0 1 9 - 2 0 3 3}$ \\
\hline Residencial (\%) & 1.91 \\
\hline Comercial (\%) & 2.01 \\
\hline Industrial (\%) & 1.21 \\
\hline Petroquímico + compresores (\%) & -0.10 \\
\hline Vehicular (\%) & 3.52 \\
\hline Petrolero (\%) & 6.34 \\
\hline Termoeléctrico (\%) & 4.30 \\
\hline Total (\%) & $\mathbf{2 . 9 6}$ \\
\hline
\end{tabular}

TABLA NRO. 2. Tasas de crecimiento anual promedio por sector de consumo, septiembre de 2019. Tomada de [16].

Teniendo en cuenta el déficit de gas natural que se espera, sin contar con la escasez que se presentaría en las centrales térmicas por posibles fenómenos del niño y ante la falta de cobertura de la red de gasoductos, surge la necesidad de plantear soluciones que permitan no solo cubrir la demanda de gas natural a nivel nacional, sino ampliar la cobertura hacia zonas no interconectadas a la red. Por lo anterior, es claro que un esquema de suministro de GNL podría cumplir con los dos propósitos anteriores: cubrir demanda y ampliar la cobertura en el territorio nacional.

\subsubsection{Cadena de valor y escenarios para inclusión de GNL}

Considerando las características propias en relación al GN en Colombia, la cadena de valor para el GNL puede estar constituida tal como se muestra en la Figura NRo. 4. Así, la cadena de valor tipo 1 es aquella en la cual todo el GNL es obtenido únicamente por licuefacción del GN disponible en la red nacional de transporte; es decir, el GNL se obtendría mediante la localización de plantas de licuefacción tipo satélite en lugares estratégicos relacionados con la demanda para su utilización en sistemas masivos de transporte, para su transporte y posterior regasificación en regiones donde no llegue actualmente el gasoducto o para su regasificación en centrales termoeléctricas y sectores industriales tales como parques industriales o zonas francas. 

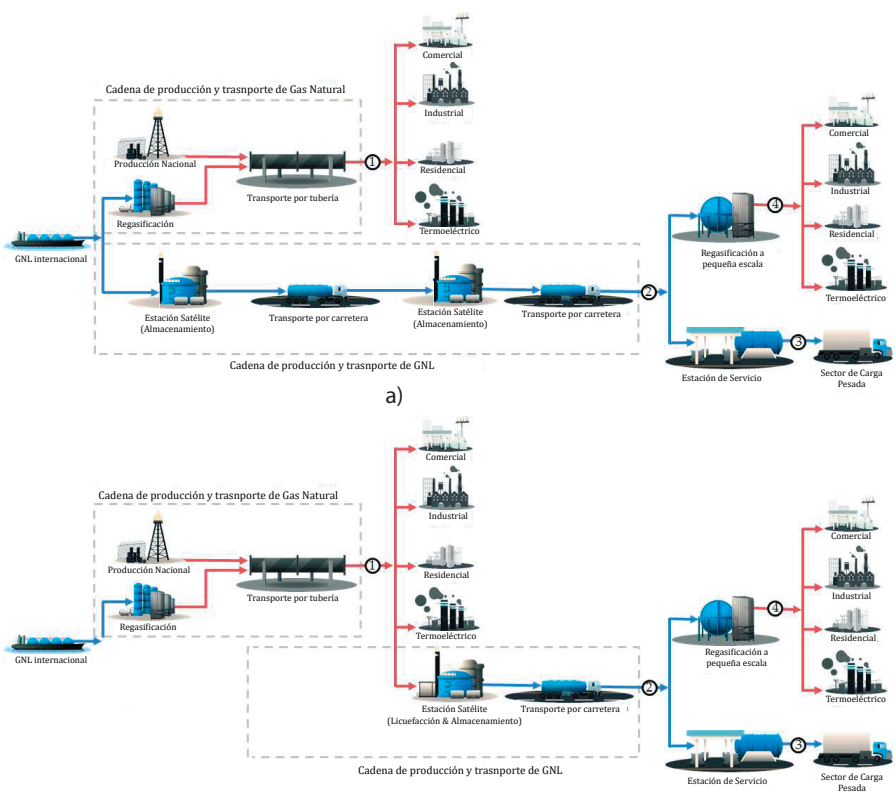

b)

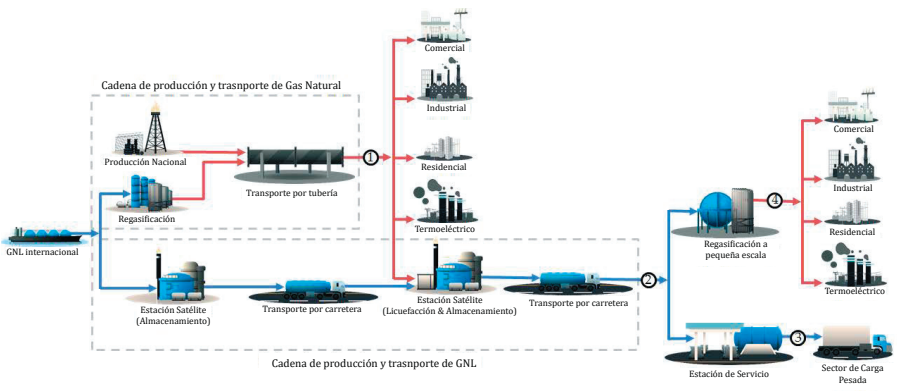

c)

Figura NRo. 4. Cadenas de valor del GNL. a) Solo licuefacción nacional. b) Solo importación. c) Combinación importación-licuefacción nacional.

Elaboración propia.

\subsection{Ventajas y desventajas del uso del gas natural}

Los principales beneficios del uso del GN, tanto a nivel residencial como comercial e industrial, implican su disponibilidad, la sencillez de la distribución, su bajo costo y la reducción en las emisiones. Su uso directo no exige una infraestructura robusta como tanques de 
almacenamiento, bombas o intercambiadores de calor; no requiere un procesamiento posterior y previo a su combustión como el carbón, el cual requiere ser molido previamente y retiradas las cenizas después de su uso. En caso de fugas no representa mayor peligro, pues el $\mathrm{GN}$, al ser más liviano que el aire, se disipa rápidamente en este y disminuye el riesgo de explosión por posibles altas concentraciones. Es más amigable con el medio ambiente respecto al petróleo, por ello se ha defendido a nivel global como un combustible de transición de corto y mediano plazo para un futuro con bajas emisiones de dióxido de carbono, convirtiéndose en una opción rentable para reemplazar centrales eléctricas de carbón [17].

En el sector transporte, algunos estudios indican que los vehículos ligeros que funcionan con gas natural emiten un $15 \%$ menos de GEI en comparación con otros combustibles [18]. Los automóviles que operan con gas natural comprimido (GNC) no producen emisiones por vaporización debido a que los tanques son completamente sellados. Así, en cuanto a economía, el costo del GN como combustible es mucho menor que el de la gasolina o el diésel y, además, al presentar una combustión más completa, muestra una baja contaminación de los aceites y las bujías, amplía la vida útil de las unidades motoras y reduce los costos asociados a las actividades de mantenimiento [19]. Adicionalmente, el GN permite diversificar la flota de transporte.

En el sector termoeléctrico y según estudios realizados en Europa, reemplazar las plantas de carbón para la generación de energía eléctrica mediante plantas combinadas a gas natural puede llegar a reducir alrededor del 70 al $80 \%$ de las emisiones de $\mathrm{CO}_{2}$ y aumentar en un $40 \%$ el rendimiento de la eficiencia energética. En cuanto al uso doméstico para calefacción y calentamiento del agua, substituir el uso directo de electricidad o gas licuado de petróleo (GLP) puede representar una reducción en el costo de energía cercana al $19 \%$ y al $13 \%$ respectivamente. Así mismo, las emisiones de $\mathrm{CO}_{2}$ pueden ser reducidas significativamente con valores que pueden llegar al $33 \%$ [20]. También vale la pena indicar que, dependiendo del país y de sus regulaciones, se pueden obtener más beneficios económicos, todo ello al tener en cuenta los posibles incentivos financieros y/o sanciones para alentar la participación del gas natural en su canasta energética. 
De igual forma, existen desventajas en el uso del GN en los diferentes sectores económicos nombrados anteriormente. Las posibles fugas durante el transporte y el almacenamiento son las causantes de los impactos negativos del uso de este recurso en cuanto a las emisiones de metano. Respecto a su cadena de valor, existen algunos impactos ambientales inherentes a la industria de los hidrocarburos como la irrupción en ecosistemas naturales para su extracción y transporte; la producción asociada de agua contaminada, la cual requiere un tratamiento específico para su posterior vertimiento o uso; el impacto auditivo que pueden generar los equipos como compresores empleados durante el transporte del mismo; entre otros. Adicionalmente, en algunos campos de producción donde el tratamiento y transporte del gas natural no es económicamente viable o contiene altas concentraciones de sulfuro de hidrógeno $\left(\mathrm{H}_{2} \mathrm{~S}\right)$, se opta por reinyectarlo en la formación para mantener la presión del yacimiento y ayudar en la extracción de los demás hidrocarburos o por quemarlo en torres altas denominadas teas, lo cual produce emisiones de $\mathrm{CO}_{2}$ y otros compuestos contaminantes del aire; sin embargo, quemarlo es más seguro que liberarlo y resulta en un impacto menor al medio ambiente debido a la reducción en la emisión de $\mathrm{CH}_{4}$ [21].

Como combustible para vehículos presenta desventajas en cuanto a su oferta, debido a la falta de infraestructura. Algunos estudios indican menores rendimientos de los automóviles que operan con gas natural, comparados con autos a gasolina y diésel, debido a que se puede almacenar menor contenido de energía en el mismo tamaño de tanque. Sin embargo, es posible mitigar dicha desventaja mediante la utilización del GN en otra condición, sea como gas comprimido o en fase líquida (GNL) y al diversificar la tecnología empleada en los motores [22].

\subsection{Sectores de consumo del gas natural}

Como todo recurso fósil, el GN puede emplearse como combustible para generar potencia, electricidad o calor; y como insumo para producir varios productos de la industria química a través de procesos de separación. Los principales sectores de su aplicación son el termoeléctrico, el industrial, el comercial, el residencial y el transporte [23]. 
El sector eléctrico usa el GN como insumo para la generación de calor y energía eléctrica en centrales termoeléctricas mediante plantas de ciclos combinados. El sector industrial, además de usarlo como combustible para cogeneración, también lo emplea como materia prima para producir químicos, fertilizantes, hidrógeno $\mathrm{y}$, asimismo, ser un elemento, de las pinturas, los anticongelantes, los colorantes, las películas fotográficas, los medicamentos, los explosivos. Este es adecuado para la producción de amoníaco (utilizado para la generación de abonos nitrogenados) y de metanol (empleado en la fabricación de plásticos y proteínas sintéticas) [24]. Tanto el sector residencial como el comercial emplean el gas natural para la calefacción, para cocinar alimentos, para secar ropa y para calentar agua; adicionalmente, este primero lo aprovecha para operar equipos de climatización y refrigeración, así como para la iluminación. Por su parte, el sector transporte usa gas natural para operar compresores que logran la distribución de fluidos energéticos a través de tuberías y como combustible para vehículos como GNC y GNL.

La FIGURA NRO. 5 indica la participación de cada sector en el consumo de GN en Colombia para el año 2018. En dicho año, la industria y el comercio fueron los mayores consumidores [10].

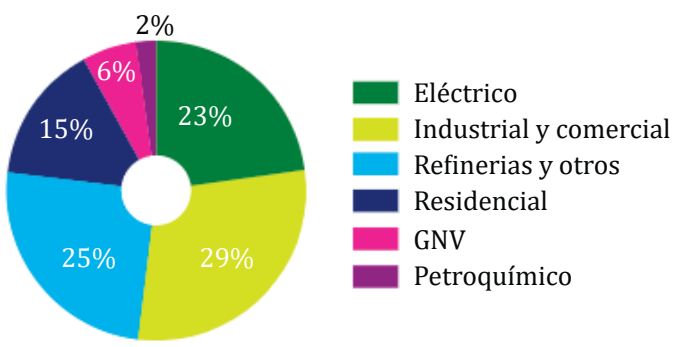

Figura NRo. 5. Consumo de gas natural en Colombia 2018. Tomada de [10].

A partir de lo anterior, es claro que las reservas comprobadas y el crecimiento económico del país hacen que se deba pensar en incrementar la fuente de GN en el territorio nacional. Una alternativa es la inclusión del GNL al seguir alguna de las cadenas de valor antes analizadas, lo cual será el tema central en los capítulos siguientes del presente documento. 


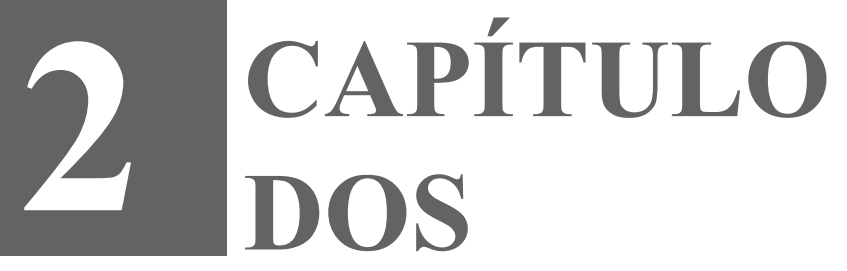




\section{El gas natural licuado (GNL)}

\subsection{Gas natural licuado (GNL)}

El gas natural licuado (GNL) es la denominación que se le da al GN cuando alcanza la fase líquida. Este cambio de fase ocurre a una temperatura de $-162{ }^{\circ} \mathrm{C}$ a una atmósfera de presión. Debido a su composición química, el GNL es considerado como la forma más limpia del GN y, además, al ser no tóxico y no corrosivo, es considerado como un combustible con un importante potencial de aplicación en el transporte terrestre, en la industria, a nivel residencial y para la generación de potencia.

El GNL es incoloro e inodoro, no es explosivo y posee un bajo volumen específico (aproximadamente 600 veces menor al del GN a condiciones ambiente). Esta situación permite que el GN pueda ser transportado en grandes cantidades a través de buques o camiones cisterna de una manera económicamente atractiva [25], [26]. 
A condiciones de referencia, la densidad del GNL varía entre los 400 y $500 \mathrm{~kg} / \mathrm{m}^{3}$, está compuesta entre un 87 y un $99.8 \%$ por metano y su densidad calorífica inferior varía entre 21 y $24 \mathrm{GJ} / \mathrm{m}^{3}$ [27]. La conductividad térmica de este gas es de 0.19 y $0.22 \mathrm{~W} / \mathrm{mK}$ [28].

La cadena de valor del GNL está compuesta por cuatro partes, tal como se indica en la Figura NRO. 6. La primera es la etapa de extracción del GN desde la fuente, la segunda la obtención de GNL en la planta de licuefacción, la tercera el almacenamiento en lo que se conoce como estación satélite y, por último, se tiene el uso final por parte del consumidor [27].

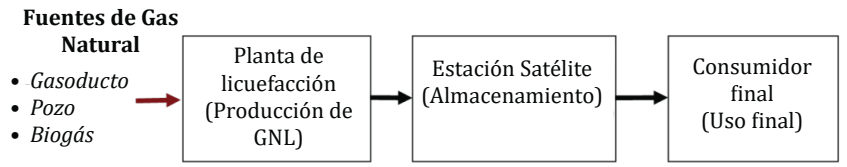

Figura NRo. 6. Cadena de valor del GNL.

Elaboración propia.

\subsection{Producción de GNL}

La producción del GNL se presenta en las denominadas plantas de licuefacción, mediante estas se llevan a cabo dos procesos principales: el pretratamiento y la licuefacción del gas. Durante el primero, los compuestos ácidos como el $\mathrm{CO}_{2} \mathrm{y}$ el $\mathrm{H}_{2} \mathrm{~S}$, además del vapor de agua, el mercurio y otras impurezas son removidas. En el segundo se extrae calor sensible y latente del GN y, posteriormente, se expande hasta alcanzar una presión aproximada a la atmosférica. En general, las plantas de licuefacción de GN se clasifican por su tamaño o escala como grande, mediana, pequeña y mini. Esta última se subclasifica en micro y nano escala de licuefacción [25], tal como se describen a continuación:

- Plantas de licuefacción a gran escala (base load).

Son plantas que presentan una producción de GNL mayor a 3 MTPA. Generalmente se comunican de manera directa con los campos de extracción de GN. La mayor parte de la producción de GNL en el mundo se da en este tipo de instalaciones. 
- Plantas de licuefacción a mediana escala (peak shaving).

A diferencia de las plantas a gran escala, estas se comunican directamente con una red de distribución de GN y permiten flexibilizar la operación de la red, pues, en épocas de baja demanda, estas plantas licúan el GN de la red y lo almacenan en tanques. Pero, cuando la demanda es alta, dichos espacios regasifican el GNL y lo reinyectan en la red, lo cual aumenta la oferta. Estas instalaciones cuentan con una capacidad de licuefacción de aproximadamente 1.5 MTPA y una capacidad de almacenamiento y regasificación de 2 MTPA.

- Plantas de licuefacción a pequeña escala.

Al igual que las de mediana escala, estas plantas se conectan directamente a la red de GN. Sin embargo, su producción de GNL es continua. Una vez se produce el GNL, este se distribuye por camiones cisterna a consumidores con demandas energéticas moderadas. Estas instalaciones tienen una capacidad de licuefacción menor a $300 \times 10^{3}$ TPA.

- Plantas de licuefacción a mini escala.

El esquema de operación de estas plantas es similar a las de pequeña escala. Cuentan con una capacidad de licuefacción menor a $18 \times 10^{3}$ TPA.

La TABLA NRO. 3 presenta las características de las escalas de licuefacción de GN disponibles comercialmente en el mundo [29], [31].

\begin{tabular}{lllll}
\hline \multirow{2}{*}{ Parámetro } & \multicolumn{4}{c}{ Producción de GNL } \\
\cline { 2 - 5 } & Mínimo & Máximo & Mínimo & (MBTUD) \\
\hline Gran escala & 9589 & 21918 & 497669 & 1137544 \\
\hline Mediana escala & 2740 & 5480 & 142206 & 584412 \\
\hline Pequeña escala & 60 & 800 & 3114 & 41520 \\
\hline Mini escala & 10 & 50 & 519 & 2595 \\
\hline Micro escala & 16 & 50 & 779 & 2595 \\
\hline Nano escala & 10 & 15 & 519 & 778.5 \\
\hline
\end{tabular}

TABLa NRO. 3. Escalas de las plantas de licuefacción de GN. Elaboración propia. 


\subsubsection{Pretratamiento}

Antes de llevar el GN al proceso de licuefacción, las especies químicas, tales como el agua, el dióxido de carbono, el ácido sulfhídrico, los hidrocarburos pesados y el mercurio deben ser removidos. Lo anterior con el propósito de inhibir procesos de corrosión en materiales y evitar daños y problemas importantes durante el proceso de licuefacción. Para ello, el GN debe ser sometido a una serie de procesos que permitan realizar la remoción de estas especies químicas con potencial de solidificación, para así alcanzar las especificaciones recomendadas para ejecutar la licuefacción y atender requisitos de seguridad y responsabilidad ambiental. Estos procesos y requisitos mínimos son presentados a continuación en la TABLA NRO. 4.

\begin{tabular}{|c|c|c|}
\hline Proceso & Descripción & $\begin{array}{l}\text { Requerimientos } \\
\text { mínimos }\end{array}$ \\
\hline Endulzamiento & $\begin{array}{ll}- & \text { Reducción de fenómenos de corrosión. } \\
\text { - } & \text { Transformación del sulfuro de hidrógeno en } \\
\text { azufre. } \\
\text { - } \\
\text { Proceso basado en el uso de metil- } \\
\text { dietanolamina. }\end{array}$ & $\begin{array}{l}\mathrm{H}_{2} \mathrm{~S}(3.3 \mathrm{ppm}) \\
\mathrm{CO}_{2}(50 \mathrm{ppm})\end{array}$ \\
\hline Deshidratación & 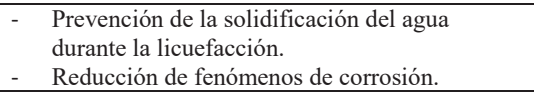 & $\mathrm{H}_{2} \mathrm{O}(1 \mathrm{ppm})$ \\
\hline Remoción de mercurio & $\begin{array}{l}\text { Reducción de problemas en los equipos } \\
\text { fabricados en aluminio. }\end{array}$ & $\mathrm{Hg}\left(10 \mathrm{ng} / \mathrm{m}^{3}\right)$ \\
\hline Remoción $N L G s$ & $\begin{array}{l}\text { - Prevención de la solidificación de } \\
\text { hidrocarburos y compuestos aromáticos en los } \\
\text { intercambiadores de calor criogénicos. }\end{array}$ & $\begin{array}{l}\mathrm{C}_{5}+\text { hidrocarburos } \\
(1000 \mathrm{ppm}) \\
\text { Aromáticos }(10 \mathrm{ppm})\end{array}$ \\
\hline $\begin{array}{l}\text { Remoción de } \\
\text { mercaptanos }\end{array}$ & $\begin{array}{ll}\text { - } & \text { Los mercaptanos son corrosivos y tóxicos. } \\
\text { - } & \text { Deben separarse del sulfuro de hidrógeno. } \\
\text { - } & \text { Pueden ocasionar problemas durante el } \\
\text { proceso de remoción de compuestos ácidos. }\end{array}$ & $0 \mathrm{ppm}$ \\
\hline Remoción de nitrógeno & $\begin{array}{l}\text { - } \quad \text { Uso de evaporadores tipo flash. } \\
\text { - } \\
\text { Reducción de la probabilidad de ocurrencia del } \\
\text { - } \\
\text { Reducción de la temperatura y la presión del } \\
\text { GNL sin consumo energético adicional. } \\
\text { - El punto de ebullición del nitrógeno es similar } \\
\text { al punto de ebullición del metano. } \\
\text { - Uso de columnas de destilación para reducción } \\
\text { de pérdidas de metano. }\end{array}$ & $1 \% \mathrm{~V} / \mathrm{V}$ \\
\hline $\begin{array}{l}\text { Remoción de gas } \\
\text { líquido de propano } \\
\text { (GLP) }\end{array}$ & $\begin{array}{l}\text { Uso de una columna de destilación simple para } \\
\text { una remoción moderada. } \\
\text { El proceso de remoción de GLP depende de } \\
\text { factores como la composición del gas, la } \\
\text { capacidad disponible y el nivel de remoción } \\
\text { requerido. }\end{array}$ & No especificado \\
\hline
\end{tabular}

TABLA NRO. 4. Remoción de impurezas en el proceso de pretratamiento. Tomada de [28]. 
A partir del pretratamiento del GN, el proceso de licuefacción puede ser diseñado para que el GNL alcance una concentración de metano de aproximadamente un $100 \%$ o para que este cuente con una proporción de especies químicas que le permita satisfacer los estándares de transporte de GN mediante gasoducto hasta el usuario final [25]. La TABLA NRO. 5 presenta la composición típica del GN y del GNL. En esta se observa que el gas natural, en fase líquida, posee una mayor concentración de metano, lo cual implica un mayor poder calorífico de la sustancia en comparación a su fase gaseosa, dado que disminuye la proporción de hidrocarburos más pesados de menor poder calorífico.

\begin{tabular}{lcc}
\hline Especie química & \multicolumn{3}{c}{ Fracción molar } \\
\cline { 2 - 3 } & Gas natural & GNL \\
\hline $\mathrm{CH}_{4}$ & $70-90 \%$ & $85-97 \%$ \\
\hline $\mathrm{C}_{2} \mathrm{H}_{6}$ & $0-20 \%$ & $<4 \%$ \\
\hline $\mathrm{C}_{3} \mathrm{H}_{8}, \mathrm{n}-\mathrm{C}_{4} \mathrm{H}_{10}$ & $0-20 \%$ & $<2 \%$ \\
\hline $\mathrm{C}_{5} \mathrm{H}_{12}, \mathrm{C}_{6} \mathrm{H}_{14}$ & $0-20 \%$ & $<0.02 \%$ \\
\hline $\mathrm{H}_{2} \mathrm{O}$ & $0-5 \%$ & $<0.1 \mathrm{ppm}$ \\
\hline $\mathrm{CO}_{2}$ & $0-8 \%$ & $<50 \mathrm{ppm}$ \\
\hline $\mathrm{H}_{2} \mathrm{~S}$ & $0-5 \%$ & $<1 \mathrm{ppm}$ \\
\hline $\mathrm{Hg}$ & $0-5 \%$ & $<1 \mathrm{ppm}$ \\
\hline
\end{tabular}

TABLA NRO. 5. Composición típica del GN y del GNL.

Tomada de [32].

\subsubsection{Licuefacción}

La licuefacción es un proceso donde el GN intercambia calor con un fluido más frío, seguido por una expansión que causa una reducción en la temperatura [33]. En este asunto, el GN se lleva hasta la fase de mezcla líquido-vapor [34] y, para ello, se usa una planta de licuefacción donde un refrigerante es sometido a una serie de procesos de expansión y compresión, y se rechaza calor hacia un ambiente de baja temperatura. En la actualidad, las plantas de licuefacción emplean ciclos como: en cascada, de refrigerante mixto y de expansión [35], los cuales se describen a continuación:

- Ciclo de refrigeración en cascada.

En este proceso se emplean múltiples subciclos de refrigeración que son controlados de manera independiente. En cada uno de los circuitos, el refrigerante se evapora a diferentes condiciones de temperatura y 
presión. Este tipo de técnicas se emplean principalmente en plantas con grandes capacidades de producción, por lo que demandan altos costos de inversión, pero presentan bajos riesgos técnicos. Su operación cuenta con limitaciones importantes a bajas tasas de producción y su flexibilidad no es suficiente para atender variaciones en la composición del GN. En el mercado, las tecnologías que operan con este tipo de ciclos cuentan con capacidades de licuefacción entre 4 y 9 MTPA [36].

- Ciclo de refrigeración de refrigerante mixto.

En este ciclo, el proceso de enfriamiento se realiza mediante el uso de una mezcla de hidrocarburos livianos y nitrógeno. Esta mezcla no solo permite alcanzar temperaturas criogénicas, sino reducir el número de compresores requeridos por el sistema y disminuir el consumo de energía. Así mismo, estos sistemas requieren una menor cantidad intercambiadores de calor, los cuales, a su vez, son de menores dimensiones y derivan en un sistema de refrigeración más compacto. Esta tipología de ciclos se pueden subclasificar en:

Ciclo de refrigerante mixto simple: es un ciclo Rankine invertido que emplea un refrigerante mixto o propano como fluido de trabajo. Puede producir GNL en tasas entre 0.2 y 3 MTPA [36].

Ciclo de refrigerante mixto dual: está compuesto por dos ciclos de refrigeración independientes. En el primero, el GN es preenfriado mediante un refrigerante mixto. Posteriormente, dicho gas se lleva a un proceso de condensación en un segundo intercambiador de calor que emplea un refrigerante más liviano. En el mercado, estas tecnologías pueden producir GNL a tasas que varían entre los 0.5 y los 8 MTPA [36].

- Ciclo de expansión de gas.

En este ciclo, el GN es licuado mediante el uso de nitrógeno, el cual se mantiene en fase gaseosa en todo el proceso e intercambia calor sensible con el GN. Generalmente, estos ciclos cuentan con procesos de expansión que pueden ser simples o dobles, y son aprovechados para 
reducir la demanda de energía de los compresores. Así mismo, pueden emplear propano para preenfriar el GN y mejorar la eficiencia del ciclo. Estas tecnologías son principalmente empleadas para la licuefacción a pequeña escala [37].

A continuación, la TABLA NRO. 6 presenta datos de consumo de energía de cada ciclo de refrigeración. Por su parte, la TABLA NRO. 7 muestra un recuento de las ventajas y desventajas de los ciclos empleados en los procesos de licuefacción de GN.

\begin{tabular}{ll}
\hline Ciclo de refrigeración & Consumo de energía (kWh/kg GNL) \\
\hline Cascada & 0.35 \\
\hline Refrigerante mixto con etapa simple & 0.44 \\
\hline Refrigerante mixto multietapa & 0.37 \\
\hline Expansión simple & 0.70 \\
\hline Expansión simple con preenfriamiento de propano & 0.60 \\
\hline Doble expansión & 0.60 \\
\hline
\end{tabular}

TABLA NRo. 6. Consumo de energía de los ciclos de licuefacción.

Tomada de [37].

\begin{tabular}{|c|c|c|}
\hline Ciclo & Ventajas & Desventajas \\
\hline Ciclo de cascada & 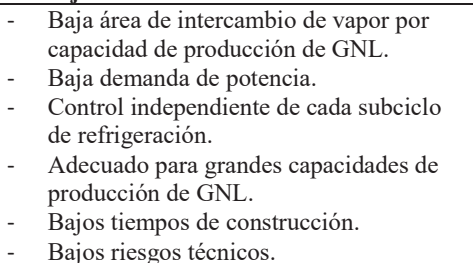 & $\begin{array}{l}\text { - } \quad \text { Costo de capital alto. } \\
\text { - Poca flexibilidad de operación } \\
\text { ante cambios en la } \\
\text { composición del GN. } \\
\text { - Limitaciones en la capacidad } \\
\text { de los trenes de producción. }\end{array}$ \\
\hline $\begin{array}{l}\text { Ciclo de } \\
\text { refrigerante } \\
\text { mixto }\end{array}$ & 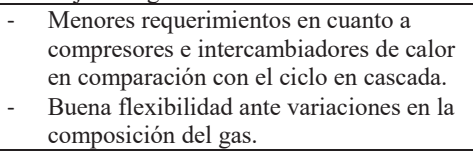 & $\begin{array}{ll}\text { - } & \text { Bajo rendimiento. } \\
\text { - } & \text { Lentos procesos de inicio y } \\
\text { estabilización. }\end{array}$ \\
\hline $\begin{array}{l}\text { Ciclo de } \\
\text { refrigerante } \\
\text { mixto simple }\end{array}$ & $\begin{array}{ll}- & \text { Bajo costo. } \\
\text { - } & \text { Configuración simple. }\end{array}$ & $\begin{array}{l}\text { - } \quad \text { Baja eficiencia. } \\
\text { - } \quad \text { Recomendado únicamente para } \\
\text { plantas a pequeña y mediana } \\
\text { escala. }\end{array}$ \\
\hline $\begin{array}{l}\text { Ciclo de } \\
\text { refrigerante } \\
\text { mixto doble }\end{array}$ & $\begin{array}{l}\text { - Menor consumo de energía en } \\
\text { comparación con el ciclo de refrigerante } \\
\text { mixto simple. }\end{array}$ & $\begin{array}{ll} & \text { Mayor número de equipos. } \\
\text { - } & \text { Mayor complejidad del } \\
& \text { proceso. }\end{array}$ \\
\hline $\begin{array}{l}\text { Ciclos de } \\
\text { expansión del } \\
\text { gas }\end{array}$ & $\begin{array}{ll}\text { - } & \text { Operación simple. } \\
\text { - } & \text { Menor flexibilidad ante variaciones en la } \\
\text { composición del gas. } \\
\text { - } \quad \text { Usado para licuefacción a pequeña escala. }\end{array}$ & $\begin{array}{l}\text { Menor rendimiento que los } \\
\text { ciclos de cascada y de } \\
\text { refrigerante mixto. }\end{array}$ \\
\hline
\end{tabular}

TABLA NRo. 7. Ventajas y desventajas de los ciclos de licuefacción de gas natural. Tomada de [37]. 


\subsubsection{Almacenamiento de GNL}

Una vez licuado, el GNL es llevado a tanques criogénicos localizados en lo que se denomina estación satélite. Estos tanques cuentan con un recipiente interno fabricado con una aleación de níquel y una cubierta de refuerzo de concreto para garantizar la contención del fluido en una eventual ruptura del tanque interior. Generalmente, en la producción de GNL a pequeña escala se emplean tanques de fondo plano con capacidades de almacenamiento entre 7500 y $160000 \mathrm{~m}^{3}$, tanques esféricos cuya capacidad varía entre 1000 y $8000 \mathrm{~m}^{3}$, o tanques de tipo bala que pueden almacenar entre 50 y $1200 \mathrm{~m}^{3}$ de GNL [38], [39].

- $\quad$ Tanques de fondo plano.

Los tanques de fondo plano cuentan con sistemas secundarios de contención en caso de derrame. Dependiendo de la tipología de contención empleada, estos pueden clasificarse como: de contención simple, de contención doble y de contención integral. Los primeros cuentan con un tanque interior compuesto en un $9 \%$ por níquel y también tienen un tanque externo fabricado en acero al carbono con un aislamiento de perlita en medio. Los segundos son tanques de contención simple con una pared externa de concreto reforzado que permite contener el GNL en caso de una ruptura en el tanque interior. Los terceros están compuestos por un tanque interior encerrado completamente por otro exterior que permite contener el GNL en fase gaseosa y líquida en caso de ruptura. Este último es el más empleado a nivel comercial en la última década, puesto que cuenta con un mayor nivel de seguridad para la contención de fluidos criogénicos [25], [29].

Los tanques de fondo plano realizan el almacenamiento del GNL a presión del mismo a presión atmosférica, tienen una capacidad de almacenamiento entre 7500 y $160000 \mathrm{~m}^{3}$, producen boil-off gas (BOG) a una tasa que varía entre el 0.05 y el $0.1 \%$ del volumen almacenado por día y su instalación puede tardar entre 18 y 36 meses. 
- Tanques esféricos.

Esta tipología de almacenamiento es raramente utilizada, pues, dada su geometría, requiere una menor área superficial por unidad de volumen y reduce la transferencia de calor y, por tanto, la generación de $B O G$. Estos cuentan con una estructura resistente, una mejor distribución de esfuerzos a lo largo del tanque [29] y con capacidades de almacenamiento entre 1000 y $8000 \mathrm{~m}^{3}$ de GNL [29].

- Tanques tipo bala.

Los tanques tipo bala están construidos en acero inoxidable con un aislamiento de perlita o de vacío multicapa. Generalmente, cuentan con una lámina de acero interior que resiste condiciones criogénicas y un casquete de acero no resistente al contacto con fluidos criogénicos. Debido a su diseño y operación, estos tanques almacenan el GNL a una presión absoluta entre 0.5 y 8 bar, cuentan con una baja tasa de generación de $B O G$ (entre el 0.05 y el $0.15 \%$ del volumen de GNL almacenado por día), demandan un bajo tiempo de instalación (solo algunas semanas) y no requieren de un compresor de $B O G$ [29].

En este tipo de tecnologías, el GNL es almacenado modularmente en múltiples tanques; arreglos que permiten alcanzar capacidades de almacenamiento de hasta $20000 \mathrm{~m}^{3}$ [29]. Adicionalmente, los tanques tipo bala pueden ser utilizados en configuración vertical $u$ horizontal, de forma tal que el arreglo puede ser ajustado de acuerdo a la capacidad de almacenamiento requerida. Debido a esto, dichos tanques son ampliamente empleados en instalaciones pequeñas. Particularmente, en aplicaciones en el sector transporte se recomienda el uso de tanques verticales con capacidades entre 10 y $120 \mathrm{~m}^{3}$, aun cuando su capacidad máxima de almacenamiento puede llegar a $\operatorname{los} 300 \mathrm{~m}^{3}$ [40]. Por su parte, los tanques horizontales son generalmente utilizados en estaciones satélites de GNL, pues su capacidad de almacenamiento puede llegar hasta los $1200 \mathrm{~m}^{3}$ [29], [40]. A continuación, la FiguRA NRO. 7 presenta esquemáticamente la disposición de las diferentes tipologías de tanques de almacenamiento. 


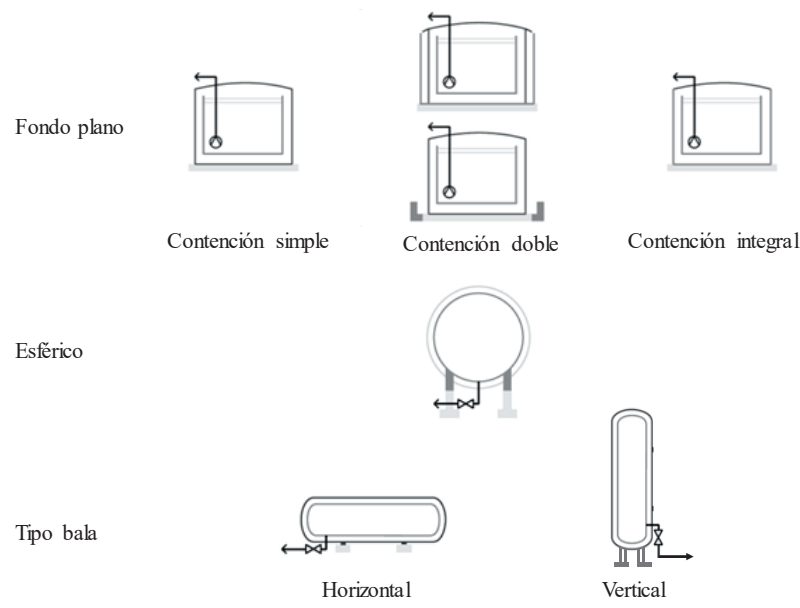

Figura Nro. 7. Disposición de los tanques por tipo. Elaboración propia.

Durante el almacenamiento, los tanques transfieren constantemente calor con el ambiente, lo cual, junto con el funcionamiento de las bombas y los cambios en la presión atmosférica, hace que una fracción del GNL se vaporice y dé lugar a lo que se conoce como boil-off gas $(B O G)$ [41], [42]. La presencia del $B O G$ al interior de los tanques induce un aumento de su presión en el tiempo. Particularmente, los tanques de acopio de GNL deben la presión en valores por debajo de 175 y 200 psi; por tanto, cuando dicha presión alcanza entre 150 y 175 psig, se debe extraer el $B O G$ para reducirla a valores aceptables [42]. Luego de extraído, el $B O G$ (predominantemente metano y nitrógeno) puede ser controlado mediante las siguientes estrategias: 1) venteo, el cual es usado principalmente en situaciones de emergencia que involucran la presurización del tanque por encima de los niveles permitidos; 2) quema en antorcha; 3) retorno del $B O G$ al tanque de suministro de GNL (método usado principalmente durante la transferencia del GNL desde el buque metanero hacia la estación de almacenamiento); 4) recondensación del $B O G$ y bombeo hacia atrás; 5) combustión en un sistema de generación de potencia para suplir el consumo eléctrico del sistema; 6) recirculación y aspersión; 7) bombeo a una línea de baja presión $(\mathrm{P}<10$ bar); 8) bombeo a una línea de alta presión (10 bar $<\mathrm{P}$ $<103$ bar) y 9) relicuefacción [43]. 
Adicionalmente, durante el proceso de transferencia de calor entre el tanque y el ambiente, los procesos de transferencia de masa y calor por efectos convectivos aumentan considerablemente en la región más cercana a la superficie libre del GNL y fomentan la generación de $B O G$. Este proceso evaporativo hace que la temperatura del fluido se mantenga en valores relativamente constantes y que la región cercana a la superficie libre del GNL aumente su densidad y llegue a un punto tal que el fluido comience a reestratificarse y dé inicio a un proceso de recirculación natural mediante el fenómeno denominado roll over, el cual es descrito esquemáticamente mediante la Figura NRO. 8.

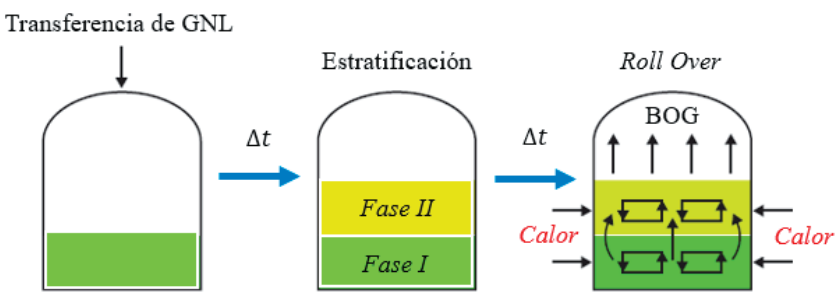

Figura NRO. 8. Proceso de generación de BOG-Estratificación y roll over. Tomada de [28].

\subsubsection{Transporte de GNL}

Si la distribución se realiza en tierra, se recomienda que para distancias mayores a $150 \mathrm{~km}$, el gas natural sea transportado en fase líquida mediante camiones cisterna que cuenten con capacidades de almacenamiento entre 40 y $50 \mathrm{~m}^{3}$, los cuales operan con el $B O G$ generado y cuentan con un consumo de aproximadamente $0.75 \mathrm{l} / \mathrm{km}$ [31], [44]. A continuación, la FiguRA NRO. 9 presenta la tecnología de suministro de GNL asociado a los camiones cisterna que lo transportan y lo transfieren a las estaciones de recarga y de regasificación a pequeña escala. 


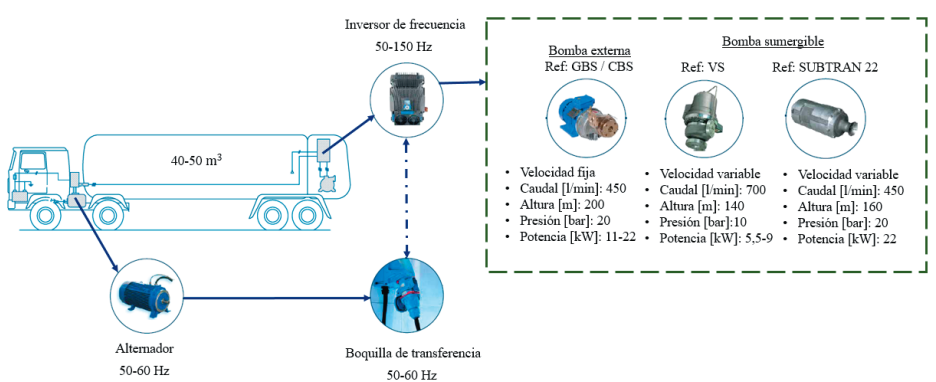

Figura nRo. 9. Tecnología de los camiones cisterna.

Tomada de [45].

Una vez el GNL es transportado vía camión cisterna, este debe ser descargado en los tanques de almacenamiento. La FIGURA NRO. 10 muestra el esquema general del proceso de descarga de dichos camiones, el cual cuenta con tres líneas de flujo: línea de GNL desde el camión cisterna hasta el depósito de almacenamiento, línea de salida de GNL del camión cisterna hacia el regasificador de descarga y línea de GNL regasificado de retorno hacia el camión cisterna. Se considera que, una fracción del GNL almacenado en la cisterna se regasifica con el fin de elevar la presión al interior y poder tener una presión mayor a la del depósito de almacenamiento. El regasificador de descarga no se halla incorporado a la cisterna, sino que es una instalación fija de la planta. Gracias al regasificador es posible mantener una mayor presión de la cisterna durante la descarga que la de almacenamiento del depósito; así se consigue la descarga de cisternas sin necesidad de un equipo de bombeo [40].

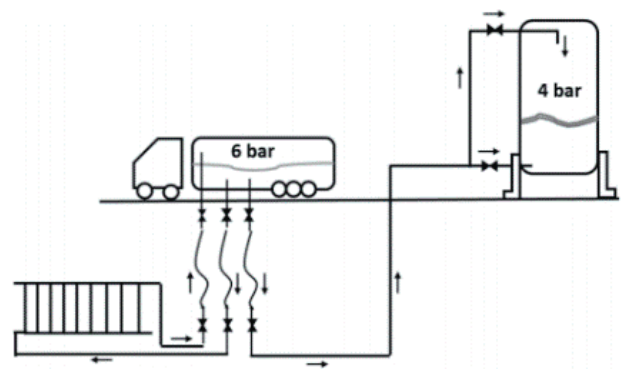

Figura NRO. 10. Descarga por diferencia de presión. Tomada de [40]. 


\subsubsection{Regasificación del GNL}

Para el proceso de regasificación se dispone de varias alternativas tecnológicas comúnmente utilizadas, las cuales, dependiendo de la localización geográfica, resultan más o menos convenientes que otras [46]:

- Bu que-unidad de regasificación y almacenamiento flotante (Floating Storage and Regasification Unit, FSRU, por sus siglas en inglés).

- FSRU de régimen permanente/estacional.

- Floating Storage Unit (FSU), de régimen permanente estacional y regasificación en tierra [46].

- Planta de regasificación sin almacenamiento con buque convencional de transporte de GNL (Buques LNGC, Liquiefied Natural Gas Carrier).

- Planta regasificación y almacenamiento en tierra.

La operación de las FSRU está basada en buques de transporte de GNL que emplean tecnologías de regasificación en tierra, pues la diferencia radica en que los equipos empleados deben ser aptos para aplicaciones marinas. Dado que la mayoría de las terminales on-shore están instaladas cerca de la costa, muchos de los equipos empleados en la regasificación deben ser aptos para operar en ambientes marinos y cumplir requisitos como resistencia a la humedad, deposiciones salinas y, cargas dinámicas y estáticas de las estructuras de soporte. En las FSRU los equipos se integran y se construyen en conjunto con el buque. En aras de reducir tiempos de construcción e instalación, los sistemas son fabricados de manera modular y, posteriormente, ensamblados en el astillero durante la fabricación de la FSRU [46]. Las FSRU pueden ser de tipo empty and leave o de tipo estacional donde las primeras, a diferencia de las segundas, no necesitan de un buque transportador. 
Una planta de regasificación de GNL de tipo FSU (floating storage unit) se caracteriza por permanecer amarrada al puerto con el fin de almacenar dicho gas, mientras que las unidades de regasificación pueden estar situadas en tierra (on-shore) o en el propio puerto (off-shore). El GNL es almacenado en la FSU y, posteriormente, es bombeado hacia la planta de regasificación mediante una tubería criogénica. Cuando la unidad de regasificación está ubicada en el puerto, el GN en fase gaseosa se lleva a la conexión en tierra mediante un gasoducto submarino o aéreo. Adicionalmente, las FSU se encuentran equipadas con brazos de descarga de GNL, lo cual permite realizar la transferencia de forma segura, desde la conexión en el FSU a la tubería de descarga que lo lleva a la planta de regasificación [46].

Una planta de regasificación sin almacenamiento de GNL en buque convencional consta de una estación de regasificación y unas instalaciones portuarias con un puerto donde se amarran los buques metaneros que llegan para descargar el GNL.

Una planta de regasificación de GNL y de almacenaje en tierra se encuentra conectada con un buque donde se efectúa la descarga de GNL desde buques metaneros. Los buques están equipados con los brazos de descarga, los cuales se encargan de la transferencia del GNL desde el buque a la tubería de descarga que lo transporta a la planta. Una vez en esta, el GNL proveniente del buque se dispone en tanques para almacenar el gas líquido en condiciones criogénicas [46].

En las siguientes líneas se muestra una descripción de los principales elementos de una planta de regasificación de GNL.

\section{- Elementos de descarga.}

Brazos de descarga: los brazos son accionados hidráulicamente y tienen dos articulaciones giratorias que permiten maniobrarlos para ponerlos en posición. Los brazos deben resistir las bajas temperaturas del GNL que fluye por su interior; por esto, los materiales tienen una aleación especial (invar, aleación de hierro y níquel al 36 \%) y, además, deben resistir el movimiento del buque y el FSRU [47]. 
Mangueras criogénicas de descarga: estos elementos, por su flexibilidad, proporcionan seguridad al descargar y cargar respectivamente el buque y el FSRU, todo ello al tener en cuenta que se genera un cambio de alturas para ambos y, además, al transferir GNL, las bajas temperaturas pueden generar fracturas en los dispositivos de suministro. Las mangueras criogénicas están compuestas por capas poliméricas no adheridas y capas de tela tejida encapsuladas entre dos hélices de alambre de acero inoxidable, una interna y otra externa [47].

Vaporizador: un vaporizador de GNL es un dispositivo que induce el proceso de cambio de fase del GNL de líquido a vapor. Para ello se utiliza aire ambiente que pasa a través de una serie de tuberías por donde este fluye. El calor requerido para la vaporización del GNL depende principalmente de la presión de suministro al consumidor. En la TABLA NRO. 8 se presentan valores típicos de presión de suministro para diferentes usos [27]

\begin{tabular}{ll}
\hline Tipo de proceso & Presión (bar) \\
\hline Centrales de vapor & 6 \\
\hline Estaciones de ciclo combinado & 25 \\
\hline Distribución local & 30 \\
\hline Distribución a larga distancia & 70 \\
\hline
\end{tabular}

TABLA NRO. 8. Valor de presión de acuerdo al uso de GN. Tomada de [27].

Los vaporizadores de GNL se pueden clasificar en cuatro tipos [40]:

- Vaporizadores de bastidor abierto (OVR).

- Vaporizadores de combustión sumergida (SCV).

- Vaporizadores de fluido intermedio (IFV).

- Vaporizadores de aire ambiente (AAV).

Los vaporizadores de bastidor abierto y los vaporizadores de combustión sumergidos son los tipos de vaporizadores comúnmente utilizados en procesos de regasificación de GNL a gran escala con una participación del $70 \%$ y el $20 \%$ respectivamente [27]. 
- Recondensador.

Para todos los modos de operación, las instalaciones de regasificación de GNL (en tierra y en alta mar) producen gas de ebullición $(B O G)$ a baja presión. Este $B O G$ requiere un procesamiento y ventilación para minimizar las pérdidas de gas y las emisiones ambientales de dichas instalaciones. El recondensador se ha utilizado durante mucho tiempo en terminales de GNL en tierra como un medio económico y eficaz para manejar el $B O G$ a bajas presiones [48].

Actualmente hay varios diseños de recondensadores disponibles para las instalaciones de GNL que logran recondensar el gas natural al utilizar una corriente de GNL. La adopción de estrategias operativas que resultan en la conservación de una tonelada de gas a bordo (en lugar de quemarlo en la GCU) para que pueda contribuir al envío del mismo (la carga vendida) o se use para la generación de energía abordo tiene claros beneficios comerciales. El consumo de cualquier gas en la GCU implica eliminación, sin ningún beneficio positivo, de su contenido de energía [48]. Una tonelada de $B O G$ quemada en la unidad de gas de combustión (GCU), la cual es equivalente a 52.7 MBTU (de acuerdo al valor del poder calorífico superior del metano, el cual es $52.7 \mathrm{kBTU} / \mathrm{kg}$ ) tendría un valor de USD \$370 si se vende a USD \$7/MBTU.

- Compresores.

A continuación, la TABLA NRO. 9 presenta las características técnicas de los compresores de etapa simple y doble etapa comúnmente utilizados para la transferencia de $B O G$ dentro del sistema de regasificación de un FSRU. Se caracterizan por poseer álabes ajustables y sellados de gas. 


\begin{tabular}{ll}
\hline & Compresor de etapa simple \\
\hline Caudal $\left(\mathrm{m}^{3} / \mathrm{h}\right)$ & $3500-40000$ \\
\hline Presión de descarga (bar) & 2.03 \\
\hline Presión de succión (bar) & 1.03 \\
\hline Aplicaciones & Transferencia de $B O G$ para: \\
& $-\quad$ Puerto \\
& $-\quad$ Enfriamiento \\
& $-\quad$ Calentamiento de tanques de almacenamiento \\
\hline & Compresor de doble etapa \\
\hline Caudal $\left(\mathrm{m}^{3} / \mathrm{h}\right)$ & $2500-6000$ \\
\hline Presión de descarga (bar) & 6.5 \\
\hline Presión de succión (bar) & 1.03 \\
\hline Aplicaciones & Mantener el nivel de presión de los tanques de almacenamiento al \\
& transferir $B O G$ a una unidad de combustión o motor utilizado en la \\
& navegación del buque. \\
\hline
\end{tabular}

TABLA NRO. 9. Compresor de $\mathrm{BOG}$ de etapa simple.

Tomada de [45].

- Bombas criogénicas.

A continuación, la TABLA NRO. 10 presenta las características técnicas de una típica bomba criogénica sumergible, la cual es utilizada para el bombeo de líquidos criogénicos en plantas de regasificación de GNL como la FSRU. Esta se caracteriza por tener un aislamiento de presión de vacío junto con una pintura criogénica especial, situación que le permite operar a temperaturas criogénicas.

\begin{tabular}{|c|c|c|c|c|}
\hline & \multicolumn{4}{|c|}{ Modelo } \\
\hline & 60721 & $60721-2$ & $60721-3$ & $60721-4$ \\
\hline Parámetro/Tipo & \multicolumn{4}{|c|}{ Sumergible } \\
\hline Caudal $\left(\mathrm{m}^{3} / \mathrm{h}\right)$ & $700-1900$ & $700-1900$ & $500-1900$ & $500-1900$ \\
\hline Altura $(\mathrm{m})$ & $70-300$ & $200-500$ & $400-850$ & $600-1200$ \\
\hline Parámetro/Tipo & \multicolumn{4}{|c|}{ Motor trifásico de inducción sumergido } \\
\hline Número de polos & \multicolumn{4}{|l|}{$2 / 4$} \\
\hline Voltaje & \multicolumn{4}{|c|}{$200 / 400 / 3000 / 3300 / 6000 / 6600$} \\
\hline Frecuencia $(\mathrm{Hz})$ & \multicolumn{4}{|c|}{$50 / 60$} \\
\hline Tipo aislante & \multicolumn{4}{|c|}{ Clase F: Impregnación de presión de vacío con pintura criogénica especial } \\
\hline
\end{tabular}

TABLA NRO. 10. Características técnicas de una bomba criogénica sumergible típica. Tomada de [49].

EnlaFigURANRO. 11 semuestrauna centralderegasificacióna pequeña escala, la cual se usa para atender los sectores termoeléctrico, industrial y residencial. Esta tiene una estructura similar, independientemente del sector, y sus componentes típicos son uno o varios tanques de almacenamiento, vaporizadores, sistema de odorización, control de vaporización y sistema de regulación de presión de despacho. 
De acuerdo a la aplicación, las centrales se diferencian según el requerimiento de la demanda de gas, pues de acuerdo a este se calculan las dimensiones del sistema de almacenamiento y las condiciones de vaporización requeridas. Finalmente se seleccionan los equipos de acuerdo a lo disponible en el mercado [29].

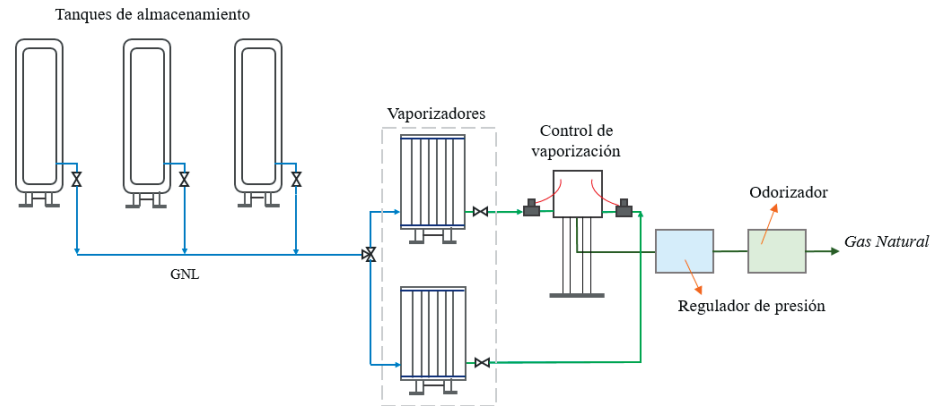

FigURA NRO. 11. Central de regasificación a pequeña escala.

Tomada de [50].

Ahora, se presenta la descripción de los elementos de una planta de regasificación de GNL a pequeña escala [29]:

- $\quad$ Tanques de almacenamiento.

En el almacenamiento de GNL se usan los mismos tanques utilizados en las centrales de regasificación. De tal manera, el tipo de tanque a usar en cada aplicación depende del volumen de GNL para almacenar.

- Vaporizador.

En aplicaciones a pequeña escala los vaporizadores más utilizados usan el aire del entorno como fluido para calentar el GNL. Estos vaporizadores operan bajo las siguientes condiciones:

- Caudales entre 400 y $600 \mathrm{~m}^{3} / \mathrm{h}$ a condiciones estándar (STP).

- Presión máxima de operación de 420 bar.

- Presión entrada del GNL entre 200 y 250 bar. 
Generalmente dichos vaporizadores se fabrican en acero inoxidable AISI 304L y tienen un sistema de odorización. En la TABLA NRO. 11 se encuentran datos técnicos de estos, los cuales están disponibles comercialmente.

\begin{tabular}{|c|c|c|c|c|}
\hline $\begin{array}{l}\text { Gas natural } \\
\left(\times 10^{3} \mathrm{pie}^{3}{ }_{\text {std }} / \mathrm{h}\right)\end{array}$ & $\begin{array}{l}\text { Longitud } \\
\text { (pie) }\end{array}$ & $\begin{array}{l}\text { Ancho } \\
\text { (pie) }\end{array}$ & $\begin{array}{l}\text { Alto } \\
\text { (pie) }\end{array}$ & $\begin{array}{l}\text { Peso } \\
\text { (lb) }\end{array}$ \\
\hline 1 & 1.8 & 1.8 & 7.5 & 132 \\
\hline 2 & 1.8 & 1.8 & 12.4 & 200 \\
\hline 4 & 1.8 & 3.4 & 12.4 & 366 \\
\hline 6 & 2.6 & 3.4 & 12.4 & 538 \\
\hline 8 & 3.4 & 3.4 & 12.4 & 661 \\
\hline 10 & 4.3 & 3.4 & 12.4 & 833 \\
\hline 12 & 3.4 & 5.0 & 12.4 & 981 \\
\hline 15 & 4.3 & 5.0 & 12.4 & 1190 \\
\hline 18 & 5.0 & 5.0 & 12.4 & 1413 \\
\hline 20 & 5.9 & 5.0 & 12.4 & 1635 \\
\hline 15 & 4.3 & 8.4 & 12.4 & 1948 \\
\hline
\end{tabular}

TABLA NRO. 11. Características técnicas de vaporizadores de GNL. Tomada de [51].

- Control de vaporización.

Después de que el GNL se ha vaporizado, se hace necesario usar un sistema de control de vaporización, el cual se encarga de controlar el flujo de volumen de gas suministrado [52].

- Odorizador.

El GN es un gas inodoro y potencialmente peligroso en concentraciones entre $4.5 \%$ y $14.5 \%$ en el aire, rango en el cual puede iniciarse la combustión. De acuerdo a esto, el gas natural debe ser sometido a un proceso de odorización mediante la adición de sustancias conocidas como odorizantes, la cuales poseen un olor fuerte y permiten detectar una fuga de dicho gas. El proceso de odorización es uno de los pasos más importantes en la operación del sistema de regasificación, por lo que debe ser llevado a cabo de manera precisa y confiable [53]. La FiguRA NRO. 11 muestra un diagrama esquemático de un sistema de odorización de gases. 


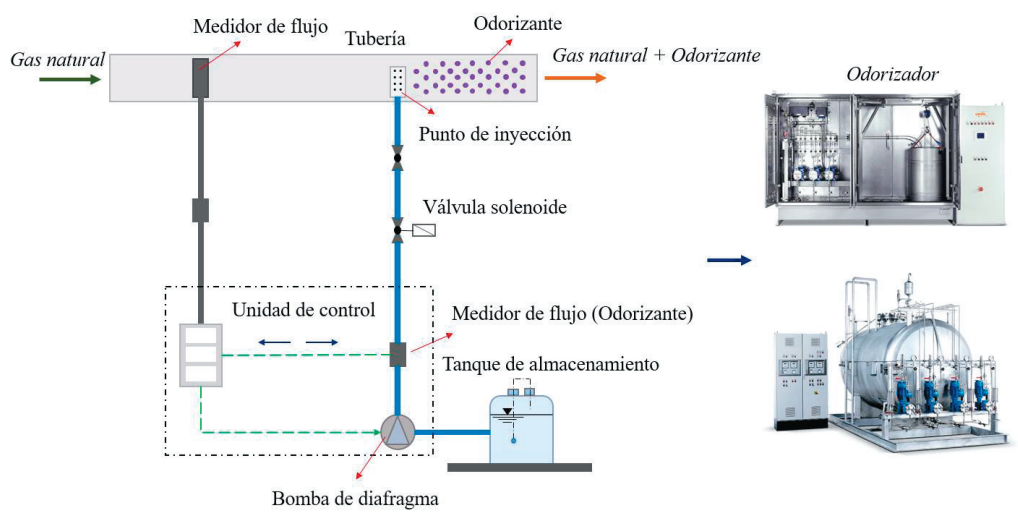

Figura NRo. 12. Esquema de un sistema de odorización de gas natural. Tomada de [53].

- Sistema de regulación de presión de despacho.

Este opera cuando se presenta una caída de la presión del gas natural por debajo de un valor determinado. Este sistema se puede disponer antes o después del vaporizador, de acuerdo a las características del sistema de regasificación, pues si se instala antes del mismo, es necesario incorporar un filtro que no permita el paso de partículas metálicas [54].

Cada uno de los elementos mencionados son distribuidos y comercializados por diferentes fabricantes con sus propias características técnicas. También hay productores que ofrecen soluciones integradas de regasificación de GNL, entre ellos:

- Chart Industries: es una compañía reconocida a nivel mundial en el diseño y suministro de equipos criogénicos. Esta ofrece una opción de almacenamiento y regasificación portable o in situ de GNL. Con esta solución de tipo portable sería posible atender demandas de gas natural en zonas donde no es posible llegar con un gasoducto. En la TABLA NRO. 12 se muestran las características técnicas de este tipo de oferta. 


\begin{tabular}{|c|c|}
\hline Característica & Especificaciones \\
\hline $\begin{array}{l}\text { Desempeño de vaporizador } \\
\text { ( } 2 \text { opciones) }\end{array}$ & $\begin{array}{l}150 \mathrm{~kW} \text { unidad con flujo de operación (a condiciones } \\
\text { estándar) de } 31.5 \times 10^{3} \mathrm{pie}^{3} / \mathrm{h}-380 \mathrm{gal} / \mathrm{h} \text {. } \\
280 \mathrm{~kW} \text { unidad con flujo de operación (a condiciones } \\
\text { estándar) de } 50 \times 10^{3} \mathrm{pie}^{3} / \mathrm{h}-600 \mathrm{gal} / \mathrm{h} \text {. }\end{array}$ \\
\hline Capacidad de agua & $15000 \mathrm{gal}-56700 \mathrm{l}$ \\
\hline Capacidad estacionaria de GNL & $13520 \mathrm{gal}-51180 \mathrm{l}$ \\
\hline Capacidad transportable de GNL & $3330 \mathrm{gal}-12600 \mathrm{l}$ \\
\hline Presión máxima permisible & $140 \mathrm{psi}_{\mathrm{g}}-25$ bar (absolutos) \\
\hline Flujo & Hasta $50 \times 10^{3} \mathrm{pie}^{3} / \mathrm{h}\left(\right.$ gas a $\left.50^{\circ} \mathrm{F}\right)$ \\
\hline Peso (Tara) & $50000 \mathrm{lb} / 22680 \mathrm{~kg}$ \\
\hline Requerimientos de potencia & $\begin{array}{ll}\text { - } & \text { Panel de control: } 480 \mathrm{~V}-60 \mathrm{~Hz}-3 \text { fases }-5 \mathrm{~A} \\
\text { - } & \text { Bomba: } 480 \mathrm{~V}-60 \mathrm{~Hz}-3 \text { fases } \\
\text { - } & \text { Vaporizador eléctrico: } 480 \mathrm{~V}-60 \mathrm{~Hz}-3 \text { fases }\end{array}$ \\
\hline Códigos de diseño & $\begin{array}{l}\text { NFPA 59A } \\
\text { ASME sección VIII División } 1 \\
\text { USDOT MC-338 }\end{array}$ \\
\hline
\end{tabular}

TABLA NRO. 12. Especificaciones técnicas: sistema de regasificación de Chart Industries.

Tomada de [55].

- Worthington Industries: La compañía Worthington Industries se dedica al manejo de GNL y comercializa sistemas de transporte, regasificación, tanques y dispositivos de GNL para diferentes vehículos de transporte de carga. Esta también ofrece sistemas portables de almacenamiento y regasificación de GNL, de acuerdo a lo establecido en el estándar NFPA 59A. Este tipo de sistemas son una opción de distribución, almacenamiento y suministro de gas natural en regiones donde no llega un gasoducto; para los sectores residenciales e industriales. En la TABLA NRO. 13 se muestran datos técnicos de dichos sistemas.

\begin{tabular}{lll}
\hline Característica & $\mathbf{3 0 0 0}$ gal & $\mathbf{6 0 0 0}$ gal \\
\hline Capacidad (gal) & 2940 & 5950 \\
\hline Caudal (pie $^{3}$ sTp/min) & 2588 & 5236 \\
\hline Peso (lbf) & 8000 & 8000 \\
\hline Dimensiones (pie) & $40 \times 8.5 \times 8$ & $53 \times 8.5 \times 8$ \\
\hline Presión máxima de operación (psig) & 145 & 145 \\
\hline
\end{tabular}

TABLA NRO. 13. Características técnicas de un sistema portable de almacenamiento y regasificación de GNL-Worthington Industries.

Tomada de [51].

EnColombia, para los sectorestermoeléctrico, industrialy residencial, se recomienda el uso de sistemas similares al mostrado en la FiguRA NRO. 13. Este se encuentra compuesto por tanques de almacenamiento, vaporizadores de aire ambiente, sistema de odorización, sistema de regulación de presión y sistema de control de vaporización. 


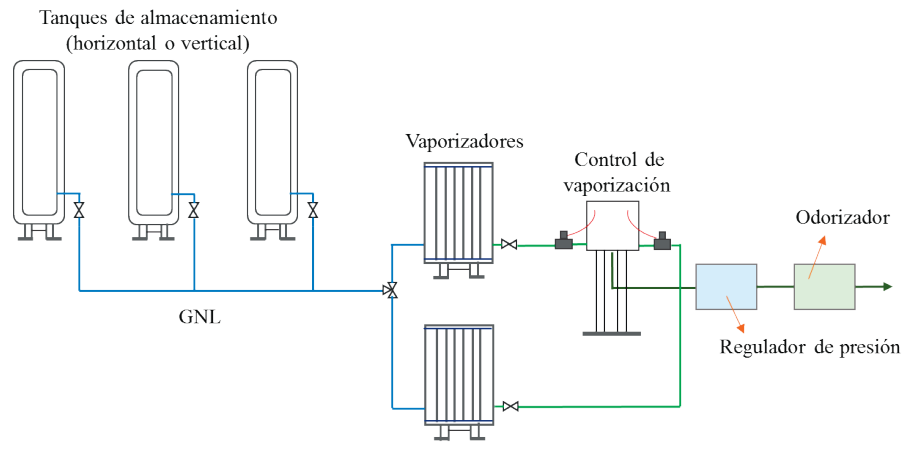

FiguRA NRO. 13. Sistema de regasificación a pequeña escala. Tomada de [50].

\subsection{Uso final del GNL}

Una vez el GNL es transportado, este se encuentra disponible para ser empleado en los sectores de consumo que lo requieran, los cuales, de manera general, pueden ser: sector de transporte, sector termoeléctrico, sector industrial y sector residencial. A continuación, la FigURA NRO. 14 presenta el esquema de suministro de GNL desde una planta de licuefacción a pequeña escala hasta el usuario final.

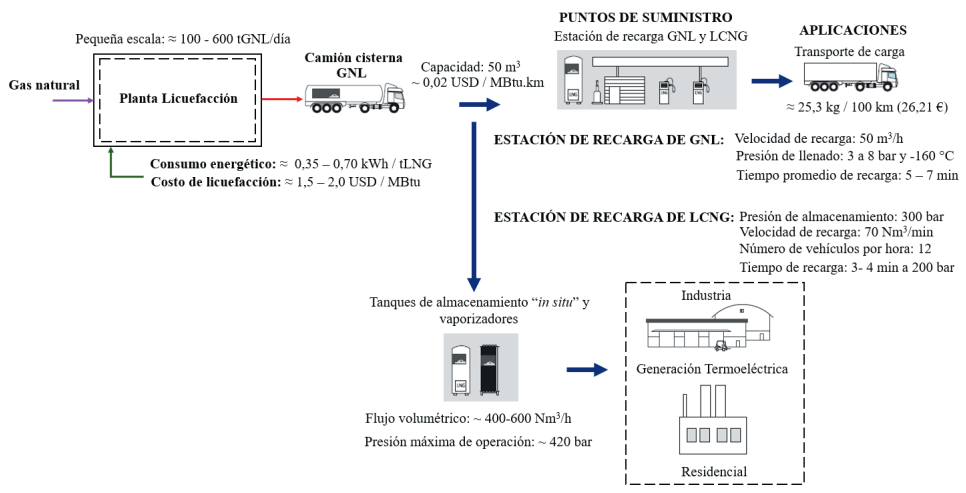

Figura NRo. 14. Esquema de distribución y suministro de GNL. (Los valores en USD mostrados fueron obtenidos para el año 2019).

Elaboración propia. 


\subsubsection{Sector transporte}

El transporte es el sector económico encargado de trasladar mercancías o personas de un lugar a otro. Esta definición incluye el transporte terrestre por carretera, el ferroviario, el marítimo, el fluvial y el aéreo. El sector transporte está caracterizado por tener una alta dependencia energética de recursos fósiles derivados del petróleo, tales como la gasolina y el diésel; y por ser uno de los mayores emisores de gases de efecto invernadero (GEI) y gases contaminantes.

El GNL se destaca como una opción para reducir los efectos negativos relacionados con la operación del sector transporte, ya que es considerado como la forma más limpia de GN, pues comprende hasta un $98 \%$ de metano y su contenido de azufre es menor que el presente en la gasolina y el diésel [56], [57]. Como un combustible de bajas emisiones, la combustión del GNL, comparada con otros combustibles de origen fósil, tiene menores emisiones de NOx, SOx y PM [58], [59]. Además, la expulsión que se generan de $\mathrm{CO}$ es prácticamente nula [56], [57].

De acuerdo a los estudios analizados se concluye que, en el sector transporte, el uso de GNL permite que se logren niveles bajos de emisiones sin que sea necesario el uso de equipos de control costosos como los requeridos por los vehículos que usan combustible diésel [56], [60]. Esta característica de la combustión del GNL hace que, mediante su uso, se puedan alcanzar los estándares Euro VI [18], [62], [65]. De tal forma, el GNL se visualiza como una alternativa para sustituir el combustible diésel [65], [66] en los vehículos de transporte de carga [56], [67], [68]. En Colombia, dicho tipo de transporte representa el $5 \%$ del parque automotor y se estima que consume el $88 \%$ del diésel comercializado en el país. Las estimaciones también concluyen que, en dicho país, este tipo de vehículos generan alrededor del $80 \%$ de las emisiones de material particulado (PM), el $60 \%$ de los NOx, el $65 \%$ de los SOx, el $50 \%$ del $\mathrm{CO}$, y el $42 \%$ del $\mathrm{CO}_{2}$ emitido a nivel nacional [69], [70]. 
Existen tres formas de implementar el uso del gas natural en vehículos de carretera:

- Dedicados a GNL: diseñados para transitar usando solamente gas natural.

- Bicombustible: tienen sistemas separados con líneas de inyección de gas natural o gasolina.

Dual-combustible: usan el gas natural y emplean diésel para la asistencia en la ignición [71].

En los vehículos de carga dedicados a GNL, el combustible se encuentra almacenado en fase líquida de forma criogénica y pasa posteriormente por un evaporador donde se realiza un cambio de fase de líquido a gas [72] y se dirige al motor. Allí, al igual que en los motores a gasolina, se tiene un sistema de encendido por chispa [73].

El GNL es llevado a los vehículos del sector transporte mediante estaciones de servicios (EDS) con capacidad de proveer GNC o GNL según la tecnología de motorización de los vehículos. Actualmente, las tipologías de estaciones de servicio (EDS) de GNL más usadas son: la estación estándar permanente, la estación móvil y la estación combinada [74], [75]. Las EDS de GNL poseen capacidades de almacenamiento entre 30 y $70 \mathrm{~m}^{3}$, y una capacidad de suministrar combustible a 12 vehículos/h con un tiempo promedio de recarga de 3-4 min a 200 bar. Además, una dedicada estación de recarga de GNL puede servir a 10 vehículos/h con un tiempo promedio de recarga de 5-7 min a 3-8 bar $\mathrm{y}-160{ }^{\circ} \mathrm{C}$ [45]. Las EDS usan dos métodos de acondicionamiento de GNL: en masa y sobre la marcha. Ver Figura NRO. 15. 


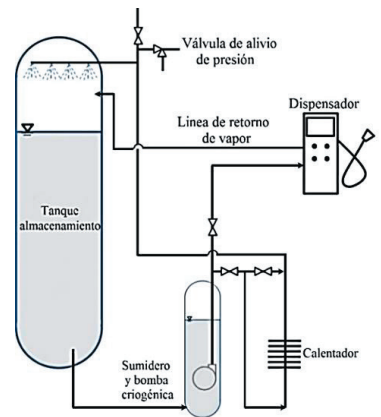

(a)

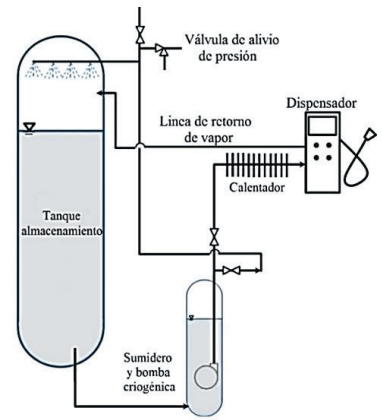

(b)

Figura NRo. 15. Proceso de acondicionamiento de GNL en EDS: (a) acondicionamiento en masa y (b) acondicionamiento sobre la marcha. Tomada de [72].

Una EDS de GNL debe contar con los siguientes elementos: tanque de almacenamiento, bomba criogénica, vaporizador de depósito, sistema de odorización, manejador de $B O G$ y dispensador. Cada uno de ellos posee características específicas de operación que deben ser seleccionadas de acuerdo a los requerimientos del consumidor final y el tamaño de la estación. A continuación se presenta un listado y descripción de los componentes principales de las EDS dedicadas al suministro de GNL a los vehículos del parque automotor.

- Depósito criogénico.

El depósito criogénico es un tanque fabricado en acero inoxidable en el interior y acero al carbono en el exterior. El GNL es almacenado a una presión de 15 bar y a una temperatura de $-162{ }^{\circ} \mathrm{C}$. Regularmente, estos depósitos pueden almacenar entre $40 \mathrm{~m}^{3}$ y $60 \mathrm{~m}^{3}$ de GNL [30], [31], [74], [76], [77]; tienen una capacidad efectiva del $90 \%$ y se reserva un $5 \%$ del volumen para efectos de seguridad. Así mismo, se debe garantizar un remanente mínimo de GNL equivalente al $5 \%$ de la capacidad del depósito con el fin de mejorar el proceso de criogenización [30], [78]. Dichos tanques cuentan con un sistema de seguridad que consta de válvulas de alivio controlados por PLC. 
- Bomba criogénica centrífuga sumergida.

Típicamente el GNL en las estaciones de servicio se bombea al usar bombas criogénicas, las cuales se encuentran sumergidas en el líquido y están encapsuladas de forma hermética con el propósito de minimizar las pérdidas de calor y recircular el GNL. La bomba se encarga de enviar el líquido desde el tanque hasta el dispensador de GNL [76], [77], y el flujo de masa presente en ellas puede variar entre 700 y 800 $\mathrm{kg} / \mathrm{min}$ y maneja una presión de hasta 34 bar con un consumo de energía aproximado de $16 \mathrm{kWh}$.

En ocasiones, las bombas criogénicas sumergidas se pueden evitar en la instalación de la estación de suministro al depender de la altura del depósito de almacenamiento (15 a 20 metros sobre el nivel del suelo) y de que el intercambiador de calor instalado permita un flujo de GNL lo suficientemente alto para elevar la presión y provocar un diferencial entre el depósito de la estación y el tanque del vehículo [76]. Algunas ventajas de no utilizar las bombas criogénicas sumergidas son:

- Capital de inversión más bajo.

- No es necesario un panel de control electrónico.

- No es necesario refrigerar la bomba antes de cada operación de llenado.

- No hay transferencia de calor adicional al GNL en el tanque.

- Menor número posibles fugas.

- Diseño más sencillo.

- Bomba criogénica de alta presión.

La bomba criogénica de alta presión o también llamada bomba criogénica alternativa tiene como función principal comprimir el GNL, aproximadamente entre 200 y 350 bar, e impulsarlo al vaporizador 
de aire ambiente de alta presión para la producción de GNC. Su funcionamiento inicia cuando disminuye el nivel de GNC almacenado, con el fin de regular automáticamente los parámetros de trabajo establecidos (temperatura y presión). Las bombas pueden ser simples dúplex o triplex y, cuando son utilizadas en estaciones de suministro convencionales, tienen los siguientes parámetros de operación [76], [77]:

- Flujo típico: 15 1/min-20 1/min.

- Presión máxima de descarga: 350 bar.

- Presión de succión típica: 5 bar-15 bar.

- Velocidad típica del impulsor: $450 \mathrm{r} / \mathrm{min}$.

- Motor eléctrico: potencia de $30 \mathrm{~kW}-45 \mathrm{~kW}$.

- Vaporizador de depósito (PPR).

Este sistema se emplea generalmente durante la recepción de GNL desde camiones cisterna, con el fin de regular y mantener la presión de servicio a 15 bar en el interior del depósito. Su función es la de extraer el GNL, vaporizarlo e introducirlo nuevamente en la zona de gases al interior del tanque cuando la presión del depósito de GNL supera en 4 o 5 bar la presión de operación [77], [79].

- Manejador de $B O G$.

En las EDS que suministran GNL, el tratamiento de los $B O G$ puede manejarse de formas diferentes, así:

- Condensarlos en intercambiadores de calor que usan nitrógeno líquido $\left(\mathrm{LN}_{2}\right)$.

- Usarlos para la producción de GNC.

- Liberarlos a la atmósfera. 
Alrededor de la mitad de las EDS disponibles comercialmente en el mundo no realizan el tratamiento de $B O G$; simplemente, por medio de válvulas de alivio, liberan el $B O G$ a la atmósfera para mantener el depósito de almacenamiento en las condiciones normales de operación. La otra mitad de las EDS se dividen, en igual proporción, entre las que condensan los $B O G$ del tanque mediante $\mathrm{LN}_{2}$ y las que producen GNC para ser suministrado a vehículos [72]. Los sistemas de condensación permiten reducir las emisiones de metano a la atmósfera y disminuir los costos asociados a las pérdidas de GNL por evaporación. Otras opciones para el manejo del $B O G$ son: la implementación de generadores eléctricos que utilicen gas para su funcionamiento o procesar los $B O G$ para ser incorporados a la red de gasoductos [80].

- Vaporizador atmosférico.

Los vaporizadores o regasificadores atmosféricos de alta presión emplean la energía térmica del aire para vaporizar el GNL y entregar GNC. Estos se componen de un banco de tubos de acero inoxidable o aluminio donde el gas natural licuado se introduce por la parte inferior y, debido a la transferencia de calor, sale en fase gaseosa. Cuando el GNL entra al vaporizador se genera una evaporación a 350 bar (presión máxima de la bomba) y se obtiene una temperatura entre $5{ }^{\circ} \mathrm{C}$ y $10^{\circ} \mathrm{C}$ por debajo de la temperatura ambiente. Después, un intercambiador de calor en la salida del vaporizador se encarga de regular la temperatura de emisión a los límites de seguridad. Las tuberías tienen un comportamiento flexible para así evitar dilataciones y contracciones provocadas por los cambios de temperatura y el equipo tiene incorporada una válvula de seguridad criogénica en caso de emergencia [77], [81].

Algunos de los parámetros de operación de estos vaporizadores en las estaciones de suministro son:

- Presión máxima de trabajo: 420 bar.

- Tubería: AISI 304L Ø 16 mm x $2.5 \mathrm{~mm}$.

- Sistema de odorización. 
- Dispensadores de GNL.

Estos dispositivos suministran el combustible a una temperatura de $-143^{\circ} \mathrm{C}$ para el GNL insaturado y $-110^{\circ} \mathrm{C}$ para el GNL saturado; todo ello a una presión de 5 a 18 bar según la referencia del dispensador. Las características del emplazamiento y del sistema de anclaje de esta tecnología son las mismas que se implementan en los sistemas de suministro de GNC. Estos dispositivos cuentan con conexiones de alta presión por tuberías de acero inoxidable y acoples de doble virola de compresión, también están dotados con líneas de suministro retorno para la recuperación de las emisiones evaporativas $(B O G)$ que se encuentran presentes en el tanque del vehículo y, adicionalmente, cuentan con un sistema de cierre automático de suministro para evitar un escape de GNL cuando se presente alguna rotura en la línea de abastecimiento o cuando el auto abandona la posición de tanqueo sin haberse realizado el desacople del surtidor. A continuación, la Figura NRO. 16 muestra el esquema de un dispensador de GNL estándar [82], [83]. Algunos parámetros de operación de los dispensadores convencionales son:

- Flujo de GNL: 100 1/min - 160 1/min.

- Presión de trabajo máxima: 14 bar - 17 bar.

- Temperatura de operación: $-195^{\circ} \mathrm{C}-35^{\circ} \mathrm{C}$.
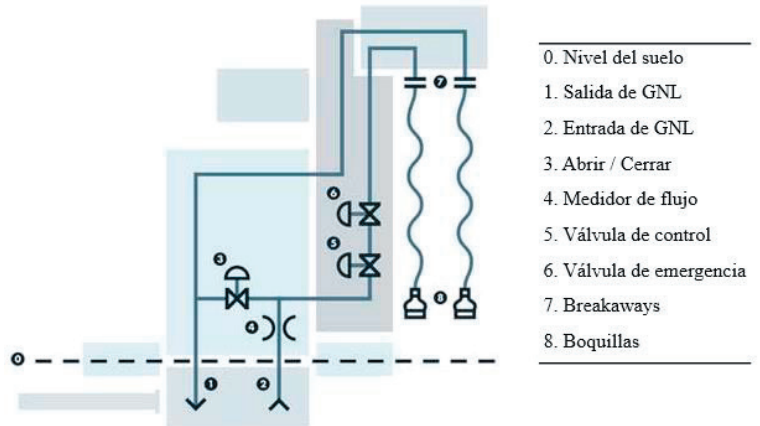

Figura NRo. 16. Esquema de funcionamiento de un dispensador estándar de GNL. Tomada de [84]. 
- Acondicionador línea de GNL.

Este es un vaporizador que se encuentra entre el tanque de GNL y el dispensador, y sirve para acondicionar el producto, ya que cada camión trabaja a una temperatura diferente de suministro de gas natural.

- Sistema de odorización.

El gas natural es inodoro e imperceptible para el ser humano, por tal motivo, se debe odorizar de manera adecuada para que pueda ser detectado inmediatamente en caso de fuga. Para ello, se pueden añadir pequeñas cantidades de THT (tetrahidrotiofeno), TBM (terbutilmercaptano) o DMS (dimetil sulfato), las cuales contienen azufre en su composición. El más usado es el THT, un líquido incoloro con olor característico, inflamable y con vapor más denso que el aire, el cual no debe entrar en contacto con agua, por lo que, en la planta, no se utiliza ni tampoco se debe disponer de ninguna toma, ni desagüe [77], [85]. Es recomendable la instalación de odorizadores por dosificación cuando las distribuciones son numerosas, puesto que, este sistema incorpora bombas que suministran, de manera proporcional, THT al caudal de gas emitido [86]. En cambio, los odorizadores de contacto son utilizados por plantas satélite destinadas al consumo industrial, debido a que, desvían una parte del gas y hacen que pase por el recipiente que contiene el odorizante y, posteriormente, lo devuelven a la corriente principal del gas [86] [77].

Una vez los vehículos reciben el GNL lo pueden emplear en tres condiciones:

- Insaturado y suministrado por debajo de $-143^{\circ} \mathrm{C}$ y a 3.4 bar de presión absoluta.

- $\quad$ Saturado y suministrado entre $-125 \mathrm{y}-131^{\circ} \mathrm{C}$, y entre 6.9 y 9.3 bar de presión absoluta.

Súper saturado y suministrado por encima de $-125{ }^{\circ} \mathrm{C}$ y a una presión absoluta entre 15 y 18 bar [72]. 
En los vehículos de transporte de carga se emplean las dos primeras condiciones, ya que permiten tener un almacenamiento energético mayor y, de esta manera, podrán recorrer mayores distancias entre repostajes de combustible. De tal forma, existen diferentes sistemas de suministro de GNL desde el tanque de combustible del vehículo hasta el motor, tales como:

- Arquitectura simple.

- Con circuito de construcción de presión.

- Usando un compresor.

- Usando una bomba.

Actualmente, el sistema más usado en los vehículos es el de suministro con bomba. Este resuelve las limitaciones de las demás configuraciones, tales como: la incapacidad de mantener flujo continuo, las altas diferencias de temperatura entre los $B O G$ y el GNL, y el alto costo de implementación. Esta configuración utiliza una bomba criogénica que lleva el GNL del tanque al vaporizador y, posteriormente, lo suministra al motor en cualquier condición de saturación (ver FiguRA NRO. 17). Este tipo de tecnologías de bombeo no requieren de estaciones con equipos de acondicionamiento de GNL o tanques de alta presión. No obstante, sus desventajas son el alto costo y la corta durabilidad de algunos de sus componentes. De cualquier forma, su versatilidad y confiabilidad en operación están por encima de las desventajas mencionadas [72]. 


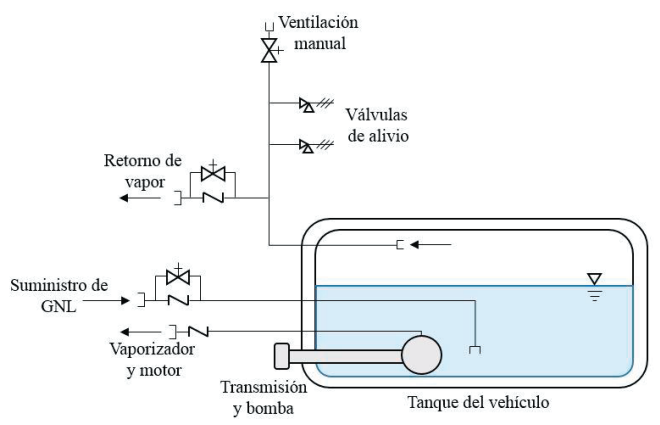

Figura NRo. 17. Diagrama de un sistema de suministro de GNL con bomba. Elaboración propia.

\subsubsection{Sectores termoeléctrico, industrial y residencial}

Para la implementación del GNL en los sectores termoeléctrico, industrial y residencial se hace necesario usar sistemas de regasificación antes de su uso final.

Estos sectores están caracterizados por:

- Sector termoeléctrico.

Se encarga de transformar la energía térmica de la combustión de un combustible como el carbón, el gas natural u otro en energía eléctrica al usar una planta térmica con turbinas de gas, turbinas de vapor o una combinación de ambas [87].

- Sector industrial.

Este sector se caracteriza por configurar un conjunto de sistemas y actividades que tienen como propósito transformar las materias primas en productos elaborados. Entre ellos se encuentran la siderurgia, las industrias mecánicas, la química, la textil, la producción de bienes de consumo y la producción de bienes alimenticios [87]. 
- Sector residencial.

Este sector está compuesto por viviendas, edificaciones, entre otros; y representa una demanda importante en el consumo de energía eléctrica y gas natural de un país o región [88]. 


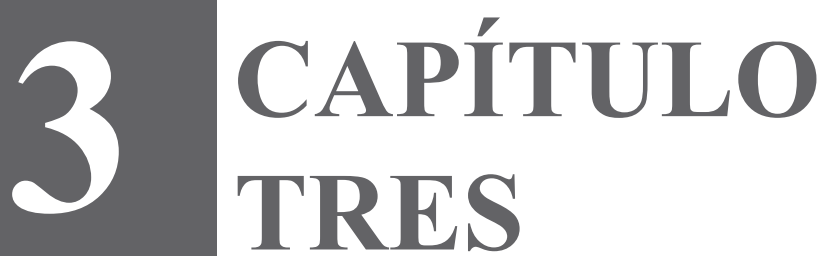




\section{GNL a pequeña escala en Colombia: producción}

A nivel comercial, las diferentes ofertas tecnológicas presentan cambios en su configuración; sin embargo, su principio de funcionamiento, de forma general, es similar. Los principales elementos de un sistema de producción de GNL a pequeña escala se muestran en la Figura NRO. 18.

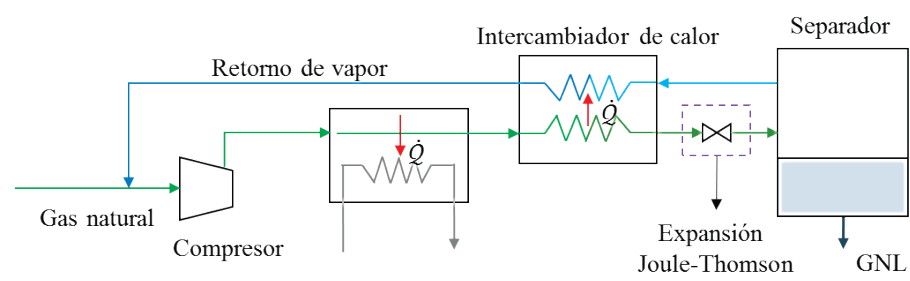

FigURA NRO. 18. Esquema de producción de GNL a pequeña escala. Elaboración propia.

\subsection{Tecnologías de licuefacción a pequeña escala}

A nivel mundial, las tecnologías de licuefacción de GNL disponibles están relacionadas con la oferta comercial de los diferentes fabricantes y pueden clasificarse de acuerdo a la escala de producción. En la 
TABLA NRO. 14 se muestran algunas de las tecnologías disponibles comercialmente para la producción a pequeña, nano y micro escala de GNL.

\begin{tabular}{|c|c|c|c|c|}
\hline Escala & Fabricante & Tecnología & Proceso de licuefacción & Producción (TPD) \\
\hline \multirow[t]{5}{*}{ Pequeña } & Linde & StarLNG & $\begin{array}{l}\text { Expansión de gas o } \\
\text { refrigerante mixto }\end{array}$ & $100-300$ \\
\hline & Wärtsilä & MiniLNG & Expansión de gas & $30-300$ \\
\hline & Black \& Veatch & PRICO & Refrigerante mixto & $20-300$ \\
\hline & Linde/Cryogas & StarLiteLNG & Expansión de gas & $20-200$ \\
\hline & Chart & $\mathrm{C} 100 \mathrm{~N}$ & Expansión de gas & 160 \\
\hline \multirow[t]{4}{*}{ Micro } & Wärtsilä & MiniLNG & Expansión de gas & $30-300$ \\
\hline & Black \& Veatch & PRICO & Refrigerante mixto & $20-300$ \\
\hline & Linde/Cryogas & StarLiteLNG & Expansión de gas & $20-200$ \\
\hline & Wärtsilä & NewMR & Refrigerante mixto & $<50$ \\
\hline \multirow[t]{3}{*}{ Nano } & Wärtsilä & NewMR & Refrigerante mixto & $<50$ \\
\hline & Galileo & Cryobox & Expansión de gas & $12-16$ \\
\hline & Dresser-Rand & LNGo & Expansión de gas & $10-14$ \\
\hline
\end{tabular}

TABLA NRO. 14. Oferta comercial de tecnologías de licuefacción.

Tomada de [89].

A continuación se describen algunas de las tecnologías disponibles comercialmente sobre la producción de GNL a pequeña y mini escala:

- Star LNG Linde.

Linde Engineering es una compañía reconocida en el manejo de GNL, la cual ha desarrollado procesos de licuefacción de GN a pequeña escala con capacidades de hasta 10000 TPA y a gran escala con producción superior a 10 MTPA. Esta enfría, licúa y subenfría el gas natural al usar un ciclo de refrigeración mixto que posee un intercambiador de calor de placas finas — plate-fine heat exchanger (PFHE)—. Dicho ciclo funciona al usar cuatro refrigerantes: nitrógeno, metano, etileno o etano y butano. Esta configuración es modular y compacta, su presión absoluta varía entre 30 y 60 bar y la temperatura entre y de 0 a $50{ }^{\circ} \mathrm{C}$.

\section{- Wärtsilä.}

Wärtsilä es una empresa que se dedica al desarrollo de tecnologías y soluciones para el mercado energético y marítimo, e incluye equipos y componentes para los procesos de producción, transporte y distribución de GNL. En el campo de la licuefacción de gas natural se ofrecen 
tecnologías basadas en ciclos termodinámicos de refrigeración Brayton invertidos, los cuales usan nitrógeno y tienen capacidades de producción que oscilan entre 60 y 800 TPD. Estos son sistemas de diseño comparto, de fácil operación y con altos estándares de seguridad en el manejo del nitrógeno. Wärtsilä también tiene a disposición tecnologías de licuefacción de biogás a mini escala, las cuales son basadas en ciclos termodinámicos de enfriamiento de refrigerante mixto, cuyo rango de producción de GNL varía entre 2000 y 30000 TPA [29].

- Gaileo Technologies.

Galileo Technologies es una empresa que ofrece tecnología y servicios relacionados con la producción; el transporte y el uso final de gas natural, biometano e hidrógeno. Esta ofrece tecnología modular y escalable para la producción de GNL a escala nano, la cual opera con ciclos termodinámicos de refrigeración de múltiples etapas y tiene disponibles sistemas de recuperación automática de $B O G$. Dicha tecnología tiene una capacidad de producción de alrededor 15 TPD por cada módulo y es de fácil traslado e instalación [31]. Estas unidades cuentan con un sistema de detección de mezclas explosivas, un sistema de ventilación automático, y un sistema de detección y extinción de incendio.

\subsection{Requerimientos de gas para producción de GNL}

En la TABLA NRO. 15 se muestran los requerimientos de suministro de GN y los consumos de energía para la producción de GNL a diferentes escalas. Es importante recordar que una tonelada de GNL es equivalente a 48700 pie $^{3}$ de gas natural a condiciones de presión y temperatura estándar (STP), y que para generar 1 MTPA de GNL se necesitan alrededor de 133 MPCD del mismo gas y en las mismas condiciones [90]. 


\begin{tabular}{|c|c|c|c|c|c|c|c|c|}
\hline \multirow[t]{3}{*}{ Parámetro } & \multicolumn{4}{|c|}{ Producción de GNL } & \multirow{2}{*}{\multicolumn{2}{|c|}{$\begin{array}{c}\text { GN requerido } \\
\text { (MPCD) }\end{array}$}} & \multirow{3}{*}{$\begin{array}{c}\text { Consumo energía } \\
(\mathrm{kWh} / \mathrm{kg}) \\
\end{array}$} & \multirow[t]{3}{*}{ Ref } \\
\hline & \multicolumn{2}{|c|}{ (TPD) } & \multicolumn{2}{|c|}{ (MBTUD) } & & & & \\
\hline & Mín & Máx & Mín & Máx & Mín & Máx & & \\
\hline Pequeña escala & 60 & 800 & 3114 & 41520 & 2.91 & 38.84 & $0.35-0.38$ & [29] \\
\hline Mini escala & 10 & 50 & 519 & 2595 & 0.49 & 2.43 & 0.70 & {$[29]$} \\
\hline Micro escala & 16 & 50 & 779 & 2595 & 0.74 & 2.43 & & [31] \\
\hline Nano escala & 10 & 15 & 519 & 778.5 & 0.49 & 0.73 & & \\
\hline
\end{tabular}

TABLA NRO. 15. Requerimientos de gas y de energía para producción de GNL a diferentes escalas.

Tomada de [29], [31].

\subsection{Potencial producción de GNL en Colombia}

Durante el año 2018, Colombia alcanzó una producción fiscalizada y comercializada de gas natural de 1170.2 MPCD, de la cual se estima que el $4.5 \%$ (52.80 MPCD) fue quemada en teas o antorchas [91]. Se considera que en dicho país, una primera alternativa para ubicar y utilizar plantas de producción de GNL son los campos de obtención de GN. Allí puede ser viable llevar el gas, el cual actualmente es quemado en teas, a un proceso de licuefacción para producir GNL. De tal forma, se estima que en el 2018, de la fracción quemada en antorcha, el $65.4 \%$ (34.54 MPCD) pudo ser utilizado para producir GNL.

La licuefacción del gas que actualmente es quemado en antorchas representa ventajas desde el punto de vista ambiental, ya que, por cada kilogramo de GN quemado, se calcula una emisión de alrededor $2.33 \mathrm{~kg}$ de $\mathrm{CO}_{2}$ y $0.053 \mathrm{~kg}$ de NO. De tal modo, si el gas quemado en teas entre los años 2016 y 2018 se hubiese usado para la producción de GNL, se hubiera dejado de generar aproximadamente 622.83 TPA de $\mathrm{CO}_{2}, \mathrm{y}$ 14.16 TPA de NO. Así, en la TABLA NRO. 16 se identifica el potencial de obtención de GNL en campo y su respectiva escala de producción a partir de la información del GN quemado en los pozos colombianos entre los años 2016 y 2018. 


\begin{tabular}{|c|c|c|c|c|c|}
\hline Campo & Departamento & Municipio & $\begin{array}{l}\text { Gas quemado } \\
\text { (MPCD) }\end{array}$ & $\begin{array}{l}\text { Producción de } \\
\text { GNL (TPD) }\end{array}$ & $\begin{array}{l}\text { Escala de } \\
\text { producción }\end{array}$ \\
\hline Acordionero & Cesar & San Martín & 1.29 & 26.445 & Micro \\
\hline Bonanza & Santander & Rionegro & 0.69 & 14.145 & Nano \\
\hline Caipal & Boyacá & Puerto Boyacá & 0.51 & 10.455 & Nano \\
\hline Caño Limón & Arauca & Arauca & 0.88 & 18.04 & Micro \\
\hline Caribe & Putumayo & Orito & 0.50 & 10.25 & Nano \\
\hline Casabe Sur & Antioquia & Yondó & 0.54 & 11.07 & Nano \\
\hline Chichimne & Meta & Acacias & 4.51 & 92.455 & Pequeña \\
\hline $\begin{array}{l}\text { Chichimene } \\
\text { SW }\end{array}$ & Meta & Guamal & 2.33 & 47.765 & Micro \\
\hline Churuyaco & Putumayo & Orito & 1.21 & 24.805 & Micro \\
\hline Cupigua & Casanare & Aguazul & 0.96 & 19.68 & Micro \\
\hline Cusiana & Casanare & Tauramena & 1.01 & 20.705 & Micro \\
\hline $\begin{array}{l}\text { Cusiana } \\
\text { Norte }\end{array}$ & Casanare & Aguazul & 1.35 & 27.675 & Micro \\
\hline $\begin{array}{l}\text { La Cañada } \\
\text { Norte }\end{array}$ & Huila & Paicol & 1.25 & 25.625 & Micro \\
\hline La Cira & Santander & $\begin{array}{l}\text { Barrancaberm } \\
\text { eja }\end{array}$ & 1.20 & 24.6 & Micro \\
\hline Moqueta & Putumayo & Mocoa & 2.19 & 44.895 & Micro \\
\hline Orito & Putumayo & Orito & 6.54 & 134.07 & Pequeña \\
\hline Palagua & Boyacá & Puerto Boyacá & 2.91 & 59.655 & Pequeña \\
\hline Pauto Sur & Casanare & Yopal & 1.48 & 30.34 & Micro \\
\hline Quillacinga & Putumayo & Puerto Asís & 0.71 & 14.555 & Nano \\
\hline Ramiriqui & Casanare & Aguazul & 1.41 & 28.905 & Micro \\
\hline Sucumbios & Nariño & Ipiales & 2.00 & 41 & Micro \\
\hline Tello & Huila & Neiva & 0.62 & 12.71 & Nano \\
\hline Tilodiran & Casanare & Yopal & 0.83 & 17.015 & Micro \\
\hline Tisquirama & Cesar & San Martín & 0.71 & 14.555 & Nano \\
\hline
\end{tabular}

TABLA NRO. 16. Potencial de producción de GNL en pozos con quema de gas en el país 2016-2018.

Tomada de [91].

En Colombia se identificaron 24 pozos con potencial de producción de GNL a partir del gas natural quemado en antorcha o teas; 3 de ellos podrían emplear plantas de licuefacción a pequeña escala, 14 a micro y 7 a nano escala. En estos pozos se lograría emplear tres procesos de licuefacción: refrigeración en cascada, refrigerante mixto o por expansión de gas. Este último cuenta con dos ventajas: costo de capital bajo y operación simple. Adicionalmente, al operar con nitrógeno, se hace un ciclo seguro y de bajo impacto ambiental [92]. No obstante, este ciclo no permite reducir el consumo de energía del compresor, ya que, al utilizar un único refrigerante, la operación de este no se puede ajustar a la carga del intercambiador de calor; situación que ocasiona que el ciclo llegue a ser hasta un $40 \%$ menos eficiente que los otros, lo cual resulta en un costo de operación mayor [93]. 
De tal forma, para Colombia se plantea emplear procesos de licuefacción que operen con ciclos de refrigerante mixto, debido a que ofrecen la máxima eficiencia posible entre las tecnologías comercialmente disponibles.

\subsection{Manejo y/o tratamiento del $B O G$ en estaciones de GNL a pequeña escala}

El $B O G$ se genera durante el almacenamiento de GNL, debido al aumento de temperatura producto de la transferencia de calor con el ambiente, a la operación de las bombas en los tanques de almacenamiento y a las variaciones en la presión atmosférica, entre otras cosas [42]. La presión en los tanques de almacenamiento de GNL debe mantenerse entre 1200 y $1380 \mathrm{kPa}$, pues cuando se encuentra entre 1000 y 1200 $\mathrm{kPa}$ se debe extraer el $B O G$ para reducir la presión interna del tanque y los gases son llevados a un tanque configurado para realizar su almacenamiento. En las plantas de licuefacción a pequeña escala, el $B O G$ se puede usar como combustible en sitio, para generar energía, o puede ser licuado nuevamente.

\subsubsection{Generación de potencia}

Una vez la presión del tanque está entre 1000 y $1200 \mathrm{kPa}$, se usa una válvula de tres vías, la cual es activada por presión para llevar el $B O G$ hacia la línea de entrada del combustible del motor de un generador eléctrico. Es necesario llevar el gas hasta las condiciones de operación del motor, para lo cual se debe incrementar la presión del gas mediante un compresor de baja capacidad [94].

\subsubsection{Relicuefacción del $B O G$}

Para este proceso, se emplea un sistema de criogenización independiente que consta de un motor eléctrico y una unidad de control. El sistema mencionado extrae el $B O G$, lo enfría y presuriza para, nuevamente, almacenarlo en el tanque. Adicionalmente, parte del GNL es extraído y subenfriado por el sistema con el fin de rociarlo dentro del 
tanque, disminuir la temperatura del $B O G$ y, así mismo, la presión del tanque. La Figura NRo. 19 muestra el diagrama de funcionamiento de este sistema [95].

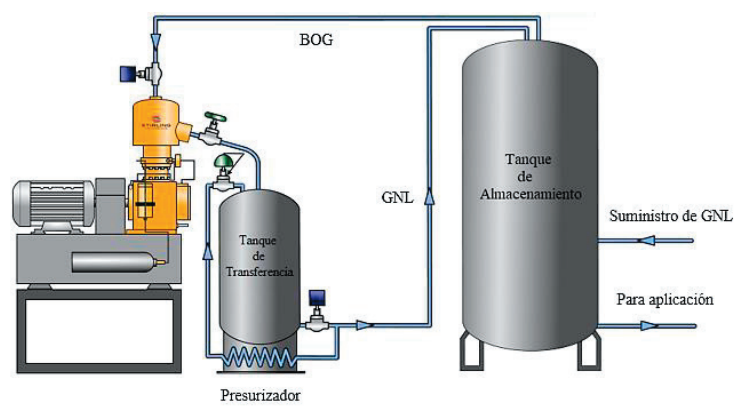

Figura NRo. 19. Diagrama de un sistema de criogenización de BOG. Tomada de [95].

\subsection{Aspectos de seguridad}

Para la aceptación pública del uso de GNL y la viabilidad económica de la industria del GNL, la seguridad es un tema muy importante. Aunque este sector está regulado a nivel mundial, las normas no requieren sistemas de gestión de seguridad de procesos — process safety management (PSM) - . En el mundo, las plantas de licuefacción de GNL y las terminales de importación de GNL han implementado sistemas de gestión de seguridad — safety management system (SMS) $\mathrm{y}$ sistemas de gestión medioambiental - environment management system (EMS) - de acuerdo a lo establecido respectivamente por las normas ISO 45001 y 14000 [37].

En las etapas de construcción y puesta en marcha de las plantas de licuefacción a pequeña escala deben tenerse en cuenta los aspectos de seguridad enmarcados para cada uno de los elementos, así [25]:

- Bombas y compresores.

- Deben ser diseñados con materiales compatibles para operar a temperaturas criogénicas y a las presiones de operación. 
- Las válvulas deben ser instaladas de forma que cada bomba o compresor pueda ser puesto fuera de funcionamiento para su respectivo mantenimiento. Las bombas y compresores deben estar equipados con válvulas tipo cheque.

- Deben instalarse válvulas de alivio en la descarga para limitar la presión en el nivel de operación establecido.

- Los cimientos sobre los cuales se instalan las bombas de transporte de GNL deben ser diseñadas al considerar los posibles daños por congelamiento que puedan presentarse.

- Las bombas utilizadas para transportar GNL a temperaturas inferiores $\mathrm{a}-30{ }^{\circ} \mathrm{C}$ deben poseer un sistema de preenfriamiento para evitar los choques térmicos y los daños por fatiga en los materiales.

- Los compresores que operan para elevar la presión de los gases inflamables deberán contar con sistemas de venteo y ubicarse en lugares seguros.

- Sistemas de tuberías.

- Los sistemas de tuberías deben ser diseñados de acuerdo con la norma ANSI/ASME B31.4. Los requerimientos descritos en esta norma han de ser aplicados a los sistemas de transporte de GNL por tubería, refrigerantes inflamables, líquidos y gases inflamables; e incluir líneas de venteo y drenaje que operen a temperaturas menores de $-30^{\circ} \mathrm{C}$.

- Los sistemas de transporte de GNL por tubería deben ser diseñados para soportar la fatiga que pudiera ocasionarse debido a esfuerzos térmicos dada la operación cíclica a la cual se encuentran sometidos este tipo de sistemas. Las juntas y secciones de expansión y contracción de las tuberías deben estar en concordancia con la norma ANSI B31.3. 
- Los parámetros de seguridad requeridos en el proceso de diseño de los sistemas de transporte por tubería pueden encontrarse en el capítulo 6 de la norma técnica NFPA59A.

- Tanques de almacenamiento.

- El diseño de los tanques de almacenamiento de GNL y de las sustancias refrigerantes, usadas en el sistema de licuefacción, deberán cumplir con los requerimientos de los estándares 2510 API y NFPA 59A, párrafo 3.3.

- Los tanques de almacenamiento pueden hacer uso de bombas internas o externas. Para las primeras, las conexiones deben realizarse en el techo. Para las segundas, las conexiones se deben realizar en el fondo.

- Los cimientos del tanque de almacenamiento deben estar dispuestos a un nivel tal que se tenga una cabeza hidrostática positiva.

- Deben ubicarse lo más alejado posible de áreas pobladas o de instalaciones con gran número de trabajadores.

- Los tanques de almacenamiento deben ser de fácil acceso despejado, desde al menos dos direcciones, con el propósito de que sea fácil atender oportunamente un posible incendio.

- El área circundante a las instalaciones debe estar libre de vegetación y materiales combustibles. Está estrictamente prohibido fumar en las inmediaciones del tanque de almacenamiento.

- En caso de incendio debe considerarse lo estipulado en el código BS 5429 del British Standards Institution (BSI). 
- Los tanques de almacenamiento de GNL deben estar provistos de válvulas de alivio como sistema de seguridad en caso de una sobrepresión; todo ello para proveer una tasa mínima efectiva de descarga. El dimensionamiento, localización e instalación de los dispositivos de alivio necesarios deben realizarse según lo establecido en el estándar 620 API. También es necesario que se tengan en cuenta los requerimientos de seguridad del capítulo cuatro de la norma NFPA 59A.

- Aislamiento térmico.

- En las instalaciones donde se opera con sustancias a bajas temperaturas como es el caso del GNL, los tanques de almacenamiento deben poseer un aislamiento térmico y usar alguno de los siguientes métodos: alto vacío, múltiples capas, potencia o espuma rígida.

- Entre el tanque interior y el exterior se debe emplear un aislamiento térmico no inflamable, y compatible con GNL y gas natural. El aislamiento, en presencia de una conflagración fuera del tanque externo, debe resistir los cambios de su conductividad térmica.

- Instrumentación.

- Cualquier tanque de almacenamiento de GNL debe tener un control de nivel y una alarma que se active en caso de presentarse un alto nivel de líquido.

- Todo tanque debe poseer un manómetro conectado al tanque en un punto por encima del nivel máximo de líquido.

- Los tanques con aislamiento de vacío deben estar equipados con instrumentos y conexiones que permitan registrar la presión absoluta del espacio anular. 
Un aspecto que debe tenerse en cuenta en la construcción y montaje de las plantas de licuefacción es la distancia de seguridad. De acuerdo al estándar UNE 60210, esta distancia depende de la capacidad de almacenamiento de la planta y es clasificada por tipos, de acuerdo a lo mostrado en la TABLA NRO. 17, desde el tipo A hasta el tipo F.

\begin{tabular}{lll}
\hline Tipo & A partir $\mathbf{~ d e ~}\left(\mathbf{m}^{\mathbf{3}}\right)$ & Hasta $\left(\mathbf{m}^{\mathbf{3}}\right)$ \\
\hline A & 1 & 5 \\
\hline B & 5 & 20 \\
\hline C & 20 & 60 \\
\hline D & 60 & 200 \\
\hline E & 200 & 400 \\
\hline F & 400 & 1500 \\
\hline
\end{tabular}

TABLA NRO. 17. Clasificación por capacidad de almacenamiento.

Tomada de [40].

De acuerdo a la clasificación por capacidad de almacenamiento, se determina la distancia de seguridad mínima que debe haber entre la planta de licuefacción y los elementos o componentes que puedan encontrarse en sus alrededores, tal como se plantea en la TABLA NRO. 18.

\begin{tabular}{|c|c|c|c|c|c|c|}
\hline \multirow[t]{2}{*}{ Elementos } & \multicolumn{6}{|c|}{ Distancia de seguridad (m) } \\
\hline & $\mathbf{A}$ & B & $\mathbf{C}$ & D & $\mathbf{E}$ & $\mathbf{F}$ \\
\hline Aberturas para inmuebles, sótanos, alcantarillas o desagües. & 5 & 10 & 15 & 20 & 20 & 25 \\
\hline $\begin{array}{l}\text { Motores, interruptores (no antideflagrantes), depósitos de materiales } \\
\text { inflamables. }\end{array}$ & 5 & 10 & 15 & 15 & 15 & 15 \\
\hline Proyección de líneas eléctricas. & 10 & 15 & 15 & 15 & 15 & 15 \\
\hline $\begin{array}{l}\text { Límite de propiedad, vías públicas, carreteras, ferrocarriles, focos fijos } \\
\text { de inflamación. }\end{array}$ & 10 & 10 & 15 & 25 & 30 & 35 \\
\hline $\begin{array}{l}\text { Aberturas de edificios de pública concurrencia, uso administrativo, } \\
\text { docente, comercial, hospitalario, entre otros. }\end{array}$ & 10 & 20 & 20 & 30 & 60 & 60 \\
\hline
\end{tabular}

TABLA NRo. 18. Distancia de seguridad.

Tomada de [40].

Los riesgos que pueden presentarse durante la operación de una planta de licuefacción se muestran a continuación [96]:

- Riesgo criogénico.

Sabiendo que el GNL se encuentra a bajas temperaturas, este representa un alto riesgo para producir quemaduras por frío $\mathrm{y} / \mathrm{o}$ lesiones por congelamiento. Al entrar en contacto con estructuras puede volverlas quebradizas y susceptibles a fractura, debido a los esfuerzos 
que presentan los materiales por cambios de la temperatura. Por tal motivo, es necesario realizar las operaciones de enfriamiento a una tasa controlada.

- Riesgo por flamabilidad.

Debido a que el GNL es inflamable y que el metano es un vapor, el cual puede entrar en ignición, se hace necesaria la eliminación de toda fuente de chispa y una contención efectiva que impida el escape del gas natural a la atmósfera.

- Riesgo por oxígeno insuficiente.

En una planta de licuefacción, la falta de oxígeno en un espacio cerrado puede ocurrir por alguna de las siguientes condiciones: a) presencia de grandes cantidades de $B O G$; b) presencia de grandes cantidades de nitrógeno y c) presencia de herrumbre en las superficies de los tanques, indicativo de procesos de oxidación, los cuales consumen oxígeno.

- Riesgo por reactividad.

La probabilidad de que ocurra una reacción química entre el GNL con otros materiales es muy baja. Sin embargo, hay que tener en cuenta que dada la presencia de vapor de agua en el aire, existe formación de hidratos y de hielo en los tanques de almacenamiento; situación que puede generar taponamientos y averías en las tuberías y los equipos. Además, al considerar que el $\mathrm{CO}_{2}$ forma hielo seco a temperaturas por debajo de $-70{ }^{\circ} \mathrm{C}$, se debe tener presente la compatibilidad y las limitaciones de los materiales.

- Riesgo de auto ignición.

Las chispas son las fuentes más probables para la ignición de una sustancia combustible en fase de vapor. De tal manera, ante una fuga de $B O G$, debe considerarse una distancia segura entre el almacenamiento, las tuberías y las superficies calientes. 
- Riesgo por roll over.

El fenómeno conocido como roll over incrementa la generación de $B O G$, ya que la capa de líquido menos densa, la cual se ubica próxima a la superficie libre, se evapora. La formación de este gas en espacios cerrados, por la presentación de este fenómeno, genera riesgos de asfixia, de congelamiento y de irritación de la piel ante el contacto. También se identifica que mezclar GNL de diferentes características, en un mismo tanque, ocasiona la ocurrencia de este fenómeno, lo cual provoca una liberación rápida de $B O G$ y ocasiona un aumento repentino en la presión del tanque [28].

- Riesgo por presión.

Una tasa alta de evaporación de GNL puede producir un aumento de presión en los espacios cerrados, especialmente, en los tanques de almacenamiento. De tal forma, los sistemas de transporte y almacenamiento del GNL deben ser equipados con válvulas de alivio, pues, mediante estas, se evita el daño en los contenedores al liberar presión por la salida del $B O G$ del sistema.

- Riesgo por liberación de GNL a la atmósfera.

La liberación del GNL en la atmósfera es inicialmente visible por la producción de escarcha, pero, al aumentar su temperatura, este se vuelve incoloro e inodoro; por tanto, no es detectable ante los sentidos humanos. Así, entrar en zonas donde se encuentra puede causar inconciencia por la baja concentración de $\mathrm{O}_{2}$. Además, las bajas temperaturas del GNL pueden causar quemaduras y/o lesiones por el contacto directo con los objetos o dispositivos de manejo sin protección adecuada y su inhalación puede causar daños en los pulmones por congelación [97].

- Riesgo por derrame.

El derrame de GNL es uno de los principales peligros en una planta de licuefacción, ya que puede generarse un incendio repentino, así como explosiones de nube de vapor [97]. 
Otros aspectos de seguridad están relacionados con las terminales donde se presentan procesos de descarga y almacenamiento de GNL [37]:

- Cumplimiento de estándares nacionales e internacionales.

- Ubicación de las terminales a una distancia segura de las poblaciones.

- Uso de materiales y sistemas diseñados para aislar y contener de manera segura el GNL.

- Usar zonas de incautación para contener los derrames y controlar la propagación y la tasa de vaporización, también para disminuir las consecuencias de conflagraciones en la piscina.

- Utilizar sistemas de reducción de vapor, los cuales generan espuma para reducir la velocidad de formación de vapor.

- Los sistemas de descarga de GNL deben poseer dispositivos de monitoreo y control para detectar cualquier desviación de los parámetros aceptables de funcionamiento.

- Usar acoplamientos de liberación de emergencia en las líneas de descarga, los cuales se apagan automáticamente ante situaciones de riesgo.

- Deben usarse sistemas de protección contra sobrepresión.

- Emplear sistemas de detección de fugas y control de derrames mediante sondas de detección de temperatura y gas.

- Utilizar sistemas de control de fuente de ignición.

- Instalar detectores de fuego y sistemas para detectar vapores combustibles. 
- Establecer planes de zonificación de incendios.

- Emplear sistemas automáticos de parada y despresurización de emergencia, y válvulas de aislamiento.

- Instalar sistemas de protección pasiva y activa contra incendios.

- Tener acoplamientos de desbloqueo de emergencia en líneas de descarga.

- Operadores entrenados deben estar siempre disponibles; su respuesta incluye hacer notificaciones de emergencia a equipos especializados de emergencia e informar a la comunidad.

Con el fin de evitar descargas y chispas entre los elementos metálicos de la planta, se debe realizar la puesta a tierra de las instalaciones y seguir instrucciones, tales como las que dicta el ITC-BT-18 [40].

\subsection{Mantenimiento e inspección}

Las instalaciones de GNL deben tener su respectivo manual de procedimientos de mantenimiento, el cual debe estar basado en la experiencia, el conocimiento de instalaciones similares y las condiciones de operación de las mismas [98]. La etapa de mantenimiento e inspección debe garantizar el adecuado funcionamiento de la planta de GNL y garantizar el mayor tiempo de operación.

A continuación se describen aspectos de mantenimiento e inspección de algunos elementos de las instalaciones de GNL:

- El tanque exterior se debe probar contra fugas y las tuberías, entre el contenedor interior y la primera conexión fuera del contenedor exterior, se deben someter a las pruebas indicadas en ASME B 31.3. Además, los contenedores y las tuberías asociadas deben probar contra fugas antes del 
llenado con GNL. Después de que las pruebas de aceptación se han completado, no se debe hacer ninguna soldadura en campo sobre los contenedores de GNL.

- Los contenedores cuyo volumen sea menor a $3.8 \mathrm{~m}^{3}$ deben estar equipados con un medidor de nivel de tubo de inmersión de longitud fija. Estos, mientras presentan volúmenes por encima de este valor, deben estar equipados con dos medidores de nivel independientes donde uno de ellos suministre indicación continua sobre si está completamente lleno o vacío, y si es fácil de mantener o reemplazar sin que haya que poner el contenedor fuera de servicio.

- La instrumentación de las instalaciones de GNL debe estar diseñada de manera que, en caso de presentarse una falla en el suministro de energía o de aire en los instrumentos, el sistema entre en un modo a prueba de fallas hasta que la compañía operadora pueda tomar acciones para reactivar o asegurar el sistema.

Los contenedores deben contar con el equipo necesario para monitorear continuamente la presión. Para ello, se debe contar con un manómetro por encima del nivel máximo de líquido que tenga un indicativo de la presión máxima permitida por el contenedor. Así mismo, se debe contar con medidores de presión en el espacio anular del tanque [98].

Las válvulas de alivio se deben dimensionar al considerar condiciones de falla, desplazamiento de vapor y evaporación repentina; así mismo, deben estar comunicadas directamente con la atmósfera. Las válvulas de alivio del contenedor interior deben tener una válvula de cierre manual con apertura completa, la cual se debe encontrar bloqueada o sellada en la posición totalmente abierta. La instalación de las mismas debe permitir aislamiento individual para hacer pruebas o mantenimiento, y mantener la capacidad total de alivio. Los conductores de venteo o descarga de dichas válvulas se deben diseñar e instalar de forma tal 
que se evite la acumulación de hielo u otros elementos extraños y, si están conectados directamente con la atmósfera, la descarga debe ser verticalmente hacia arriba [98].

- Debido a que el gas natural es una sustancia incolora e inodora, las instalaciones de GNL deben contar con un indicador portátil de gas inflamable en buen estado.

La inspección de cada instalación debe cumplir con los siguientes requisitos [98]:

- Tener los procedimientos de operación, mantenimiento y capacitación por escrito.

- Mantener actualizados los diagramas de los equipos de la planta y mostrar todas las revisiones hechas después de la instalación.

- Revisar los planes, procedimientos y las condiciones de funcionamiento o instalación que requiere el equipo.

- Establecer un plan de emergencia escrito.

- Analizar y documentar fallas relacionadas con la seguridad e incidentes, con el fin de determinar su causa y prevenir la posibilidad de recurrencia.

- En los aspectos de mantenimiento se debe considerar:

- Durante la operación de la planta, se debe mantener el suelo libre de basura, escombros y otros materiales que puedan ser propensos a incendiarse.

- Los componentes de la instalación deben estar libres de hielo, maleza y cualquier otro material extraño que pueda impedir su operatividad o que represente peligro de incendio. 
- Todas las rutas de acceso para el control del fuego dentro de una instalación de GNL se deben mantener despejadas en cualquier condición climática.

- Deben considerarse también los siguientes aspectos operacionales:

- Los componentes que pueden acumular mezclas combustibles deben ser purgados después de ser puestos fuera de servicio y antes de volver a ser empleados.

- El sistema de soporte de cada componente se debe inspeccionar, por lo menos, anualmente.

- Las fuentes de energía de emergencia en la planta de GNL se deben ensayar mensualmente para asegurar que estén operativas. Igualmente, se debe verificar, anualmente, que dicha fuente de energía puede operar como se prevé en la documentación de la planta.

- Los sistemas de aislamiento de las superficies de contención se deben inspeccionar anualmente. Las mangueras de GNL y del refrigerante deben ser probadas, al menos, cada año a la presión máxima de la bomba o al ajuste de la válvula de alivio y deben inspeccionarse visualmente antes de ser usadas para verificar daños o defectos.

- Si un sistema de control ha estado fuera de servicio, por más de 30 días, debe examinarse su funcionamiento antes de ponerlo en operación. Así mismo, los sistemas de control usados por temporadas deben ser inspeccionados y probados antes de ser usado.

- Después de que ocurran eventos meteorológicos o geofísicos, las plantas de GNLy, en particular, el contenedor de almacenamiento y sus suportes se deben inspeccionar externamente para asegurar la integridad estructural de la planta. 
Los componentes metálicos de la planta de GNL, los cuales se pueden ver perjudicados en la confiabilidad por corrosión durante su vida de servicio, deben cumplir con la protección contra corrosión de acuerdo con el numeral 9.10 de la NTC 6276, el cual toma como referencia la norma NFPA 59A [98]. En el numeral 14.8.13 de la NTC 6276 se sugieren periodos para realizar el control de corrosión en la planta de GNL.

\subsection{Aspectos normativos de las plantas de producción de GNL} a pequeña escala

La TABLA NRO. 19 presenta la propuesta para complementar la norma nacional NTC 6276, la cual se sugiere como base para establecer los lineamientos técnicos asociados a la producción de GNL a pequeña escala en Colombia al tener en cuenta aspectos a fortalecer en materia de:

- Diseño, construcción y seguridad.

- Tanques de almacenamiento.

- Intercambiadores de calor.

- Mantenimiento.

- Compresores.

- Sistemas de transferencia.

- Medio ambiente. 


\begin{tabular}{|c|c|c|}
\hline Aspectos & Norma & Descripción \\
\hline \multirow{14}{*}{$\begin{array}{l}\text { Diseño, } \\
\text { construcción y } \\
\text { seguridad }\end{array}$} & $\begin{array}{l}\text { ISO/DIS } \\
16903\end{array}$ & $\begin{array}{l}\text { Industrias del petróleo y del gas natural: características del GNL que } \\
\text { influyen en el diseño y en la selección de materiales. }\end{array}$ \\
\hline & 49 CFR 193 & Instalaciones de GNL. Normas federales de seguridad. \\
\hline & $\begin{array}{l}\text { AGA } \\
\text { XL1001 } \\
\end{array}$ & $\begin{array}{l}\text { Clasificación de las ubicaciones para instalaciones eléctricas en áreas } \\
\text { de uso de gas. }\end{array}$ \\
\hline & ISO 15649 & Industrias del petróleo y del GN: tuberías. \\
\hline & $\begin{array}{l}\text { ISO/TS } \\
16901\end{array}$ & $\begin{array}{l}\text { Guía para la evaluación de riesgos en el diseño de instalaciones } \\
\text { terrestres de GNL, la cual incluye la interfaz buque/puerto. }\end{array}$ \\
\hline & ISO 16904 & $\begin{array}{l}\text { Industrias de petróleo y GN. Diseño y prueba de brazos de } \\
\text { carga/descarga de GNL para terminales convencionales en tierra. }\end{array}$ \\
\hline & ISO 23251 & $\begin{array}{l}\text { Industrias de petróleo, petroquímica y GN. Sistemas de alivio a } \\
\text { presión y depresión. }\end{array}$ \\
\hline & ISO 45001 & $\begin{array}{l}\text { Sistemas de gestión de seguridad y salud laboral. Requisitos con } \\
\text { orientación para su uso. }\end{array}$ \\
\hline & NAG 501 & $\begin{array}{l}\text { Norma mínima de seguridad para plantas de almacenamiento de GNL } \\
\text { en tierra. }\end{array}$ \\
\hline & NFPA 59A & Norma para la producción, almacenamiento y manejo del GNL. \\
\hline & NGTS-02 & $\begin{array}{l}\text { Condiciones generales sobre el uso y la capacidad de las instalaciones } \\
\text { del sistema de gas. }\end{array}$ \\
\hline & $\begin{array}{l}\text { UNE-EN } \\
12066 \\
\end{array}$ & $\begin{array}{l}\text { Instalaciones y equipos para GNL. Ensayo de revestimientos aislantes } \\
\text { para cubetas de retención de gas natural licuado. }\end{array}$ \\
\hline & $\begin{array}{l}\text { UNE-EN } \\
13645\end{array}$ & $\begin{array}{l}\text { Instalaciones y equipamiento para GNL. Diseño de instalaciones } \\
\text { terrestres con capacidad de almacenamiento comprendida entre } 5 \text { y } \\
200 \text { t. }\end{array}$ \\
\hline & $\begin{array}{l}\text { UNE-EN } \\
1473\end{array}$ & $\begin{array}{l}\text { Instalaciones y equipos para GNL. Diseño de las instalaciones } \\
\text { terrestres. }\end{array}$ \\
\hline $\begin{array}{l}\text { Tanques de } \\
\text { almacenamiento }\end{array}$ & ISO 18132 & $\begin{array}{l}\text { Combustibles gaseosos licuados a base de hidrocarburos refrigerados } \\
\text { y no derivados del petróleo. Requisitos generales para medidores } \\
\text { automáticos de tanques. }\end{array}$ \\
\hline \multirow{5}{*}{$\begin{array}{l}\text { Intercambiadores } \\
\text { de calor }\end{array}$} & API 660 & Intercambiadores de calor de carcasa y tubo. \\
\hline & API 661 & $\begin{array}{l}\text { Industrias del petróleo, petroquímica y gas natural. Intercambiadores } \\
\text { de calor refrigerados por aire. }\end{array}$ \\
\hline & API 662 & $\begin{array}{l}\text { Industrias del petróleo, petroquímica y gas natural. Intercambiadores } \\
\text { de calor de placas. }\end{array}$ \\
\hline & API 663 & Intercambiadores de calor tipo horquilla. \\
\hline & API 664 & Intercambiadores de calor en espiral. \\
\hline \multirow[t]{3}{*}{ Mantenimiento } & $\begin{array}{l}\text { AGA } \\
\text { XO1084 }\end{array}$ & Guía de mantenimiento preventivo (GNL). \\
\hline & $\begin{array}{l}\text { AGA } \\
\text { XK0101 }\end{array}$ & Principios y prácticas de purga. \\
\hline & NGTS-08 & Plan de mantenimiento. \\
\hline \multirow[t]{5}{*}{ Compresores } & ISO 10439 & $\begin{array}{l}\text { Industrias del petróleo y del GN: compresores axiales, centrífugos y } \\
\text { compresores/expansores. }\end{array}$ \\
\hline & ISO 10440 & $\begin{array}{l}\text { Industrias del petróleo y del GN: compresores rotativos de } \\
\text { desplazamiento positivo. }\end{array}$ \\
\hline & ISO 10442 & $\begin{array}{l}\text { Industrias del petróleo y del GN: compresores centrífugos de aire } \\
\text { herméticos con engranajes integrales. }\end{array}$ \\
\hline & ISO 13631 & $\begin{array}{l}\text { Industrias del petróleo y del GN: compresores herméticos } \\
\text { reciprocantes. }\end{array}$ \\
\hline & ISO 13707 & Industrias del petróleo y del GN: compresores reciprocantes. \\
\hline $\begin{array}{l}\text { Sistema de } \\
\text { transferencia }\end{array}$ & ISO 20519 & $\begin{array}{l}\text { Navíos y tecnología marina: especificación para el abastecimiento de } \\
\text { buques alimentados con gas natural licuado (GNL). }\end{array}$ \\
\hline \multirow[t]{2}{*}{ Medio ambiente } & $\begin{array}{l}\text { EPA-230- } \\
\text { B-06-001 } \\
\end{array}$ & Hoja de ruta regulatoria de GNL de la EPA. \\
\hline & ISO 14001 & Sistemas de gestión ambiental. \\
\hline
\end{tabular}

TABLA NRO. 19. Recomendaciones normativas para complementar la NTC 6276. Elaboración propia. 


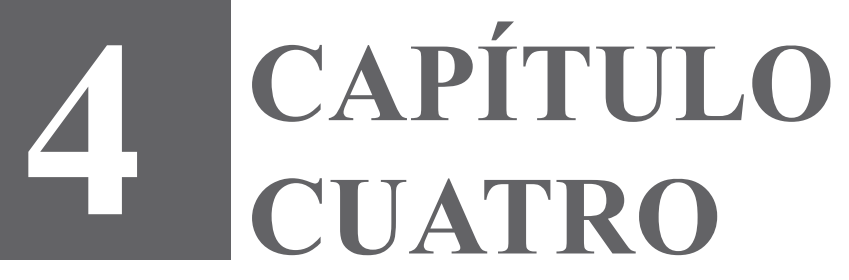




\section{GNL a pequeña escala en Colombia: aprovechamiento}

\subsection{Importación de GNL en el país}

En la actualidad, Colombia es uno de los eslabones activos de la cadena comercial de GNL en el mundo mediante la importación de este recurso en la Unidad Flotante de Regasificación y Almacenamiento (FSRU), la cual está en el área metropolitana de la ciudad de Cartagena. Esta FSRU es una planta de regasificación de GNL que atiende la demanda de gas solicitada por las termoeléctricas ubicadas en el norte del país (Termobarranquilla, Termocandelaria y Zona Franca Celsia), y tiene una producción de 400 MPCD y una capacidad de almacenamiento de GNL de $171000 \mathrm{~m}^{3}$ [99].

En la FSRU, el GNL se regasifica al interior del buque al utilizar agua de mar mediante intercambiadores de calor. Este es transportado, a través de un gasoducto de $45.7 \mathrm{~cm}$ (18 pulgadas) de diámetro y $860 \mathrm{~m}$ de longitud, hasta una estación de medición en tierra donde se filtra y se registra la presión, la temperatura, el poder calorífico y el caudal del gas natural mediante sensores ultrasónicos. Seguidamente, 
el GN es inyectado a un gasoducto de $9.2 \mathrm{~km}$ de longitud que se conecta al Sistema Nacional de Transporte (SNT) en la estación de gas Mamonal, la cual es perteneciente a la red de transporte de Promigas, y es inyectado a una presión de 60 bar. Cada tanque de la FSRU posee una bomba centrífuga criogénica sumergible, la cual impulsa el GNL a los vaporizadores que utilizan agua de mar; todo ello a una presión manométrica de descarga entre $17 \mathrm{kPa}$ y $30 \mathrm{kPa}$. Los flujos de gas están condicionados a las características técnicas y capacidad de la bomba, y logran operar con un flujo mínimo de 50 MPCD y un máximo de 400 MPCD. La planta de regasificación FSRU tiene capacidad para atender una demanda energética de cerca de 2000 MW, la cual es generada en las centrales termoeléctricas ubicadas en la región norte del país y es equivalente, aproximadamente, al $27 \%$ de la demanda total nacional de energía eléctrica [100].

El «Plan transitorio de abastecimiento» de la Unidad de Planeación Minero-Energética (UPME) asume la continuidad en el servicio de la planta de Cartagena (19 años de contrato), lo que aumentaría el factor R/P en 8.4 años y llegaría a 24.4 años [16]. A continuación, en la FigurA NRO. 20, se presenta la cadena de valor del GNL, esquema bajo el cual opera SPEC-LNG en la ciudad de Cartagena.

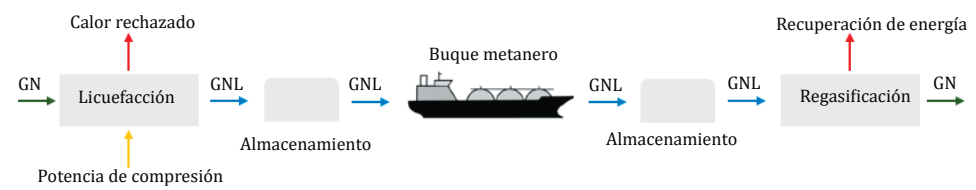

Figura NRo. 20. Cadena de valor del GNL. Elaboración propia.

El GNL que se regasifica en SPEC-LNG proviene principalmente de Louisiana-EE.UU y Trinidad y Tobago. En esta FSRU, el costo unitario de regasificación es de 0.4 USD/MBTU [101]. Se identificó que las fuentes optimizan el costo de transporte de GNL hacia Cartagena, al considerar la distancia recorrida son Trinidad y Tobago, y Estados Unidos (Costa del Golfo) con un costo de 0.18 USD/MBTU y 0.22 USD/MBTU respectivamente [101]. Los valores de USD mostrados acá son obtenidos para el año 2019. De esta forma, se determinó que las 
fuentes optimizadoras del costo de transporte del GNL hacia la planta de regasificación proyectada en Buenaventura, al considerar la distancia recorrida, serían Perú y Chile con un costo de 0.18 USD/MBTU y 0.26 USD/MBTU respectivamente [101].

A continuación, se presentan algunas características técnicas de la FSRU, las cuales son suministradas por su operadora, la Sociedad Portuaria el Cayao (SPEC-LNG):

- El tiempo de descarga del GNL desde el buque metanero a la FSRU es de 36 horas.

- El flujo volumétrico de descarga es de $\sim 9000 \mathrm{~m}^{3} / \mathrm{h}$.

- En 2018 se recibieron 7 buques con cargas parciales de GNL.

- Se recomienda no mezclar en un mismo tanque de almacenamiento GNL de diferente procedencia, dado que, se acentúa el fenómeno de roll over, la generación de $B O G$ y se corre el riesgo de experimentar aumentos súbitos de presión en los tanques en cortos períodos de tiempo, lo cual obliga a expulsar parte del combustible a través del disipador con consecuentes pérdidas monetarias.

- El GNL sufre un proceso de degradación, el cual se presenta cuando este se almacena por largos periodos de tiempo. Dicho proceso consiste en: a) la evaporación de las especies químicas más livianas, principalmente $\mathrm{N}_{2}$ y $\mathrm{CH}_{4}$, las cuales forman lo que se conoce como boil-off gas $(B O G)$. b) «Estratificación» por fases definidas por las diferentes especies químicas que forman el GNL; proceso que tiene lugar a razón de la diferencia de densidades de las diferentes especies. Las especies más pesadas se decantan y las más livianas se desplazan hacia la superficie libre por la acción de fuerzas boyantes. 
- El GNL es un fluido «autorefrigerante», puesto que, un eventual aumento en la energía interna del fluido, por efectos de transferencia de calor, eleva la tasa de evaporación de una fracción del GNL en la región de la superficie libre; razón por la cual se mantiene el líquido a una temperatura relativamente constante. Situación que, a su vez, genera una recirculación del GNL (roll over) por diferencia de densidades entre la zona más fría cerca de la superficie libre y la zona más caliente en la región central del líquido.

- Se requiere una línea de retorno de vapor para que los tanques de almacenamiento no colapsen. No se utiliza ningún equipo para circular el GNL, con el fin de no adicionar energía en forma de calor al sistema. Por esta razón, se conectan los tanques y se asegura una diferencia de presión para que el tanque, en el momento de la descarga, se encuentre con presión mayor a la del tanque desde el cual fluye el GNL.

- Por su composición química, el $B O G$ es un gas de efecto invernadero mucho más nocivo que el $\mathrm{CO}_{2}$. Por esta razón, la FSRU cuenta con una unidad de combustión para quemar una fracción de este y, así, disminuir el impacto ambiental y transformar el $\mathrm{CH}_{4}$ en $\mathrm{CO}_{2}$.

- El BOG generado en los tanques de almacenamiento de la FSRU en Cartagena es de aproximadamente $0.15 \%$ del volumen almacenado.

\subsection{Potencial de aprovechamiento de GNL en Colombia}

\subsubsection{Sector transporte}

En el presente documento se hace especial énfasis sobre el transporte terrestre por carretera. Según el Registro Único Nacional de Tránsito (RUNT), este sector abarca las siguientes categorías vehiculares: 
automóvil, bus, camión, camioneta, campero, cuatrimoto, microbús, motocarro, mototriciclo, tractocamión y volqueta [102].

En Colombia se recomienda emplear el GNL para abastecer el transporte de carga por carretera, es decir, para camiones y tractocamiones; debido a que, en estos vehículos, se pueden almacenar grandes cantidades de energía en tanques con reducidos requisitos de peso y espacio y, así, recorrer distancias importantes antes de cada recarga [66], [103]. De esta manera, en el sector transporte, el uso de GNL se recomienda principalmente en flotas cautivas donde los autos operan en recorridos cíclicos o extendidos, tales como los camiones interurbanos, urbanos y tractocamiones. Esta situación permite que el suministro de combustible sea realizado en el inicio o en el final del recorrido del vehículo, mientras no haya una red extendida de EDS que permitan abastecer la totalidad del parque automotor [104]. En cambio, el aprovechamiento de GNL no es recomendado para carros de transporte de pasajeros como microbuses y buses, puesto que esta tipología de automotores cuentan con períodos prolongados de inactividad y aumentan, considerablemente, las pérdidas por evaporación [56].

Mediante la Resolución 5443 de 2009 [107], el Ministerio de Transporte definió los camiones como aquellos vehículos que son empleados para el transporte de carga, dado su tamaño y destinación; y que tienen como peso bruto vehicular, según el fabricante, más de cinco toneladas. Así, los tractocamiones son carros empleados para arrastrar uno o varios remolques, o semirremolques, y están equipados con acoples adecuados para tal fin [102].

Actualmente, los vehículos terrestres de carga, los cuales emplean GNL para su operación, pueden ser dedicados o dual-combustible. Los primeros están diseñados para emplear únicamente $\mathrm{GN}$, mientras que los segundos emplean combustible diésel con el fin de asistir la combustión del GN [71]. En Colombia se recomienda emplear vehículos dedicados, puesto que, a comparación con los duales, estos presentan menores emisiones de NOx, SOx, metano y material particulado [18], [105], [106]. Así, para cada una de las etapas de uso final de GNL en el transporte en Colombia, se recomienda emplear las siguientes tecnologías: 
- Estaciones de servicio.

Se recomienda el uso de EDS tipo estándar permanente, ya que, al ser la tecnología más empleada a nivel internacional, presenta buenas prestaciones en cuanto capacidad y velocidad de abastecimiento de GNL y logra atender a más de cinco camiones simultáneamente en un periodo de 3 a 5 minutos [74], [77], [78], [107]. Estructuralmente, estas EDS son similares a las empleadas en el despacho de gasolina y diésel, pueden operar en autoservicio y contar con surtidores de GNL saturado e insaturado, ajustándose a los requerimientos de los usuarios. Cuentan con un tanque de almacenamiento criogénico con capacidades de 20 a $60 \mathrm{~m}^{3}$ [30], [31], [74], [76], [77], con una bomba criogénica sumergida y un dispensador de GNL. Así, dicha tecnología demanda un área de aproximadamente $2000 \mathrm{~m}^{2}$ y pueden costar entre 0.5 y 3 millones de dólares, pues esto depende de los equipos empleados, la ubicación y la complejidad de la EDS [76], [108].

A continuación se presentan las recomendaciones tecnológicas para la instalación de EDS de GNL en el país:

- Tanque o depósito de almacenamiento.

Los tanques pueden almacenar entre 40 y $130 \mathrm{~m}^{3}$ de GNL a presiones entre 15 y 23 bar y a una temperatura de $-162^{\circ} \mathrm{C}$. La capacidad de estos depende de la demanda que se desee atender; sin embargo, la mayoría de las EDS de GNL en Europa, Estados Unidos y Asia se emplean en tanques con una capacidad de $60 \mathrm{~m}^{3}$ [30], [31], [74], [76], [77] y hacen de estos los más comerciales a nivel internacional y, por tanto, los más recomendados para EDS de tipo permanente.

- Regasificador de depósito (PPR).

Este sistema se emplea principalmente durante la descarga del GNL desde camiones cisterna. Su objetivo es regular y mantener la presión de operación en 15 bar, tanto para la EDS como para el vehículo cisterna. Para tal fin, cuando la presión del tanque de la EDS o de la cisterna se reduce en 4 o 5 bar, parte del GNL es regasificado y llevado a este depósito para regular su presión de operación [77], [79]. 
- Bomba criogénica.

Por lo general, en las EDS el GNL se bombea por medio de bombas criogénicas, las cuales se sumergen en el fluido, se encapsulan herméticamente y reducen pérdidas de calor. Este dispositivo se encarga de impulsar el combustible desde el tanque de almacenamiento hasta el dispensador [76], [77]. A nivel comercial, las bombas criogénicas tienen capacidad de bombear GNL a tasas entre 700 y $800 \mathrm{~kg} / \mathrm{min}$ a una presión máxima de trabajo de 34 bar y con una demanda energética de $16 \mathrm{kWh}$ aproximadamente [76].

\section{- Odorizador.}

El proceso de odorización es llevado a cabo al añadir pequeñas cantidades de tetrahidrotiofeno (THT), terbutilmercaptano (TBM) o sulfato de dimetilo $(D M S)$ que contienen azufre en su composición. El más empleado a nivel comercial es el THT, un líquido incoloro, con olor característico, inflamable y más denso que el aire cuando se encuentra en fase gaseosa. Esta sustancia no debe entrar en contacto con el agua, por lo que, en la EDS de GN, se instalan líneas de suministro o extracción de agua [77], [85].

Los sistemas de odorización pueden ser por dosificación y por contacto. Es recomendable la instalación de los primeros, pues estos sistemas incorporan bombas que suministran THT de manera proporcional al caudal de gas suministrado [86].

- Manejador de $B O G$.

Para las EDS que solo suministren GNL a los vehículos, se recomienda emplear manejadores de $B O G$ basados en el método de condensación, puesto que, reducen las emisiones de metano a la atmósfera y permiten recuperar los costos asociados a las pérdidas por evaporación. Otras alternativas recomendadas son: emplear generadores eléctricos a gas, con el fin de producir energía eléctrica para consumo interno, o incorporar el $B O G$ al sistema de transporte de gas [80]. Además, se recomienda desarrollar regulaciones nacionales que establezcan lineamientos para el tratamiento de los $B O G$ en EDS. 
- Acondicionador línea de GNL (calentador).

Este dispositivo es una unidad de vaporización pequeña que se ubica entre el tanque de almacenamiento de la EDS y el dispensador de GNL. Permite acondicionar el combustible de acuerdo a los requerimientos de saturación y temperatura de cada vehículo.

- Dispensador.

Estos dispositivos se encargan de suministrar el GNL a presiones que oscilan entre los 5 y los 18 bar según la referencia comercial empleada. Generalmente están equipados con dos líneas: una de suministro y otra de retorno. Esta última se encarga de recuperar el $B O G$ del tanque del vehículo. Por seguridad, los dispensadores deben contar con un sistema de cierre automático de flujo, con el fin de evitar un escape de GNL en caso de rotura de la línea de suministro o de que el vehículo abandone la posición sin el respectivo procedimiento de desacople del surtidor.

Además, los surtidores pueden emplear diferentes tipos de boquillas, las cuales pueden ser: de acción dual de conexión radial, de acción simple de conexión coaxial o de acción simple de conexión radial. En la actualidad, las EDS comerciales emplean estas últimas, las cuales están diseñadas para operar con altos caudales y altas presiones; situación que las hace propicias para tener un suministro de GNL rápido y seguro para vehículos de transporte de carga terrestre. Esta tecnología cuenta con una conexión coaxial de tubo; la carcasa de la válvula; dos asas similares a unas tijeras; y lengüetas de bloqueo reforzadas con resorte, sellos y otros componentes de sujeción y activación.

\subsubsection{Sectores termoeléctrico, industrial y residencial}

A continuación se presenta una primera aproximación del análisis de los sectores termoeléctrico, industrial y residencial, en los cuales se considera que toda la demanda de GN proyectada por la UPME, en el escenario medio, es atendida por medio del GNL. Para ello, se consideran las siguientes regiones de análisis [16]: 
- Centro: Bogotá D.C., Boyacá, Casanare, Cundinamarca, Guaviare y Meta.

- Costa: Atlántico, Bolívar, Córdoba, La Guajira, Magdalena y Sucre.

- CQR: Caldas, Quindío y Risaralda.

- Noreste: Cesar, Norte de Santander y Santander.

- Noroeste: Antioquia.

- Suroeste: Cauca, Nariño, Putumayo y Valle del Cauca.

- Tolima Grande: Caquetá, Huila y Tolima.

- Sector termoeléctrico.

Este sector se encarga de obtener energía eléctrica a partir de la energía térmica producto de la combustión de algún combustible como el carbón o gas natural. Para ello, se emplean plantas térmicas que emplean turbinas de gas, vapor o ambas [87]. Así, a partir de la proyección de la demanda de GN en las termoeléctricas de Colombia, se estima la cantidad equivalente de GNL requerida por la totalidad de la demanda, tal como se muestra en la TABLA NRO. 20.

\begin{tabular}{lllllll}
\hline Región & \multicolumn{3}{l}{$\begin{array}{l}\text { Demanda de gas natural } \\
\left(\mathbf{M m}^{\mathbf{3}} / \mathbf{d i ́}\right)\end{array}$} & & \multicolumn{4}{l}{$\begin{array}{l}\text { Demanda GNL } \\
\left(\mathbf{1} \times \mathbf{~ 1 0}^{\mathbf{3}} \mathbf{T P D}\right)\end{array}$} \\
\cline { 2 - 7 } & $\mathbf{2 0 2 0}$ & $\mathbf{2 0 2 5}$ & $\mathbf{2 0 3 0}$ & $\mathbf{2 0 2 0}$ & $\mathbf{2 0 2 5}$ & $\mathbf{2 0 3 0}$ \\
\hline Centro & 1.67 & 0.92 & 1.60 & 1.22 & 0.67 & 1.17 \\
\hline Costa & 3.84 & 2.41 & 2.41 & 2.79 & 1.75 & 1.76 \\
\hline CQR & 0.22 & 0.03 & 0.20 & 0.16 & 0.02 & 0.15 \\
\hline Noreste & 1.01 & 0.13 & 0.92 & 0.73 & 0.10 & 0.67 \\
\hline Noroeste & 1.32 & 0.19 & 1.22 & 0.96 & 0.14 & 0.89 \\
\hline Suroeste & 1.64 & 0.22 & 1.52 & 1.20 & 0.16 & 1.10 \\
\hline
\end{tabular}

TABLA NRO. 20. Proyección de demanda de GNL por regiones para el sector termoeléctrico.

Tomada de [87]. 
Adicionalmente, la TABLA NRO. 21 presenta una estimación de la demanda de GNL proyectada para algunas termoeléctricas susceptibles a cambiar de tecnología de almacenamiento y regasificación in situ. Lo anterior bajo el escenario en el que toda la demanda de GN es abastecida con GNL.

\begin{tabular}{lllllll}
\hline Termoeléctrica & \multicolumn{2}{l}{$\begin{array}{l}\text { Demanda de gas natural } \\
\text { (GBTU/día) }\end{array}$} & \multicolumn{4}{l}{$\begin{array}{l}\text { Demanda GNL } \\
\left(\mathbf{1} \times \mathbf{1 0}^{\mathbf{3}} \mathbf{T P D}\right)\end{array}$} \\
\cline { 2 - 7 } & $\mathbf{2 0 2 0}$ & $\mathbf{2 0 2 0}$ & $\mathbf{2 0 3 0}$ & $\mathbf{2 0 2 0}$ & $\mathbf{2 0 2 5}$ & $\mathbf{2 0 3 0}$ \\
\hline Termocartagena & 7.53 & 6.89 & 6.95 & 0.15 & 0.14 & 0.14 \\
\hline Termosierra & 52.79 & 7.52 & 48.71 & 1.05 & 0.15 & 0.97 \\
\hline Termovalle/EmCali & 65.61 & 9.01 & 60.50 & 1.30 & 0.18 & 1.20 \\
\hline Termocentro & 35.18 & 5.18 & 32.42 & 0.70 & 0.10 & 0.64 \\
\hline Termoyopal & 29.53 & 29.52 & 29.53 & 0.59 & 0.59 & 0.59 \\
\hline
\end{tabular}

TABLA NRo. 21. Demanda de GNL de termoeléctricas susceptibles a cambio de tecnología.

Tomada de [87].

- Sector industrial.

Este sector se caracteriza por contar con una serie de procesos y actividades productivas donde las materias primas se transforman en productos elaborados. Generalmente, este sector abarca las siderúrgicas; las industrias mecánicas, químicas y textiles; la producción de bienes alimenticios y de consumo general; entre otros [87]. A continuación, la TABLA NRO. 22 presenta la proyección de demanda de GNL que se requeriría para atender la solicitud total de GN proyectada para el sector industrial de Colombia.

\begin{tabular}{|c|c|c|c|c|c|c|}
\hline \multirow[t]{2}{*}{ Región } & \multicolumn{3}{|c|}{$\begin{array}{l}\text { Demanda de gas natural } \\
\left(\mathrm{Mm}^{3} / \mathrm{día}\right)\end{array}$} & \multicolumn{3}{|c|}{$\begin{array}{l}\text { Demanda GNL } \\
\left(1 \times 10^{3} \text { TPD }\right)\end{array}$} \\
\hline & 2020 & 2025 & 2030 & 2020 & 2025 & 2030 \\
\hline Centro & 2.04 & 2.14 & 2.26 & 0.67 & 0.70 & 0.74 \\
\hline Costa & 2.42 & 2.54 & 2.69 & 0.79 & 0.83 & 0.88 \\
\hline CQR & 0.18 & 0.18 & 0.20 & 0.06 & 0.06 & 0.07 \\
\hline Noreste & 0.40 & 0.42 & 0.45 & 0.13 & 0.14 & 0.15 \\
\hline Noroeste & 0.71 & 0.74 & 0.79 & 0.23 & 0.24 & 0.26 \\
\hline Suroeste & 1.16 & 1.21 & 1.28 & 0.38 & 0.40 & 0.42 \\
\hline Tolima Grande & 0.01 & 0.01 & 0.01 & 0.67 & 0.70 & 0.74 \\
\hline
\end{tabular}

TABLA NRO. 22. Proyección de demanda de GNL por regiones para el sector industrial.

Tomada de [87]. 
- Sector residencial.

Este sector está caracterizado por los bienes inmuebles (viviendas, edificaciones, entre otros) y muebles. Representa una participación importante en la demanda de GN y de energía eléctrica en Colombia [88]. A continuación, la TABLA NRO. 23 presenta la cantidad de GNL requerida para atender la totalidad de la demanda de GN proyectada para el sector residencial.

\begin{tabular}{lllllll}
\hline Región & \multicolumn{3}{l}{$\begin{array}{l}\text { Demanda de gas natural } \\
\left(\mathbf{M m}^{\mathbf{3}} / \mathbf{d} \mathbf{a}\right)\end{array}$} & \multicolumn{5}{l}{$\begin{array}{l}\text { Demanda GNL } \\
\left(\mathbf{1} \times \mathbf{1 0}^{\mathbf{3}} \mathbf{T P D}\right)\end{array}$} \\
\cline { 2 - 7 } & $\mathbf{2 0 2 0}$ & $\mathbf{2 0 2 5}$ & $\mathbf{2 0 3 0}$ & $\mathbf{2 0 2 0}$ & $\mathbf{2 0 2 5}$ & $\mathbf{2 0 3 0}$ \\
\hline Centro & 1.52 & 1.63 & 1.71 & 1.11 & 1.19 & 1.24 \\
\hline Costa & 0.75 & 0.80 & 0.83 & 0.54 & 0.58 & 0.61 \\
\hline CQR & 0.25 & 0.29 & 0.32 & 0.18 & 0.21 & 0.23 \\
\hline Noreste & 0.36 & 0.38 & 0.40 & 0.26 & 0.28 & 0.29 \\
\hline Noroeste & 0.49 & 0.60 & 0.68 & 0.36 & 0.44 & 0.50 \\
\hline Suroeste & 0.42 & 0.48 & 0.52 & 0.31 & 0.35 & 0.38 \\
\hline Tolima Grande & 0.23 & 0.26 & 0.27 & 0.17 & 0.19 & 0.20 \\
\hline
\end{tabular}

TABLA NRO. 23. Proyección de demanda de GNL por regiones para el sector residencial.

Tomada de [87].

Para el sector residencial, una de las alternativas más atractivas, asociadas con el suministro de GNL, es abastecer la demanda de municipalidades no interconectadas a la red nacional de transporte de GN. La TABLA NRO. 24 presenta los departamentos que cuentan con cubrimiento de GN por gasoducto menor al $70 \%$.

\begin{tabular}{lllll}
\hline Departamento & Municipios & Municipios con gas & Cubrimiento (\%) & No cubrimiento (\%) \\
\hline Huila & 37 & 26 & 70 & 30 \\
\hline Quindío & 12 & 8 & 67 & 33 \\
\hline Bolívar & 46 & 28 & 61 & 39 \\
\hline Boyacá & 123 & 67 & 54 & 46 \\
\hline Santander & 87 & 39 & 45 & 55 \\
\hline Cauca & 42 & 18 & 43 & 57 \\
\hline Putumayo & 13 & 4 & 31 & 69 \\
\hline Norte de & 40 & 12 & 30 & 70 \\
Santander & & & & 75 \\
\hline Guaviare & 4 & 1 & 25 & 94 \\
\hline Caquetá & 16 & 1 & 6 & 98 \\
\hline Nariño & 64 & 1 & 2 & d \\
\hline
\end{tabular}

TABLA NRO. 24. Porcentaje de cubrimiento de gas natural por departamento.

Tomada de [87]. 
Así, la TABLA NRO. 25 presenta la cantidad de GNL, la cual es requerida para atender los departamentos anteriormente listados, al considerar los siguientes factores: 3.6 habitantes por vivienda, $1 \%$ de crecimiento poblacional anual, $7 \%$ en aumento del número de usuarios de GN anual y $13.7 \mathrm{~m}^{3}$ de consumo promedio de GN por usuario [10], [87].

\begin{tabular}{lllllll}
\hline Departamento & \multicolumn{7}{l}{ Demanda con gas natural $\mathbf{( \mathbf { M m } ^ { 3 } / \mathbf { d } \text { á) }}$} & \multicolumn{3}{l}{ Demanda GNL (TPD) } \\
\cline { 2 - 7 } & $\mathbf{2 0 2 0}$ & $\mathbf{2 0 2 5}$ & $\mathbf{2 0 3 0}$ & $\mathbf{2 0 2 0}$ & $\mathbf{2 0 2 5}$ & $\mathbf{2 0 3 0}$ \\
\hline Bolívar & 11.85 & 12.54 & 13.28 & 3.85 & 4.12 & 4.32 \\
\hline Norte de Santander & 22.00 & 23.28 & 24.65 & 7.22 & 7.63 & 8.03 \\
\hline Santander & 32.09 & 33.96 & 35.95 & 10.53 & 11.14 & 11.75 \\
\hline Boyacá & 17.02 & 18.02 & 19.07 & 5.54 & 5.87 & 6.21 \\
\hline Quindío & 1.06 & 1.12 & 1.18 & 0.34 & 0.34 & 0.41 \\
\hline Huila & 5.16 & 5.46 & 5.78 & 1.69 & 1.76 & 1.89 \\
\hline Guaviare & 1.68 & 1.78 & 1.89 & 5.54 & 5.81 & 6.14 \\
\hline Cauca & 33.65 & 35.61 & 37.70 & 11.00 & 11.68 & 12.35 \\
\hline Caquetá & 24.90 & 26.35 & 27.89 & 8.17 & 8.64 & 9.11 \\
\hline Putumayo & 11.91 & 12.61 & 13.34 & 3.92 & 4.12 & 4.39 \\
\hline Nariño & 146.54 & 155.10 & 164.17 & 47.99 & 50.76 & 53.73 \\
\hline
\end{tabular}

TABLA NRO. 25. Proyección de demanda de GNL para departamentos con cubrimiento parcial del servicio de gas natural 2020-2030.

Tomada de [87].

Los sectores industrial, termoeléctrico y residencial pueden emplear centrales de regasificación a pequeña escala con estructuras físicas idénticas, las cuales están caracterizadas por contar con: tanques de almacenamiento, vaporizadores, odorizador, control de vaporización y sistema de regulación de presión de despacho. La diferencia radicaría, básicamente, en las dimensiones y capacidades de los equipos, tales como los tanques de almacenamiento y los vaporizadores, ya que estos deben ajustarse a los requerimientos de la demanda de gas y a la disponibilidad comercial de los mismos [29].

\subsection{Ajustes normativos para uso de GNL en Colombia}

EnColombia,lanormatividadestá enfocadaenestablecerlineamientos y criterios técnicos asociados a la seguridad y a la operación de los vehículos de transporte público, en aras de fomentar un transporte eficaz y seguro. Así mismo, normas, decretos y leyes nacionales establecen los requerimientos de conducción, almacenamiento, manejo y distribución de combustibles derivados de petróleo, los cuales incluyen el GLP y el 
GNC que están incluidos en el listado de mercancías peligrosas según el Decreto 1609 de 2002.

En el mencionado país existen resoluciones que fijan criterios de seguridad en temas de conversión, pesos y dimensiones máximas para vehículos de transporte de carga y pasajeros; además, según el Ministerio de Transporte, se establecen requisitos de la cadena de suministros, los cuales disponen los niveles permisibles de emisiones contaminantes para fuentes móviles e indican criterios de almacenamiento, manejo, comercialización y distribución de GLP y GNC. Adicionalmente, estos regulan las EDS de suministro de combustible y los talleres de conversión de vehículos con unidades de motorización a GNC.

Asimismo, las Normas Técnicas Colombianas (NTC) establecen estándares de diseño, de construcción, de reparación, de modificación, de marcado, de rotulado, de inspección, de ensayos y de operación de los vehículos cisterna para el transporte de mercancías peligrosas. Estas fijan condiciones que deben cumplir las EDS de abastecimiento de GLP y/o GNC, así como los requerimientos y métodos de ensayo establecidos para garantizar la seguridad de los autos con capacidad de transportar entre diez y setenta y nueve pasajeros. Del mismo modo, se abarcan lineamientos de seguridad y métodos de ensayo para automóviles que operan con GNC, y también para la carga y descarga de GNL desde y hacia vehículos cisterna.

A nivel internacional, las normas AGA consideran aspectos relacionados con la seguridad y la operación de carros usados para el transporte de GNL. Así mismo, los códigos NFPA establecen requisitos para equipos, edificios y estructuras empleadas para la manipulación del GNL y el GNC en vehículos; e indican también los criterios de diseño, instalación, inspección, ensayo, almacenamiento, distribución, ubicación, seguridad y operación. Además, las normas CGA plantean criterios de diseño, de materiales, de instalación, de pruebas y de marcado de los tanques empleados para la carga de líquidos criogénicos no inflamables. 
La Organización Internacional de Estandarización - International Organization for Standarization (ISO) - a través de las normas ISO 12614-1 hasta la ISO 12614-19, establece los componentes de los sistemas de combustible de GNL, así como los requisitos relacionados con las actividades de construcción, purgas y ensayos en elementos conectores de reabastecimiento, diseño y operación de tanques de almacenamiento de GNL a bordo y uso del GNL como combustible en vehículos automotores. Del mismo modo, la ISO 16924 considera criterios de diseño, construcción, operación, mantenimiento, inspección, ensayos, riesgos, seguridad y protección contraincendios de las EDS de suministro de GNL a carros del sector transporte.

La Sociedad de Ingenieros Automotrices - Society of Automotive Engineers (SAE) - establece criterios de estandarización de la construcción, operación y mantenimiento, tanto para vehículos de servicio público o comercial a GNL, como para los sistemas de suministro de GNL para automóviles.

A nivel europeo, las normas UNE-EN establecen requerimientos para adaptadores de carga y descarga de GNL, desde y hacia vehículos cisterna de transporte de mercancías peligrosas. Estas normas consideran criterios de operación y seguridad. Adicionalmente, la Comunidad Andina (CAN) plantea las directrices relacionadas con la importación y el uso de vehículos limpios y eficientes al considerar criterios normativos, regulatorios y sancionatorios del transporte de mercancías a nivel internacional.

A continuación, la TABLA NRO. 26 presenta las principales normas recomendadas para el uso del GNL en el sector transporte. 


\begin{tabular}{|c|c|c|}
\hline Aspectos & Norma & Descripción \\
\hline \multirow[t]{7}{*}{$\begin{array}{l}\text { Sistema de combustible para } \\
\text { vehículos de transporte terrestre }\end{array}$} & NFPA 52 & $\begin{array}{l}\text { Código para los sistemas de combustible de gas } \\
\text { natural en vehículos. }\end{array}$ \\
\hline & ISO 12614 & $\begin{array}{l}\text { Requerimientos generales de los sistemas de } \\
\text { combustible de GNL. }\end{array}$ \\
\hline & ISO 12617 & Conectores para el abastecimiento de GNL. \\
\hline & ISO 12991 & $\begin{array}{l}\text { Tanques para el almacenamiento a bordo de GNL } \\
\text { para su uso en vehículos. }\end{array}$ \\
\hline & ISO 19723 & $\begin{array}{l}\text { Requerimientos de seguridad para los sistemas de } \\
\text { combustible a GNL. }\end{array}$ \\
\hline & ISO 21104 & $\begin{array}{l}\text { Conectores para el abastecimiento de GNL a baja } \\
\text { presión. }\end{array}$ \\
\hline & SAE J 2343 & $\begin{array}{l}\text { Prácticas recomendadas para vehículos pesados a } \\
\text { GNL. }\end{array}$ \\
\hline \multirow[t]{5}{*}{$\begin{array}{l}\text { Tanques de almacenamiento y/o } \\
\text { camiones cisterna }\end{array}$} & NFPA 385 & $\begin{array}{l}\text { Estándar para los tanques de vehículos de líquidos } \\
\text { combustibles e inflamables. }\end{array}$ \\
\hline & CGA 341 & $\begin{array}{l}\text { Especificaciones para camiones cisterna de líquidos } \\
\text { criogénicos no inflamables. }\end{array}$ \\
\hline & $\begin{array}{l}\text { UNE-EN } \\
13083 \\
\end{array}$ & $\begin{array}{l}\text { Tanques para el transporte de mercancías } \\
\text { peligrosas. }\end{array}$ \\
\hline & $\begin{array}{l}\text { UNE-CEN/TR } \\
15120\end{array}$ & $\begin{array}{l}\text { Cisternas destinadas al transporte de mercancías } \\
\text { peligrosas. }\end{array}$ \\
\hline & $\begin{array}{l}\text { ISO/AWI } \\
22103\end{array}$ & $\begin{array}{l}\text { Requerimientos operacionales para vehículos } \\
\text { automotores. Tanques para GNL a bordo. }\end{array}$ \\
\hline \multirow[t]{2}{*}{ Estaciones de GNL } & ISO 16924 & $\begin{array}{l}\text { Estaciones de GNL para el abastecimiento } \\
\text { vehicular. }\end{array}$ \\
\hline & SAE J 2645 & $\begin{array}{l}\text { Medidores y dispensadores para el suministro de } \\
\text { GNL a buses y camiones. }\end{array}$ \\
\hline \multirow[t]{2}{*}{ Calidad del GNL } & ISO 15403 & $\begin{array}{l}\text { Designación de la calidad del gas natural como } \\
\text { combustible para vehículos. }\end{array}$ \\
\hline & SAE J 2699 & GNL como combustible vehicular. \\
\hline
\end{tabular}

TABLA NRO. 26. Recomendaciones normativas para el transporte por carretera. Elaboración propia. 



\section{Consideraciones finales}

En general, para la obtención y la utilización del GNL en Colombia, se sugiere considerar aspectos como:

- Para producir GNL, el GN de Colombia debe pretratarse en un proceso que considere: endulzamiento, deshidratación, remoción y recuperación de los líquidos del gas natural. Particularmente, para la licuefacción del GN de La Guajira, la deshidratación debe ser priorizada; mientras que, para la de Cusiana y Cupiagua se recomienda, además de la deshidratación, incluir esquemas de endulzamiento y remoción de los líquidos del gas natural.

- En Colombia se podría producir GNL a partir del gas quemado en antorcha de veinticuatro pozos; en tres de estos se podría licuar a pequeña escala, en catorce a micro y en siete a nano escala. En estas aplicaciones se recomienda emplear procesos de licuefacción de ciclo de refrigerante mixto, dado que, presentan una mejor eficiencia en comparación con otras tecnologías disponibles en el mercado.

- La NTC 6276 es propuesta como la base para el establecimiento de los lineamientos técnicos de producción de GNL en Colombia a pequeña escala. Esta norma debe ser complementada al considerar aspectos relacionados con el medio ambiente, el diseño, el mantenimiento, la instalación y la seguridad de dispositivos como tanques de almacenamiento, intercambiadores de calor, compresores y sistemas de transferencia.

- Para el sector transporte se recomienda priorizar la utilización del GNL en flotas de transporte de carga que operen en viajes largos o recorridos cíclicos (camiones interurbanos, urbanos y tractocamiones). Así mismo, se sugiere que, mientras no exista una red de EDS lo suficientemente amplia para atender la demanda del parque vehicular del país, el suministro de GNL sea realizado en los puntos de inicio y/o final de las respectivas rutas. 
- Se recomienda que, para el abastecimiento de GNL al parque automotor, se empleen EDS de tipo permanente, las cuales deben ser equipadas con: sistemas de acondicionamiento en masa, tanques de almacenamiento tipo bala con capacidad de $60 \mathrm{~m}^{3}$, manejador de $B O G$ y dispensadores con boquillas de acción simple de conexión coaxial.

- Finalmente, para emplear el GNL en los sectores industrial, termoeléctrico y residencial, se propone utilizar unidades de regasificación que cuenten con: vaporizadores de aire ambiente, sistema de control de vaporización, odorizador, regulador de presión y tanques de almacenamiento con capacidades ajustadas a cada aplicación particular. 


\section{Referencias}

[1] International Energy Agency, "Key World Energy Statistics," IEA, 2018. [Online]. Available: https://www.iea.org/events/keyworld-energy-statistics-2018.

[2] Unidad de Planeación Minero Energética (UPME), "Balance energético colombiano - BECO," 2019. [Online]. Available: http://www1.upme.gov.co/InformacionCifras/ Paginas/BECOCONSULTA.aspx.

[3] World Health Organization, "Ten Threats to Global Health in 2019," News, 2019. [Online]. Available: https://www.who.int/ vietnam/news/feature-stories/detail/ten-threats-to-global-healthin-2019.

[4] D. Yergin, S. Gross, N. Meyer and L. Tillemann-Dick, Energy Vision 2013 Energy Transitions: Past and Future. Geneva, Switzerland: World Economic Forum, 2013.

[5] D. Serrato, J. Zapata-Mina, Á. Restrepo and J. Torres, "Assessment of Liquefied Natural Gas (LNG) Regasified Through Gas Interchangeability in Energy Consumption Sectors," Energy Reports, vol. 7, pp. 2526-2533, 2021.

[6] S. Faramawy, T. Zaki and A. A. E. Sakr, "Natural Gas Origin, Composition and Processing: A Review," Journal of Natural Gas Science and Engineering, vol. 34. pp. 34-54, 2016.

[7] B. Guo and A. GHalambor, Natural Gas Engineering Handbook, 2nd ed. Houston, Texas: Gulf Publishing Company, 2012.

[8] K. Lambert and M. Izquierdo, "Límites de inflamabilidad," CFBT-BE. pp. 1-10, 2016. 
[9] Promigas. "Composición del gas vigente," Promigas. $\quad$ http://52.247.87.160:52345/BEO/Paginas/ ComposicionGasVigente.aspx (2019).

[10] Promigas, "Informe del sector gas natural 2018," 2018. [Online]. Available: https://www.promigas.com/ InversionistasDocumentos/PROMIGAS_Informe_Anual_de_ Gestion_2018.pdf.

[11] Ministerio de Minas y Energía, "Boletín estadístico de minas y energía 2018," UPME, 2018. [Online]. Available: https://www1. upme.gov.co/PromocionSector/SeccionesInteres/Documents/ Boletines/Boletin_Estadistico_2018.pdf.

[12] Ministerio de Minas y Energía, "Cobertura del servicio de gas natural-III trimestre de 2019," 2019. [Online]. Available: https://www.minenergia.gov.co/documents/10192/24109840/ Consolidado+Reporte + Cobertura $+\mathrm{GN}+2019+-+\mathrm{II}+$ Trimestre . pdf.

[13] Transportadora de Gas Internacional (TIG), "Informe sobre la situación financiera TGI según los estados financieros," Bogotá, Colombia, 2019.

[14] Promigas, "Informe del Sector Gas Natural 2019," 2019. [Online]. Available: http://52.247.87.160:52345/Documents/ InformedelSectorGasNaturalenColombia2019.pdf.

[15] Unidad de Planeación Minero Energética (UPME), "Estudio técnico para el plan de abastecimiento de gas natural," Bogotá, Colombia, 2020. [Online]. Available: https://www1.upme.gov. co/Hidrocarburos/publicaciones/PAGN_2019-2028.pdf.

[16] Unidad de Planeación Minero Energética (UPME), "Plan transitorio de abastecimiento de gas natural," 2016. [Online]. Available: https://www1.upme.gov.co/Hidrocarburos/ publicaciones/Plan_Transitorio_Abastecimiento_Gas_Natural. pdf. 
[17] M. A. Mac Kinnon, J. Brouwer and S. Samuelsen, "The Role of Natural Gas and Its Infrastructure in Mitigating Greenhouse Gas Emissions, Improving Regional Air Quality, and Renewable Resource Integration," Prog. Energy Combust. Sci., vol. 64, pp. 62-92, 2018.

[18] R. Verbeek and M. VerbeeK, "LNG for Trucks and Ships: Fact Analysis-Review of Pollutant and GHG Emissions," TNO, 2015. [Online]. Available: https://www.nationaallngplatform.nl/wpcontent/uploads/2016/04/TNO-report_LNG_fact_analysis.pdf.

[19] Alternative Fuel Data Center, "Natural Gas Benefits and Considerations," U. S. Departament of Energy, 2019. [Online]. Available: https://afdc.energy.gov/fuels/natural_gas_benefits. html.

[20] A. T. De Almeida, A. C. Lopes, A. Carvalho, J. Mariano, A. JAHN and M. Broege, "Examining the Potential of Natural Gas Demand-Side Measures to Benefit Customers, the Distribution Utility and the Environment: Two Case Studies from Europe," Energy, vol. 29, no. 7, pp. 979-1000, 2004.

[21] U. S. Energy Information Administration (EIA), "Natural Gas Explained Natural Gas and the Environment," 2020. [Online]. Available: https:/www.eia.gov/energyexplained/natural-gas/ natural-gas-and-the-environment.php.

[22] U. S. Departament of Energy, "Natural Gas," 2020. [Online]. Available: https://www.fueleconomy.gov/feg/bifueltech.shtml.

[23] U. S. Energy Information Administration (EIA), "Natural Gas Explained Use of Natural Gas," 2020. [Online]. Available: https://www.eia.gov/energyexplained/natural-gas/use-ofnatural-gas.php.

[24] J. G. Speight, Natural Gas A Basic Handbook, 2nd ed. Cambridge, United States: Gulf Professional Publishing, 2019. 
[25] A. Bahadori, Natural Gas Processing: Technology and Engineering Design. Waltham, United States: Gulf Professional Publishing, 2014.

[26] M. Badami, J. C. Bruno, A. Coronas and G. Fambri, "Analysis of Different Combined Cycles and Working Fluids for LNG Exergy Recovery During Regasification," Energy, vol. 159, pp. 373-384, 2018.

[27] B. B. Kanbur, L. Xiang, S. Dubey, F. H. Choo and F. Duan, "Cold Utilization Systems of LNG: A Review," Renew. Sustain. Energy Rev., vol. 79, no. May, pp. 1171-1188, 2017.

[28] International Gas Union, "Guidebook to Gas Interchangeability and Gas Quality," 2011. [Online]. Available: https://www.igu.org/wp-content/uploads/2011/08/Guidebookto-Gas-Interchangeability-and-Gas-Quality-August-2011-min. pdf.

[29] WÄrtsilä, "LNG Plants-Mini and Small Scale Liquefaction Technology," 2016. [Online]. Available: https://cdn.wartsila.com/ docs/default-source/product-files/ogi/lng-solutions/brochure-oogi-lng-liquefaction.pdf.

[30] Linde Group, "LNG Technology: Optimised Solutions for Small to World-Scale Plants," 2021. [Online]. Available: https://www. linde-engineering.com/en/images/LNG-technology_tcm194577.pdf.

[31] Galileo Technologies, "Soluciones de producción distribuida de GNL: GNL en pequeña escala," 2020. [Online]. Available: https://www.galileoar.com/produccion-distribuida-de-gnl-enpequena-escala/.

[32] L. A. Pellegrini, G. De Guido and V. Valentina, "Energy and Exergy Analysis of Acid Gas Removal Processes in the LNG Production Chain," J. Nat. Gas Sci. Eng., vol. 61, no. July, 2018, pp. 303-319. 
[33] Perry's Chemical Engineers' Handbook, 7. ${ }^{a}$ ed., R. H. Perry, D. W. Green and J. O. Maloney, New York, United States: McGraw-Hill, 1997.

[34] D. E. Winterbone and A. Turan, "Liquefaction of Gases," $A d v$. Thermodyn. Eng., pp. 423-445, 2015.

[35] S. Mokhatab, J. MaK, J. Valappil and D. Wood, "Natural Gas Liquefaction," in Handbook of Liquefied Natural Gas. Elsevier, 2014, pp. 147-183.

[36] M. A. Qyyum, K. QAdeer and M. Lee, "Comprehensive Review of the Design Optimization of Natural Gas Liquefaction Processes: Current Status and Perspectives," Ind. Eng. Chem. Res., vol. 57, no. 17, pp. 5819-5844, 2018.

[37] S. Mokhatab, J. Y. Mak, J. V Valappil, and D. A. Wood, Handbook of Liquefied Natural Gas, 1 Edition. Oxford, United Kingdom: Gulf Professional Publishing, 2014.

[38] CRYOLOR, "LNG Solutions: Energy Transition at the Heart of Our Strategy," 2019. [Online]. Available: https://www.cryolor. com/lng-liquefied-natural-gas.

[39] Chart Industries, "Cryogenic Storage TanksandRegasification," 2019. [Online]. Available: http://www.chartindustries.com/ Energy/LNG-Solutions-Equipment/Storage.

[40] R. Valencia Chapi, G. Collaguazo Galeano, L. Lorente Leyva and I. Herrera Granda, "Planta satélite de gas natural licuado para el abastecimiento del sector industrial en CuencaEcuador," Delos Dllo. Local Sost., no. 27, 2016.

[41] M. S. Khan, S. Effendy, I. A. A. Karimi and A. Wazwaz, "Improving Design and Operation at LNG Regasification Terminals Through A Corrected Storage Tank Model," Appl. Therm. Eng., vol. 149, no. December, pp. 344-353, 2019. 
[42] Đ. Dobrota, B. Lalić and I. Komar, "Problem of Boil - off in LNG Supply Chain,” Trans. Marit. Sci., vol. 2, no. 2, pp. 91-100, 2013.

[43] WÄrtsilä, "Small and Medium Scale LNG Terminals," 2018. [Online]. Available: https://www.wartsila.com/docs/defaultsource/Power-Plants-documents/lng/small-and-medium-scalelng-terminals_wartsila.pdf.

[44] J. G. De las Heras, “Análisis comparativo de gasoductos virtuales frente a otras alternativas de abastecimiento energético," Tesis. Ingeniería Industrial, Instituto Tecnológico de Buenos Aires, Buenos Aires, Argentina, 2013.

[45] Cryostar, "LNG/LCNG Vehicle Refueling," 2019. [Online]. Available: https://cryostar.com/natural-gas/land-based/lng-lcngvehicle-refueling/.

[46] Consorcio Sener Pacífico, Sener Ingeniería and S. Colombia, "Definición y elaboración de las condiciones técnicas de ingeniería conceptual para la construcción de la planta de regasificación en la bahía de buenaventura, pacifico colombiano, de conformidad con las normas técnicas, la reglamentación específica del sector de gas natural, la normatividad de la prestación de los servicios públicos, la función estatal y todo aquello relacionado con el proceso de selección de adjudicatario para la expansión en el suministro de gas natural en Colombia," 2018. [Online]. Available: http://bdigital.upme.gov.co/handle/001/1337.

[47] A. Martínez Pereira, "Buques LNG: FSRU," Tesis, Esc. Téc. Sup. de Náutica y Máquinas, Uni. da Coruña, Coruña, España, 2018. [Online]. Available: https://ruc.udc.es/dspace/bitstream/ handle/2183/21196/MartinezPereira_Alan_TFG_2018.pdf.pdf.

[48] M. Kulitsa and D. A. Wood, "Enhanced Application for FSRU Recondensing Equipment During Periods of Low or no Gas Send Out to Minimize LNG Cargo Losses," Petroleum, vol. 4, no. 4, pp. 365-374, Dec. 2018. 
[49] LEWA: Creating Fluid Solutions, "Bomba criogénica Nikkiso," 2019. [Online]. Available: https://www.lewa-inc.com/ es/bombas/bombas-centrifugas/bomba-criogenica-nikkiso.

[50] Chart Industries, "DAGR 2.0 Regasification Station," 2018. [Online]. Available: https://files.chartindustries.com/21211693_ Drop\&GoLNGRegas.pdf.

[51] Worthington Industries, "Small Scale LNG Custom Capabilities," 2019. [Online]. Available: https://dev. worthingtonindustries.com/Products/Small-Scale-LNG/LNGCustom-Capabilities.

[52] GiIgnL, GNL Custody Transfer Manual, 3rd ed. 2011.

[53] LEWA, "Sistemas de odorización LEWA," 2019. [Online]. Available: https://www.lewa-inc.com/es/sistemas/instalacionesde-odorizacion.

[54] M. Lombarte, "Especificaciones técnicas de SEDIGAS para las actividades de técnico de plantas satélite de GNL," 2019. [Online]. Available: https://www.sedigas.es/certificacion/pagina. $\mathrm{php} ? \mathrm{p}=352$.

[55] Chart Industries, "LNG Mobile Regasification Trailer," 2020. [Online]. Available: https://files.chartindustries.com/ MobileLNGRegasTrailer.pdf.

[56] S. Kumar et al., "LNG: An Eco-Friendly Cryogenic Fuel for Sustainable Development," Appl. Energy, vol. 88, no. 12, pp. 4264-4273, 2011.

[57] M. P. Hekkert, F. H. J. F. Hendriks, A. P. C. Faaij and M. L. NeELIS, "Natural Gas as an Alternative to Crude Oil in automotive fuel chains well-to-wheel analysis and Transition Strategy Development," Energy Policy, vol. 33, no. 5, pp. 579-594, 2005. 
[58] C. R. Rejeesh, J. Anoob and G. Chinmayakrishan, "Impact of Using Liquefied Natural Gas for Transportation in the City of Cochin: A Review," J. Altern. Energy Sources Technol., vol. 8, no. 3, pp. 29-35, 2017.

[59] J. Osorio-Tejada, E. Llera and S. Scarpellini, "LNG: an Alternative Fuel for Road Freight Transport in Europe," Transactions on The Built Environment, vol. 168, pp. 235-246, 2015.

[60] U.S. Department of Energy, "Alternative Fuels Data Center: Natural Gas Vehicle Emissions,” 2019.

[61] J. L. Osorio-Tejada, E. Llera-Sastresa and S. Scarpellini, "Liquefied Natural Gas: Could It be a Reliable Option for Road Freight Transport in the EU?," Renew. Sustain. Energy Rev., vol. 71, pp. 785-795, 2017.

[62] Transport and Environment, "CNG and LNG for Vehicles and Ships-the Facts," 2018. [Online]. Available: https://www.transportenvironment.org/wp-content/ uploads/2021/07/2018_10_TE_CNG_and_LNG_for_vehicles and_ships_the_facts_EN.pdf.

[63] D. Peteres-von, S. Siegemind, U. Bunger and P. Schmidt, "LNG in Germany: Liquefied Natural Gas and Renewable Methane in Heavy-Duty Road Transport," DENA, 2014. [Online]. Available: https://www.dena.de/fileadmin/dena/Dokumente/Pdf/9126 Studie_LNG_englisch.pdf.

[64] R. Vermeulen, R. Verbeek, S. van Goethem and R. Smokers, "Emissions Testing of Two Euro VI LNG Heavy-Duty Vehicles in the Netherlands: Tank-To-Wheel Emissions," Den Haag, 2017. 
[65] X. Ou and X. Zhang, "Life-Cycle Analyses of Energy Consumption and GHG Emissions of Natural Gas-Based Alternative Vehicle Fuels in China," J. Energy, vol. 2013, pp. $1-8,2013$.

[66] A. Arteconi and F. Polonara, "LNG as Vehicle Fuel and the Problem of Supply: The Italian Case Study," Energy Policy, vol. 62, pp. 503-512, 2013.

[67] H. HaO, Z. Liu, F. ZhaO and W. Li, "Natural Gas as Vehicle Fuel in China: A Review," Renew. Sustain. Energy Rev., vol. 62, pp. 521-533, 2016.

[68] H. Hao, H. Wang, and M. Ouyang, "Fuel Consumption and Life Cycle GHG Emissions by China's On-Road Trucks: Future Trends Through 2050 and Evaluation of Mitigation Measures," Energy Policy, vol. 43, pp. 244-251, 2012.

[69] Departamento Nacional de Planeación, "CONPES 3943," Bogotá, Colombia, 2018. [Online]. Available: https:// colaboracion.dnp.gov.co/CDT/Conpes/Económicos/3943.pdf.

[70] Asociación Colombiana de Vehículos Automotores (ANDEMOS), "Inventario de emisiones vehículos Colombia y movilidad sostenible," Bogotá, Colombia, 2017. [Online]. Available: https://andemos.org/wp-content/uploads/2017/03/ Presentacion-ANDEMOS-Emisiones-01.25.2017-v8.pdf.

[71] “Cuál es la diferencia entre el GNL y GNC, y qué uso se le da a cada uno de ellos?," IVECO, 2018. [Online]. Available: https:// www.iveco.com/spain/sala-de-prensa/noticias/pages/iveco_ gas4.aspx.

[72] A. Sharafian, H. Talebian, P. Blomerus, O. Herrera and W. MÉrIDA, "A Review of Liquefied Natural Gas Refueling Station Designs," Renew. Sustain. Energy Rev., vol. 69, pp. 503-513, 2017. 
[73] U. S. Department of Energy and Energy Efficiency \& Renewable Energy, "How Do Liquefied Natural Gas Trucks Work?," 2019. [Online]. Available: https://afdc.energy.gov/ vehicles/how-do-lng-cars-work.

[74] Y. Li, W. LI, Y. YU and L. BaO, "Planning of LNG Filling Stations for Road Freight: A Case Study of Shenzhen," Transp. Res. Procedia, vol. 25, pp. 4584-4592, 2017.

[75] Chart Industries, "Equipment and Solutions for Energy," 2019. [Online]. Available: http://www.chartindustries.com/Energy/ LNG-Solutions-Equipment.

[76] F. Mariani, "Cost Analysis of LNG Refuelling Stations," 2016. [Online]. Available: http://lngbc.eu/system/files/deliverable attachments/.

[77] J. M. SANTISTEBAn ArRIBAS, "Estación de servicio de gas natural licuado y comprimido para vehículos," tesis, Ingeniería de Minas, Escuela Técnica Superior de Ingenieros de Minas y Energía, Madrid, España, 2015. [Online]. Available: https:// oa.upm.es/35443/7/PFC_JOSE_MANUEL_SANTISTEBAN_ ARRIBAS.pdf.

[78] D. J. Giraldo Luna and A. C. Sotelo Barahona, "Estudio técnico financiero de la instalación de una planta de licuefacción de gas natural a pequeña escala para uso de éste como combustible en el sector transporte automotor en Colombia," tesis, Ingeniería de Petróleos, Fundación Universitaria de América, Bogotá, Colombia, 2018. [Online]. Available: http://repository.uamerica. edu.co/handle/20.500.11839/6816.

[79] Novagas Criogenia, "Planta satélite de GNL," 2011. [Online]. Available: http://novagascriogenia.com/portfolio/laoreet-mattisquam-4/. 
[80] H. EriK and G. Linda, "How to Handle Boil-off Gases from LNG Trucks," Department of Management and Engineering, Linköping University, Linköping, Suecia, 2015.

[81] A. Álvarez Riola, "Proyecto técnico de diseño de un evaporador de 540 ton/h de GNL," tesis, Ingeniería en Tecnologías Ambientales, Universidade da Coruña, Coruña, España, 2015.

[82] Clean Energy, "LNG Equipment: LNG Dispenser," 2021. [Online]. Available: https://www.cleanenergyfuels.com/ products/equipment/lng-equipment/lng-dispenser.

[83] Cryostar, "Refueling Station," 2019. [Online]. Available: https:// cryostar.com/lngl-cng-refueling-stations/refueling-station/\#.

[84] LIQAL, "LNG Dispenser: User-Friendly, Reliable and Cos Effective," 2021. [Online]. Available: https://www.liqal.com/ index.php/de/lng-fuelling-solutions/lng-fuelling/lng-dispenser.

[85] Clean Energy, "LNG Equipment: Odorant Systems," 2021. [Online]. Available: https://www.cleanenergyfuels.com/ products/equipment/lng-equipment/odorant-systems.

[86] G. De la PeÑa, "Planta satélite de GNL adaptada a el Hierro 100 \% renovable," tesis, Ingeniería Superior de Minas, Escuela Técnica Superior de Ingenieros de Minas y Energías, Madrid, España, 2014.

[87] Unidad de Planeación Minero Energética (UPME), "Balance de gas natural en Colombia 2015-2023," 2015. [Online]. Available: https://www1.upme.gov.co/Hidrocarburos/ publicaciones/BALANCE_GAS_NATURAL_FINAL.pdf.

[88] C. A. Devia Tabares, "Caracterización de los usuarios del sector residencial como herramienta estratégica para la gestión comercial de la Empresa de Energía de Pereira SAESP," tesis, Escuela de Administración, Universidad EAFIT, Pereira, Colombia, 2017. 
[89] Tractebel Engineering S. A., "Mini and Micro LNG for Commercialization of Small Volumes of Associated Gas," 2015. [Online]. Available: https://openknowledge.worldbank.org/ handle/10986/25919.

[90] Natgas.info, "Liquefied Natural Gas Chain," 2019. [Online]. Available: http://www.natgas.info/gas-information/what-isnatural-gas/lng.

[91] Agencia Nacional de Hidrocarburos, "Estadísticas de producción-Balance de producción de gas 2018,”2018. [Online]. Available: https://www.anh.gov.co/Operaciones-Regalías-yParticipaciones/Sistema-Integrado-de-Operaciones/Paginas/ Backup/Estadisticas-de-Produccion.aspx.

[92] GE OIL \& GAS, "The Definite Guide to Small-Scale Liquefied Natural Gas (LNG) Plants," 2018. [Online]. Available: https:// docplayer.net/27098599-The-definitive-guide-to-small-scaleliquefied-natural-gas-lng-plants-helping-you-harness-theenergy-of-opportunity.html.

[93] F. Chen and J. Voda, "Air Products Manages Project Risk in Global Ventures Through its Standardization and Modularization," $L N G J$., no. June, pp. 20-22, 2018.

[94] R. SedlaczeK, "Boil-Off in Large and Small Scale LNG Chains." MS thesis, Pet. Eng. Dep. Pet. Eng. Appl. Geophys. Nor. Univ. Sci. Technol. Trondheim, 2008.

[95] StiRling Cryogenics, "StirLNG-1 Cryogenerator," 2019. [Online]. Available: https://www.stirlingcryogenics.eu/files/ documents/1/StirLNG-1ConditioningDatasheet.pdf.

[96] G. G. NASR and N. E. CONNOR, Natural Gas Engineering and Safety Challenges. New York, United States: Springer, 2014. 
[97] A. Bernatik, P. Senovsky and M. Pitt, "LNG as a Potential Alternative Fue-Safety and Security of Storage Facilities," J. Loss Prev. Process Ind., vol. 24, no. 1, pp. 19-24, 2011.

[98] ICONTEC, "Producción, almacenamiento y manejo de GNL". Colombia: NTC 6276:2018, 2018.

[99] Promigas, "Informe del sector gas natural 2017-Cifras 2016," Bogotá, Colombia, 2017.

[100] Valora Analitik, "Sociedad Portuaria El Cayao avanza en ampliar capacidad de regasificación en Colombia," 2021. [Online]. Available: https://www.valoraanalitik.com/2021/11/25/ cayao-avanza-en-ampliar-capacidad-de-regasificacion/.

[101] Unidad de Planeación Minero Energética (UPME), "Proyección de precios de los energéticos para la generación eléctrica: enero 2017-diciembre 2035," UPME, Colombia, 2017. [Online]. Available: https://www1.upme.gov.co/ Hidrocarburos/publicaciones/Proyeccion_de_los_precios_de los_combustibles_junio_2016.pdf.

[102] Ministerio de Transporte, Diario oficial No. 47.530. (2009, 10 de noviembre) Resolución 5443. Por la cual se adopta la parametrización y el procedimiento para el registro de información al Registro Nacional Automotor del Registro Único Nacional de Tránsito (RUNT).

[103] TGE Gas Engineering, "One-Stop Shop LNG a Propulsion Fuel for Trucks,” 2014. [Online]. Available: https://www.tge-gas. com/files/DOWNLOADS/BROCHURES/WEB_TGE_LNG_ Trucks_E.pdf.

[104] InSTITUTO PARA LA DiversificaCión y AHORro DE LA ENERGía (IDAE) and Ministerio de Industria Turismo Comercio, "Combustibles y vehículos alternativos-España," IDAE, Madrid, España, 2005. 
[105] D. Peters-Von Rosenstiel, "LNG in Germany: Liquified Natural Gas and Renewable Methane in Heavy-Duty Road Transport," Energy German Agency (DENA), Berlín, Alemania, 2014.

[106] Transport \& ENVIRONMENT, "GNC y GNL para vehículos y buques: los hechos," Federación Europea de Transporte y Medio Ambiente, Bruselas, Bélgica, 2018. [Online]. Available: https:// www.ecologistasenaccion.org/wp-content/uploads/2018/10/ informe-GNC-y-GNL-para-vehiculos-y-buques.pdf.

[107] Cryogas M\&T Polonia, "Instalación de GNL, diagrama de instalación de gas GNL," 2019. [Online]. Available: https:// www.cryogas.pl/o_lng.

[108] Y. BAux, "European LNG/L-CNG Technology,” 2013. [Online]. Available: https://lngbc.eu/system/files/deliverable_attachments/ LNG BC D 3.1 LNG L-CNG Technology.pdf. 
Este libro fue terminado por la editorial de la Universidad Tecnologica de Pereira en junio del 2021, bajo el cuidado de los autores.

Pereira, Risaralda, Colombia. 
Actualmente la humanidad está enfrentando un gran reto, el cambio climático. Para mitigar este fenómeno es necesario descarbonizar la economía mundial, lo que significa reducir drásticamente el uso de combustibles de origen fósil. Para lograr este propósito el Gas Natural Licuado (GNL) juega un papel muy importante, como combustible de transición hacia una economía libre de emisiones de carbono. Este libro presenta los conceptos fundamentales en relación con el uso del GNL. El lector podrá conocer los procesos que se utilizan para producir GNL y como se aprovecha este combustible en los diferentes sectores de la economía. También se analizan algunos escenarios de su posible implementación como combustible de transición energética para Colombia.

Este documento se desarrolló en el marco del proyecto de investigación: Desarrollo de una Herramienta de Modelamiento y Optimización para la Introducción de Gas Natural a Pequeña Escala en Distintos Sectores de Consumo Final de Energía en Colombia, el cual se ejecutó desde la Universidad Tecnológica de Pereira (UTP) con recursos de la Unidad de Planeación Minero Energética (UPME), a través del Ministerio de Ciencia, Tecnología e Innovación (MinCiencias) de Colombia. Los grupos de investigación Gestión Energética (GENERGÉTICA) y Desarrollo en Investigación de Operaciones (DINOP) de la UTP fueron los encargados de la ejecución del proyecto. 